\title{
WestVirginiaUniversity
}

THE RESEARCH REPOSITORY @ WVU

Graduate Theses, Dissertations, and Problem Reports

2017

\section{\#Physical Activity: Influencing Parent Behavior Change Through Social Media}

\section{Adam Keath}

Follow this and additional works at: https://researchrepository.wvu.edu/etd

\section{Recommended Citation}

Keath, Adam, "\#Physical Activity: Influencing Parent Behavior Change Through Social Media" (2017). Graduate Theses, Dissertations, and Problem Reports. 5952.

https://researchrepository.wvu.edu/etd/5952

This Dissertation is protected by copyright and/or related rights. It has been brought to you by the The Research Repository @ WVU with permission from the rights-holder(s). You are free to use this Dissertation in any way that is permitted by the copyright and related rights legislation that applies to your use. For other uses you must obtain permission from the rights-holder(s) directly, unless additional rights are indicated by a Creative Commons license in the record and/ or on the work itself. This Dissertation has been accepted for inclusion in WVU Graduate Theses, Dissertations, and Problem Reports collection by an authorized administrator of The Research Repository @ WVU.

For more information, please contact researchrepository@mail.wvu.edu. 
\#Physical Activity: Influencing Parent Behavior Change Through Social Media

\author{
Adam Keath, MAED
}

\begin{abstract}
Dissertation submitted to the College of Physical Activity and Sport Sciences Department of Coaching and Teaching Studies at West Virginia University
\end{abstract}

\author{
In partial fulfillment of the requirements \\ for the degree of \\ Doctorate of Philosophy \\ In Kinesiology \\ Eloise Elliott, $\mathrm{PhD}$, Chair \\ Sean Bulger, EdD \\ Emily Jones, $\mathrm{PhD}$ \\ Lesley Cottrell, $\mathrm{PhD}$ \\ Geah Pressgrove, $\mathrm{PhD}$
}

\author{
College of Physical Activity and Sport Sciences \\ Morgantown, West Virginia \\ July 2017
}

Keywords: Social Media, Physical Activity, Behavior Change

Copyright 2017 Adam Keath 


\section{Abstract \\ \#Physical Activity: Influencing Parent Behavior Change Through Social Media}

Adam Keath, MAED

Background: Parents play a major role in supporting physical activity in and around the home, creating a home environment that encourages physical activity as well as participation in activity with their children and supporting children's physically active lifestyles are important areas of concern for health promotion. Despite support for family-based interventions, there is still little evidence to demonstrate the most effective ways of targeting families with physical activity interventions. Social media has been one area of promise for connecting with parent participants in physical activity interventions. Sites like Facebook have an existing high prevalence of parent users and offer media-rich tools in a socially connected digital environment that are suited for connecting with parents. The purpose of this study was to determine if the use of a social media physical activity intervention could enhance physical activity behavior change in parents.

Additionally, this study sought to discover if the level of parent engagement in the social media group influenced their behavior change-related outcomes, within the same intervention.

Methods: Parent participants in this study were randomized at the school level as part of a larger physical activity intervention consisting of three different experimental conditions (Control, School, Family). Participants in the family intervention received a nineteen-week strategic messaging campaign delivered through a Facebook group in addition to existing family intervention components. Strategic messaging consisted of core messaging related to parent education as well as dedicated behavior change messaging targeting parents specific to their existing stage of change. Parent completed pre/post survey instruments to evaluate family health behaviors ((Family Health Climate (FHC), Stage of Change (SOC), Parent Support for Physical Activity (PSPA) and Physical Activity (PA) levels) and attitudes in an existing family-based physical activity intervention. Additional data were collected on interaction in the Facebook group to determine parents engagement level with Facebook content.

Results: A total of 84 parents were included in the analysis control $n=42$ and family $n=42$. A repeated measures MANOVA was used to determine if there were significant differences between groups by time. Overall Pillai's trace was statistically significant for time*group $F(8$, $75)=2.866, p=.008$, partial $\eta^{2}=.234$. Follow-up univariate ANOVA's were performed to determine which of the study variables across time points had significant mean differences, Family health climate $\mathrm{p}<.02$, parent support $\mathrm{p}<.004$, self-efficacy $\mathrm{p}<.034$ all had significant mean differences between times and groups. No other study variables were significantly different. Pairwise comparisons showed significant mean improvements for family intervention participants in Family health climate $(\mathrm{m}=4.972, \mathrm{p}<.017)$ and parent support $(\mathrm{m}=7.69, \mathrm{p}<$ $.005)$.

Conclusion: Results indicate that strategic messaging campaigns delivered through Facebook have the potential to influence parent support for physical activity, parent self-efficacy as well as the family home climate. These factors relate to the overall physical activity behaviors in families and can contribute to lifestyle behavior change when coupled with evidence-based physical activity interventions. Strategic messaging campaigns delivered through social media outlets can be considered effective communication channels for family physical activity interventions. 


\section{Dedication}

I want to dedicate this paper to my wife Tessa and my children Brooklyn, Finley, Jasper, and Theodore who sacrificed so much for me during this time. Tessa has been my biggest supporter, and best friend and my kids have been my greatest joy. Thank you all, and I love you very much! 


\section{Acknowledgments}

First and foremost, I want to take a moment to thank God for the gift of eternal love, salvation, and endless grace despite all of my failures. Where my strength fails, God is there, when I'm not able God is there, through all the trials and adversity of this process my rock my foundation my God has been there. Next, I want to thank my wife Tessa who has shown grace and humility while raising our children and whom I cannot thank or honor enough for the sacrifices that she made during the last three years. She has worked tirelessly to care for and guide our family and has been my constant companion and friend along this journey. She is and will always be my best friend.

To my wonderful children who make it so hard for me to have a bad day. Brooklyn, you are truly a gift, I love your positive attitude and wonderfully kind heart. Finley, you are a kind soul who I'm proud to say is always willing of to put others before himself. Jasper, my toeheaded surfer boy. I can't help but smile when I think of you, thank you for always being up for a good snuggle. Theodore, you have the most infectious smile that brings me so much joy. I love each of you with all of my heart.

I cannot write another word without expressing my gratitude to Dr. Eloise Elliott, she has been my adamant supporter from day one and has been instrumental in guiding me through this process. I would certainly not be anywhere near the person or professional that I am today without the motherly direction and support of my biggest cheerleader. Dr. Elliott embodies everything that I strive to be as a professional. Thank you for all your support, guidance and most of all friendship throughout this process.

I must also give a special thank you to Dr. Emily Jones, as much as Dr. Elliott helped me grow as a researcher, Dr. Jones helped me become that much better of a teacher. The passion and deep care that she has shown through her example have been inspirational and humbling to my growth as a teacher. Beyond the professional example that she has shown me, Dr. Jones and her husband Brandon have been amazing role models for what Christian leaders should do in a church body. Both are extremely talented and capable individuals, yet they are two of the humblest servants that you will ever meet. I hope to be able to show that level of humility as I continue to grow in my faith.

The rest of my committee is no less amazing; Dr. Sean Bulger somehow manages to be a perfect professional yet never takes himself too seriously. He's a terrific example of what a professor and Father should be, and I thank him for his example. To Dr. Lesly Cottrell, who has always been the most kind and accommodating person you could ever work with. I thank you for allowing me to work with activate and for the above and beyond support you gave me in completing this project. To Dr. Geah Pressgrove, who orphaned as I was and in need of help took me in and helped me to navigate the world of social media. Your insightful ideas and guidance have made much of what I've done possible.

To my colleagues and friends Brooke Towner, Cory Briethoff (I almost hope I spelled that wrong here), Hannah Kipfer, Jun Baek Karl Zang, Tyler Goad, Annie Machamer, Gentry 
Shrewsbury and all of my office pals who shared so much stress, laughter and love with me over the last three years. I most certainly would not have been able to complete this journey without your constant support encouragement and often admonition. Lastly, I want to thank all of the wonderful faculty at WVU for their leadership and mentorship during this time. 


\section{Table of Contents}



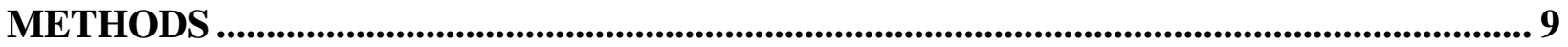

CONTEXT



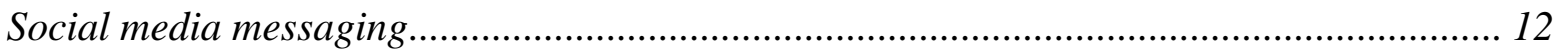

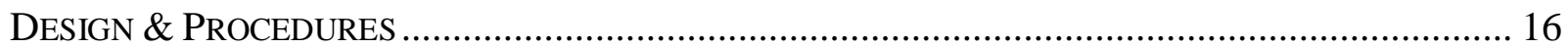

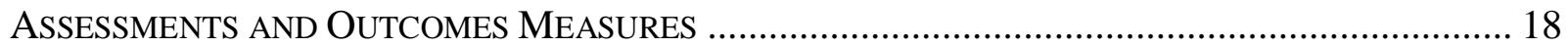

Parent Physical Activity Questionnaire. .................................................................... 18

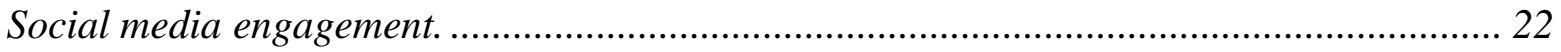

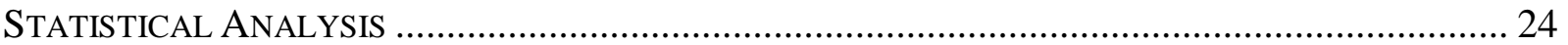

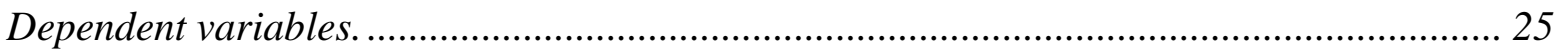

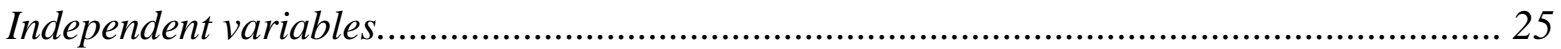





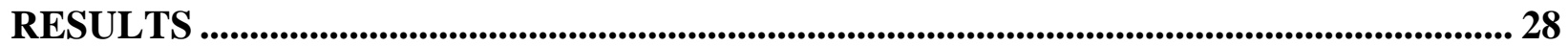

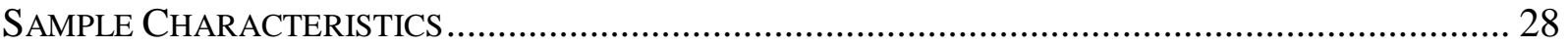

Strategic Messaging ImPact on Health Behaviors And AtTitudes............................. 29

DiFFERENCES IN PARENT OUTCOMES BASEd On SOCIAL MEDIA ENGAGEMENT ....................... 31

EFFECTIVENESS OF TAILORED MESSAGING ON SOC …........................................................... 33

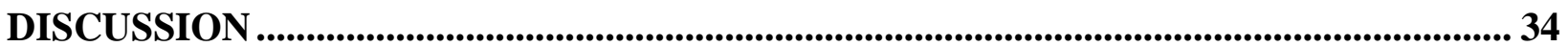



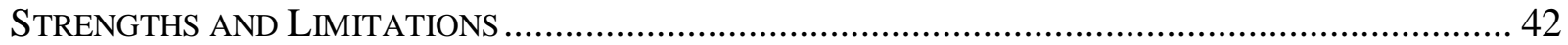






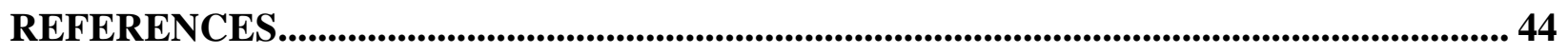

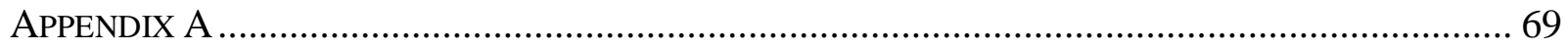



APPENDIX B: STAGE-MATCHED MESSAGES ............................................................ 133

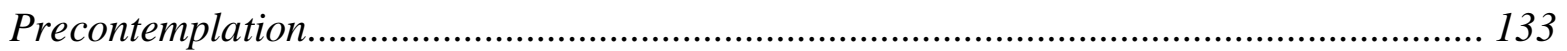

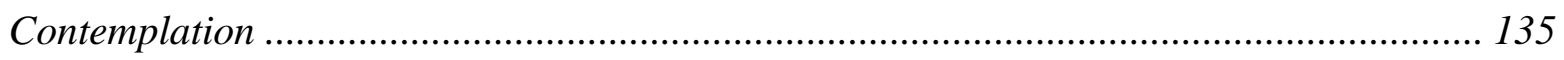

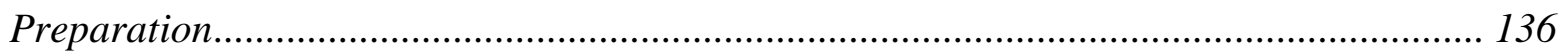



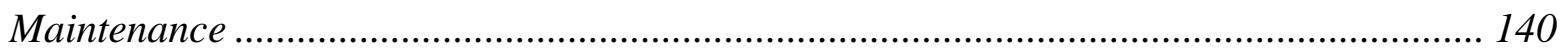

APPENDIX C: PARENT PhysicAl ACTIVITy QuestionNAIRE .............................................. 143

ApPendix D: Stage of Change Facebook Measure .................................................. 150




Regular bouts of physical activity (PA) have been associated with many positive health benefits throughout a person's lifetime. These benefits include a lower risk of premature death, obesity, depression, cardiovascular disease, type 2 diabetes, ischemic stroke, and colon and breast cancers (CDC, 2008). Benefits of PA, however, extend far beyond just the prevention of chronic diseases. Regular health-enhancing levels of PA have been linked to improving cognitive functioning across a variety of age groups (Hillman, Erickson, \& Kramer, 2008). In addition to the health and cognitive benefits of regular PA, regular exercise has been shown to have a moderate effect on reducing anxiety as well as improving self-esteem (Fox, 1999). A more tangible benefit of regular PA is the maintenance of normal weight status (Swift, Johannsen, Lavie, \& Earnest, 2014).

To achieve the benefits of health-enhancing PA, adults need to participate in at least 150 minutes of moderate-intensity PA per week, while children between the age of six and seventeen need to reach at least 60 minutes of PA per day (CDC, 2008). Unfortunately, children and adults are falling short of these minimum recommendations; in 2011 less than half of the adults met the minimum guidelines for aerobic PA, while $15.2 \%$ of youth failed to meet minimum PA recommendations (CDC, 2014). The failure to meet these minimum recommendations for PA on a broad scale is contributing to what researchers have considered the greatest public health problem of the $21^{\text {st }}$ century (Blair, 2009). If this public health issue is to be reversed there is an immediate need for innovative approaches to increase PA in our children and adults.

Lifelong health and PA behaviors are developed during childhood, leading to the advocacy of public health approaches that focus on improving health and PA behaviors in children (Lobstein, Baur, \& Uauy, 2004). Research suggests that parent influences play a major role in the 
development of these behaviors, whether through modeling healthy behaviors, providing children with physical activity opportunities, providing a healthy home environment, or participating in physical activity directly with their children. (Lindsay, Sussner, Kim, \& Gortmaker, 2006). These behaviors serve to facilitate physical activity opportunities within the family and reinforce positive PA behaviors (Perry, Luepker, Murray, Kurth, Mullis, Crockett, et al.,1988). Therefore, the home and family environment has become a key area of focus for PA interventions.

There is a consensus in the literature that by including both parents and children in PA interventions children's PA levels can be more effectively increased (Beets \& Cardinal, 2010; Ostbye, Malhotra, Stroo, Lovelady, Brouwer, Zucker, et al., 2013). The inclusion of parents in physical activity promotion interventions targeting children has allowed researchers to study a wide variety of factors that contribute to PA in the home environment. Targeting parents' behaviors have several advantages over traditional approaches that focus on children's behaviors, as parental support factors including transportation, encouragement, and co-participation have consistently been associated with positive physical activity outcomes in children (Gustafson \& Rhodes, 2006). Even parents' PA levels can have a major influence on the activity levels of their children; existing studies have discovered a significant relationship between parent and child PA levels (Fuemmeler, Anderson, \& Masse, 2011a; Gustafson \& Rhodes, 2006; Sallis, Prochaska, \& Taylor, 2000) Golan has proposed that delivering interventions to the parents is the key to the success of family-based approaches and that there is a need for additional strategies that target the parent as the agent of change in family-based interventions (Golan, 2006).

Existing reviews of literature have attempted to identify the most effective ways to involve parents in PA interventions to improve physical activity with their children, their families, and 
themselves. However, there is still little evidence to guide researchers on the most effective channels and methods necessary to reach parents (Brown, Atkin, Panter, Wong, Chinapaw, \& van Sluijs, 2016; O’Connor, Jago, \& Baranowski, 2009). Interventions that include parent education have been somewhat effective for increasing parent knowledge. However, education alone was not sufficient enough to change parent PA behaviors (David N Cavallo, Tate, Ward, DeVellis, Thayer, \& Ammerman, 2014). Recommendations from the literature suggest the need for a more comprehensive approach targeting parents, including strategic messaging that combines an educational approach with additional behavior change strategies to combat physical inactivity in the home environment (Brown et al., 2016).

While there is support to suggest that parent involvement is crucial to health promotion in children, the problem lies in the efforts needed to involve parents in these programs (Perry et al., 1988). A strategic intervention that will successfully engage, educate, and change behaviors in parents is reliant on two major factors: (a) determining the combination of behavior change strategies and educational messaging that has the most potential for success. (b) determining which delivery channels will be most effective and practical for delivery of educational and behavior change materials (Marcus, Forsyth, \& Stone, 2000).

One area that has demonstrated success in changing specific health behaviors is the area of tailored health messages (Noar, Benac, \& Harris, 2007). Tailoring health messages is defined as "any combination of strategies and information intended to reach one specific person, based on characteristics that are unique to that person, related to the outcome of interest, and derived from an individual assessment” (Kreuter \& Skinner, 2000, p. 1). Interventions that use tailoring strategies for health behavior change have shown more success than strategies that only provide generic messaging. Skinner and Colleagues (1999), reviewed the effectiveness of tailored vs. 
non-tailored interventions and found that tailored messaging was more effective in 6 of the 8 studies that were reviewed. Similarly, in cancer research, Rimer and Glassman (1999) found that behavioral outcomes from tailored communication were significantly better than non-tailored communications. From the strategies reviewed in successfully tailored interventions, the Transtheoretical Model of behavior change has been identified as the primary tool used to tailor messaging to individual participants (Maher, Lewis, Ferrar, Marshall, De Bourdeaudhuij, \& Vandelanotte, 2014; Noar et al., 2007; Vandelanotte, Kirwan, Rebar, Alley, Short, Fallon, et al., 2014).

The Transtheoretical Model (TTM) offers participants more than just an "all or nothing approach". It has the potential to withstand lifestyle factors that often interrupt physical activity behavior treatments and makes it an ideal model for use with parents (Marcus, Forsyth, \& Stone, 2000). The TTM employs five distinct stages of behavior change that relate to a person's intention to change a behavior (Table 1) and views behavior change as a continual process rather than a specific event (Adams \& White, 2003).

Table 1. Transtheoretical Model Stages of Change

\begin{tabular}{ll}
\hline Stage & Definition \\
\hline $\begin{array}{l}\text { Precontemplation } \\
\text { Contemplation }\end{array}$ & $\begin{array}{l}\text { Not ready- may deny or not recognize the need to change their behavior. } \\
\text { Getting ready- recognize the need to change a behavior and are weighing } \\
\text { the pros and cons of changing the behavior. } \\
\text { Preparation }\end{array}$ \\
$\begin{array}{l}\text { Ready- Have decided to make a change in the near future and are taking } \\
\text { steps to make the change. } \\
\text { Oction }\end{array}$ & $\begin{array}{l}\text { Overt changes- actively engaged in changing their behavior. } \\
\text { Maintenance }\end{array}$ \\
& months.
\end{tabular}


The process of making a lasting behavior change using the TTM is cyclical rather than linear and relies on a number of factors related to a person's stage of change. Messaging then must be tailored to a person by their stage of change to address the different attitudes, skills and strategies that are indicative of their current stage of change (Hutchison, Breckon, \& Johnston, 2009a). Participants in the precontemplation stage of behavior change will be more responsive to communication-related to dramatic relief, which relates to their emotional response to not changing their problem behavior. While someone in the maintenance phase would benefit more from messaging related to managing stimulus control, which involves controlling aspects of their environment, so they do not relapse to their previous problem behavior (Marcus, Selby, Niaura, \& Rossi, 1992). Tailoring messaging using the TTM allows researchers to create stage-matched intervention messaging relevant to participants in each stage of behavior change. Given the lifestyle habits and behaviors of parents, the TTM model then offers a viable option for an intervention strategy to apply towards behavior change in the context of a physical activity intervention.

While the TTM may be an effective vehicle for specific behavior change messaging, research suggests that interventions targeting families should combine educational strategies in addition to behavior change approaches in PA interventions (Brown et al., 2016). Parent educational messaging should include content related to the benefits of PA for parents and their children, the influence of the home environment on child PA, current PA recommendations, how to plan and monitor PA, and strategies to overcome PA barriers for their family (Brown et al., 2016; Shelton, Gros, \& Norton, 2007; Trost, Sallis, Pate, Freedson, Taylor, \& Dowda, 2003). These educational approaches combined with a tailored TTM approach to behavior change offer a promising 
approach for PA intervention delivery. However, the channels in which this messaging is distributed is an additional concern that must be addressed (Marcus et al., 2000).

Social media has shown early promise that it may be an effective tool to help communicate health and physical activity interventions (Maher, Lewis, Ferrar, Marshall, De Bourdeaudhuij, \& Vandelanotte, 2014). The social support component of an effective physical activity intervention is often an area of concern for researchers, however, social media now provides a way to mediate this concern by connecting intervention participants directly and allowing researchers a direct two-way means of communication to participants (Blitstein, Cates, Hersey, Montgomery, Shelley, Hradek, et al., 2016; Cavallo, Tate, Ries, Brown, DeVellis, \& Ammerman, 2012a). In addition to the connectivity features offered by social media, sites like Facebook already have a very high prevalence of parent members. Currently, parents are among the largest consumers of online social media with 2015 estimates indicating that more than $75 \%$ of parents subscribe to one form of social media or another (Duggan, Lenhart, Lampe, \& Ellison, 2015).

Since Duggan and colleagues (2015), identified Facebook as the most prevalent site used by parents in a national survey, it seems as though Facebook provides an ideal platform for a health intervention targeting parents. While literature related to social media-based health interventions is still in the early stages, a major factor in existing studies is that higher levels of engagement with the social media group were associated with positive health outcomes (David N Cavallo et al., 2014; Carol Maher, 2010; Thrul, Klein, \& Ramo, 2015a). In order to achieve higher levels of participant engagement, intervention design should take into account the platform that is most common to their target audience as participants are more likely to engage with a social media platform that they already use on a regular basis (Thackeray, Neiger, \& Hanson, 2008). The functionality and media rich tools available through Facebook combined with the prevalence of 
use in the parent population Facebook seems the most logical choice to investigate how effective of a tool social media can be for intervention messaging delivery.

Given what we know about parents' social media habits (e.g. Perrin, 2015) and the influence of parents' health behavior on children's physical activity (e.g. Fuemmeler, Anderson, \& Masse, 2011), creating a social media-based health intervention to modify parents' health behavior has the potential to have a positive impact on both parent and child physical activity. Much of the existing literature suggests a need for more information about the cost, benefits, and effectiveness of social media as a health promotion tool (Cobb \& Graham, 2012; Korda \& Itani, 2013; Maher et al., 2014).

Given the existing evidence to support the need for interventions to target parent PA behaviors, this study is designed to implement a strategic messaging campaign, made up of tailored messaging and educational messaging using social media as the delivery system to answer the following research questions: (1) What impact does the inclusion of a strategic messaging campaign within a Facebook group have on parents' physical activity behaviors (Family Health Climate (FHC), Stage of Change (SOC), Parent Support for Physical Activity (PSPA) and Physical Activity (PA) levels) and attitudes in an existing family-based physical activity intervention? (2) How does parents' level of engagement in a Facebook group affect their physical activity behaviors (FHC, SOC, PSPA, and PA levels) and attitudes in an existing family-based physical activity intervention? (3) Does the delivery of tailored messaging based on the TTM and delivered through Facebook influence a parent's readiness to change their PA behaviors?

\section{Key Terms}

For the purpose of this study the following terms were defined as: 
Family Health Climate: reflects upon the daily family life behaviors with respect to routines and interactions. A change in the family health climate can reflect the importance of physical activity as a part of daily life

Home Environment: Relates to all the factors in the home that contribute to the health and physical activity behaviors of the family. These include an "aggregation of the family's shared opinions, attitudes, feelings and behaviors that characterize the social setting." (Christina Niermann, Krapf, Renner, Reiner, \& Woll, 2014, p. 2)

Self-efficacy: Addresses the confidence to make and sustain changes and sustain the temptations to relapse.

Stage-Matched Messaging: Messaging strategy that applies concepts of the process of change that affect how a person process through each stage of behavior change. Each stage incorporates a variety of different processes that contribute to overall behavior change, stagematched messaging is messaging that emphasizes the processes of change relative to each stage of behavior change.

Strategic messaging: The combination of educational and behavior change messaging, specifically designed and tailored for parents using a specific delivery channel.

Tailored-messaging: "any combination of strategies and information intended to reach one specific person, based on characteristics that are unique to that person, related to the outcome of interest, and derived from an individual assessment” (Kreuter \& Skinner, 2000, p. 1).

Transtheoretical model (TTM): A comprehensive model of behavior change that integrates ideas and approaches from several different theories to explain and predict how and when individuals stop high-risk behaviors or adopt healthy ones. 
Social Media: Forms of digital communication where users can create online communities to share information, ideas, messages and other content.

\section{Methods}

\section{Context}

The current study was conducted within the context of a large five-year multi-component study; Project activate! designed to increase $5^{\text {th }}$-grade students' physical activity, improve aerobic fitness, combat health risks, and improve academic performance. During the five-year study, three cohorts of schools will be exposed to interventions designed to increase physical activity. The project uses a coordinated approach that incorporates both school and family-based strategies. Project activate! includes three main aims:

- Aim 1: Define and document current school recess and physical education (PE) practices among West Virginia elementary schools and compare student health outcomes on these practices.

- Aim 2: (the current intervention) Implement a three-year intervention consisting of three $5^{\text {th }}$ grade cohorts, designed to compare two emerging strategies (one family and one school based) on current PE and recess practices.

- Aim 3: Translate the intervention results into policy recommendations to increase access to physical activity and education at the local, regional and state levels

This study took place in the second cohort of Aim 2 of the project. The second year,

Cohort 2, includes 13 total schools. Schools were recruited during the spring of 2016 by obtaining approval from the targeted county superintendents. Upon approval, principals were sent a recruitment letter explaining the scope of the project and asking for their participation. After principal consent, approved schools were randomized into one of three groups: Group A: 
standard of care (physical education), Group B: standard of care (physical education) plus school-based classroom intervention, and Group C: standard of care (physical education) plus family-based intervention component. Students (and one parent) received a recruitment packet from their participating school explaining the project and seeking parental consent and student assent.

As a component of the larger activate! study, this study, \#physical activity, was conducted in the family unit of the overall intervention (Group C), using the control group of the project as a comparison group (Group A). In addition to the activate! intervention strategies for the family component, this study provides the parent participants with a structured social media intervention designed to increase their own and their family members' physical activity. Components of this study were added to the activate! Institutional Review Board (IRB) protocol and approved by the West Virginia University review board.

Participants

The $5^{\text {th }}$ grades from thirteen schools in rural West Virginia were randomly assigned to one of three groups (see Figure 1); randomization for these groups occurred at the school level to avoid contamination among children and families within the same school. Schools with the highest prevalence of free/reduced lunch were randomized equally into each of the three arms of the study. Parents then received a recruitment letter asking for their consent to participate in the activate! project.

All Cohort 2 parents (i.e. Groups A, B, \& C) who consented to the family wing of the activate! intervention had the option of enrolling in the social media component of the study by completing the entry survey and joining the activate! Facebook page. 


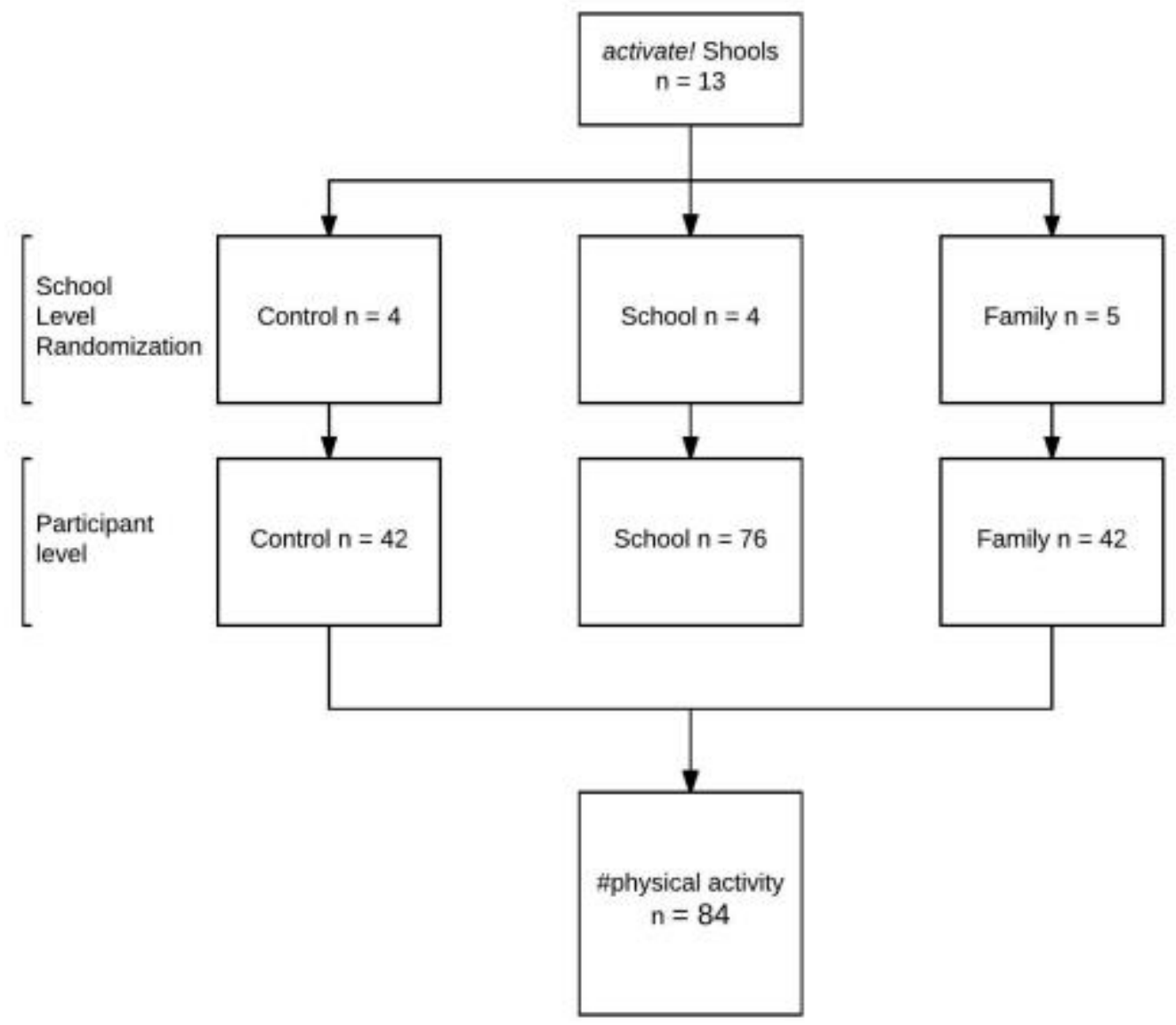

Figure 1. activate! overall project randomization

\section{Intervention}

The intervention being studied consists of social media-delivered communication to parents, including core messaging and stage-matched messaging. Core messaging was directed at six primary areas (see Table 2) that were identified through Project activate! to increase physical activity in the family. Stage-matched messages (see Table 3) targeted each participant's identified stage of change related to physical activity behavior. Parents joined a private Facebook group (activate! cohort 2), where core messages were delivered twice per week related to the each of the six primary areas. Through the same group, participants received private 
stage-matched messaging once per week, designed to advance participants to the next stage of physical activity behavior change (Table 4)

Social media messaging. The messaging strategy used for core messaging and stagematched messaging was delivered through Facebook. Both are described in detail in the following sections.

Core messaging. The relationship between parent and child physical activity is very complex and consists of a variety of factors. The literature identifies evidence to support several components that may have the potential to influence this relationship (Beets \& Cardinal, 2010; Dietz \& Gortmaker, 1985; Leonard H. Epstein, Valoski, Vara, McCurley, Wisniewski, Kalarchian, et al., 1995; Ostbye et al., 2013; Strauss \& Knight, 1999). Six of these components were selected as target areas for this intervention (see Table 2). The core messaging used in this intervention has a specific focus on targeting these critical areas, by raising awareness for each of the components. These messages were delivered twice per week through the newsfeed of the activate! Project Cohort 2 group. Parents had the opportunity to interact with core messaging content by providing feedback in the form of comments, Facebook reactions (e.g. Like, Love, Haha, Wow, Sad, Angry), views, and shares. The researcher interacted with participants by answering questions or providing feedback and social support to any user-generated content or postings.

Table 2

Focus of Core Messages for Parents

\begin{tabular}{lrcl}
\hline Core Concept & Components & Related Variable \\
\hline $\begin{array}{l}\text { Benefits and values of } \\
\text { physical activity for their }\end{array}$ & $\bullet$ & Relationship between parent \\
child and themselves. & $\begin{array}{l}\text { and child physical activity } \\
\end{array}$ & $\begin{array}{l}\text { Parents expression of belief } \\
\text { in children's physical } \\
\text { activity competence }\end{array}$ & Climate (FHC) \\
\hline
\end{tabular}




\begin{tabular}{|c|c|c|}
\hline & $\begin{array}{l}\text { Value of exercise for their } \\
\text { children } \\
\text { - Physical activity as a topic } \\
\text { of discussion in the family }\end{array}$ & \\
\hline $\begin{array}{l}\text { Planning for physical } \\
\text { activity }\end{array}$ & - $\quad$ Establishing SMART goals & $\begin{array}{ll}- & \text { Physical Activity } \\
& \text { (PA) } \\
-\quad & \text { Stage of Change } \\
& \text { (SOC) }\end{array}$ \\
\hline $\begin{array}{l}\text { Influence of the home } \\
\text { environment in promoting } \\
\text { physical activity }\end{array}$ & $\begin{array}{ll}\text { - } & \text { Parent Support } \\
\text { - } & \text { Parenting styles } \\
\text { - } & \text { Family dining behaviors }\end{array}$ & 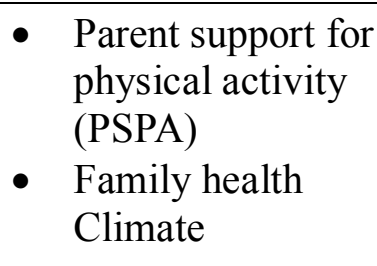 \\
\hline Overcoming barriers & $\begin{array}{ll}\text { - } & \text { Time } \\
\text { - } & \text { Space } \\
\text { - } & \text { Equipment } \\
\text { - } & \text { Community support } \\
\text { - } & \text { Access to physical activity } \\
& \text { opportunities within the } \\
& \text { community } \\
\end{array}$ & - Barriers \\
\hline $\begin{array}{l}\text { Physical activity } \\
\text { recommendations }\end{array}$ & - Informational factors & $\begin{array}{l}\text { - Stage of Change } \\
\text { (SOC) }\end{array}$ \\
\hline $\begin{array}{l}\text { Monitoring physical } \\
\text { activity }\end{array}$ & $\begin{array}{l}\text { - Fitbit Check-in reminders } \\
\text { - Importance of tracking } \\
\text { physical activity behaviors }\end{array}$ & $\begin{array}{l}\text { - Physical Activity } \\
\text { (PA) }\end{array}$ \\
\hline
\end{tabular}

*Note: Example messaging can be found in Appendix E.

Stage-matched messages. Reviews of existing interventions that have utilized tailored messaging based on an individual's readiness to change have shown that tailored messaging is an effective way to change physical activity behaviors (Jeon, Kim, \& Heo, 2014; Marcus, Emmons, Simkin-Silverman, Linnan, Taylor, \& Brock, 1998; Marcus, Bock, Pinto, Forsyth, Roberts, \& Traficante, 1998; Noar et al., 2007). Furthermore, tailored interventions utilizing the TTM to identify participant's readiness for change have shown promise in the adoption and maintenance of regular exercise behaviors (Marcus et al., 1998; Peterson \& Aldana, 1999a). Critical to each 
stage of behavior change is the process in which change occurs. Using strategies with the most empirical support, messaging was created specific to each stage of change (see Table 3. .)

(Johnson \& Cook, 2013; Marcus et al., 1998; Moore, Highstein, \& Tschannen-Moran, 2010;

Prochaska, Redding, Evers, Glanz, Lewis, \& Rimer, 2002).

Each stage-matched message was created by identifying key strategies from the process of change and motivational coaching literature and designed to advance participants from one stage of change to the next (Johnson \& Cook, 2013; M. Moore et al., 2010). Messaging was reviewed by experts in physical activity and public health research to verify that messages were aligned with strategies appropriate for each stage of change (see Appendix A.). Messages were analyzed using Flesch reading ease scale to ensure that messages were at a $7^{\text {th }}$-grade reading level or below. Participants received direct private messages from the activate! mascot "Brainy Jones" once per week specifically targeted to their stage of behavior change. After four weeks of stage-matched messaging, participants were reassessed on their stage of change and placed in an updated group dependent upon their response; this process continued every four weeks throughout the intervention.

\section{Table 3}

Focus of Stage-Matched Messages

$\begin{array}{ccc}\text { Stage of Change } & \text { Definition } & \begin{array}{c}\text { Primary } \\ \text { Goal of } \\ \text { Intervention }\end{array}\end{array}$

\begin{tabular}{|c|c|c|c|}
\hline 1. Precontemplation & $\begin{array}{l}\text { NOT READY: } \\
\text { Not yet willing to } \\
\text { change or } \\
\text { considering } \\
\text { change } \\
\text { "I won't/can't." }\end{array}$ & $\begin{array}{l}\text { To begin } \\
\text { thinking } \\
\text { about } \\
\text { changing }\end{array}$ & $\begin{array}{l}\text { A. Provide health information of } \\
\text { benefits } \\
\text { B. Reduce the actual and } \\
\text { perceived costs \& barriers } \\
\text { C. Strengthen actual and } \\
\text { perceived benefits of PA } \\
\text { D. Develop a stronger sense of } \\
\text { self-worth and confidence } \\
\text { E. Help to look at the barriers in a } \\
\text { positive and rational way so }\end{array}$ \\
\hline
\end{tabular}




\begin{tabular}{|c|c|c|c|}
\hline & & & $\begin{array}{l}\text { they can learn from them rather } \\
\text { than being overwhelmed by the } \\
\text { negative emotions generated } \\
\text { by past failures. } \\
\text { F. Social liberation - Ask } \\
\text { participants to identify social } \\
\text { trends that would make } \\
\text { exercise easier. } \\
\text { G. Environmental reevaluation - } \\
\text { Consider how sedentary } \\
\text { behavior might affect others. }\end{array}$ \\
\hline 2. Contemplation & $\begin{array}{l}\text { GETTING } \\
\text { READY: Sees the } \\
\text { possibility of } \\
\text { change but is } \\
\text { ambivalent or } \\
\text { uncertain } \\
\text { "I might" } \\
\text { Timeline: not } \\
\text { considering } \\
\text { changing in the } \\
\text { next month }\end{array}$ & $\begin{array}{l}\text { To begin to } \\
\text { adopt a } \\
\text { physically } \\
\text { active } \\
\text { lifestyle }\end{array}$ & $\begin{array}{l}\text { A. Build enthusiasm for change } \\
\text { B. Increase self-efficacy through } \\
\text { verbal persuasion } \\
\text { C. Evaluate pros and cons of } \\
\text { being PA } \\
\text { D. Motivate by role models and } \\
\text { success stories } \\
\text { E. Make the pros outweigh the } \\
\text { con's } \\
\text { F. Raise consciousness, become } \\
\text { informed. } \\
\text { G. Self-reevaluation, create a new } \\
\text { self-image- have participants } \\
\text { envision the changes in their } \\
\text { image that may occur with } \\
\text { regular PA. } \\
\text { H. Dramatic relief- Pay attention } \\
\text { to feelings- Provide examples } \\
\text { of success stories or ask } \\
\text { participants to reflect on } \\
\text { known story. Ask what if } \\
\text { questions about chronic } \\
\text { diseases and their PA habits. } \\
\text { (SS Johnson \& Cook, 2013) }\end{array}$ \\
\hline 3. Preparation & $\begin{array}{l}\text { READY: } \\
\text { Committed to } \\
\text { change but still } \\
\text { unsure of what to } \\
\text { do } \\
\text { "I will" } \\
\text { Timeline: } \\
\text { planning to }\end{array}$ & $\begin{array}{l}\text { To adopt a } \\
\text { physically } \\
\text { active } \\
\text { lifestyle _ } \\
\text { focus on } \\
\text { participant } \\
\text { preparing to } \\
\text { be successful } \\
\text { in making a } \\
\text { change. }\end{array}$ & $\begin{array}{l}\text { A. Assessment of physical and } \\
\text { psychosocial traits } \\
\text { B. Clarify the participants own } \\
\text { goals and strategies for change. } \\
\text { C. Building confidence } \\
\text { D. Self-monitoring activities } \\
\text { E. Evaluate environment and } \\
\text { social support } \\
\text { F. Evaluate and minimize barriers } \\
\text { to modifying behavior }\end{array}$ \\
\hline
\end{tabular}


change in the next

month

G. Provide a menu of physical activity options for participants to choose from.

H. Establish concrete plans for change.

\begin{tabular}{|c|c|c|c|}
\hline 4. Action & $\begin{array}{l}\text { Taking steps } \\
\text { toward change } \\
\text { "I am" } \\
\text { Timeline: 3-6 } \\
\text { months }\end{array}$ & $\begin{array}{l}\text { To establish } \\
\text { exercise as a } \\
\text { habit }\end{array}$ & $\begin{array}{l}\text { A. Find new re-enforcers } \\
\text { B. Rewards and punishment } \\
\text { C. Relapse/Slippage control } \\
\text { D. Assessment continued goal } \\
\text { setting } \\
\text { E. Take Control of your } \\
\text { environment } \\
\text { F. Helping relationships } \\
\text { G. Make a commitment } \\
\text { H. Counterconditioning- problem } \\
\text { solve to identify alternatives } \\
\text { that will work. }\end{array}$ \\
\hline 5. Maintenance & $\begin{array}{l}\text { Has achieved the } \\
\text { goal and is } \\
\text { working to } \\
\text { maintain change } \\
\text { "I have" } \\
\text { Timeline: Post } 6 \\
\text { months to } 5 \text { years }\end{array}$ & PA is a habit & $\begin{array}{l}\text { A. Re-evaluate goals at regular } \\
\text { intervals } \\
\text { B. Social support } \\
\text { C. Progression } \\
\text { D. Counterconditioning } \\
\text { E. Stimulus control } \\
\text { F. Role Modeling } \\
\text { Relapse/slippage control }\end{array}$ \\
\hline
\end{tabular}

*Note: Example messaging can be found in Appendix D

The core messages and stage-matched messages were delivered to each parent participate for nineteen weeks on the following schedule (see Table 4):

Table 4

Messaging schedule

\begin{tabular}{l|l|l|l|l}
\hline Monday & Tuesday & Wednesday & Thursday & Friday \\
Core message & & Core message & & $\begin{array}{l}\text { Stage-matched } \\
\text { message }\end{array}$ \\
\hline
\end{tabular}

\section{Design \& Procedures}

Parents and their child who consented to participate in the study completed the baseline survey (Appendix B) and were assigned to the control or intervention group of project activate! 
(see Figure 2). The control group received no additional support during the project's nineteenweek period, and then completed the post-survey (Appendix B) to measure natural changes that can be expected without exposure to the intervention treatment. After completing the baseline survey, parents in the intervention group met with trained community health workers to receive their initial twenty-five dollar gift card incentive and Fitbit ${ }^{\circledR}$ devices. At this time parents enrolled in the activate! cohort 2 private Facebook group and received a friend request from "Brainy Jones," the activate! mascot. Other face-to-face meetings (Family Orientation meeting, and Family Fun Nights, and activate! community health workers' scheduled communication) gave researchers additional opportunities to recruit parents to participate in the activate! Facebook group.

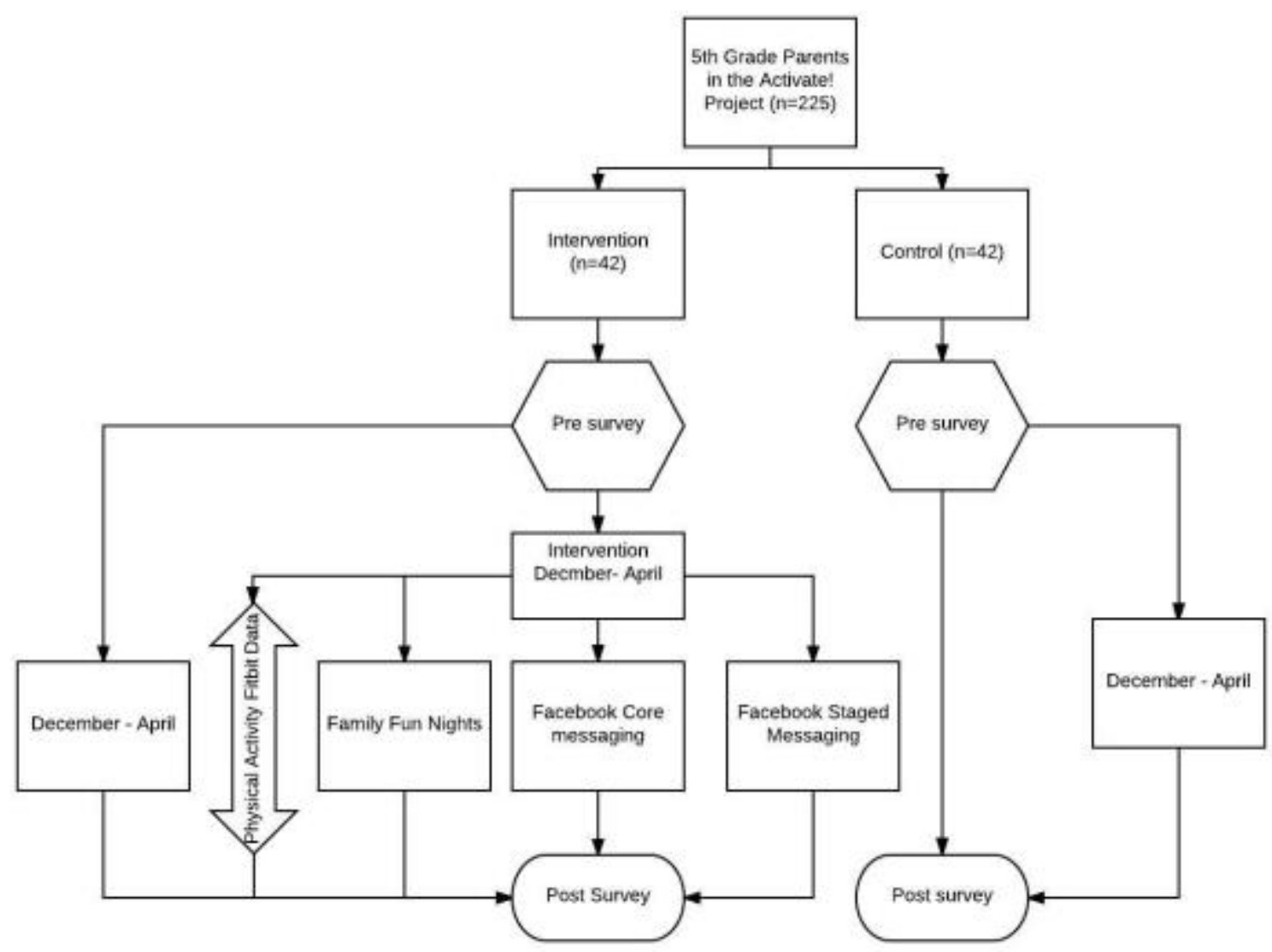


Figure 2. Study Design

\section{Assessments and Outcomes Measures}

Study outcomes were measured using the pre/post Parent Physical Activity Questionnaire, and through Facebook analytical data and monitoring.

Parent Physical Activity Questionnaire. The Parent Physical Activity Questionnaire contains survey items related to participants' stage of PA behavior change, physical activity behavior, physical activity attitudes, and the home environment. The posttest also includes items to determine perceptions of using social media (i.e. Facebook) for physical activity support and communication. The Parent Physical Activity Questionnaire was administered two times, at baseline, and at the conclusion of Week 19 (end of project year) (see Table 5). Measurement of the four specific target areas is described in more detail in the following sections.

Behavior change questionnaire items. Physical activity behavior change was assessed using several subscales on the survey instrument. The primary measure of behavior change was assessed using an adapted version of the Physical Activity Behavior Change Scale. The Kappa index of reliability for the original measure over a two-week period was $r=.78$ (Marcus et al., 1992). Reviews of interventions that are matched to a person's stage of behavior change provide evidence that messaging directed towards a person's stage of change can be extremely effective (Krebs, Prochaska, \& Rossi, 2010; Noar et al., 2007). That made it necessary to assess each person's stage of change at the beginning of the intervention and throughout to make sure that messaging stayed consistent with a person's readiness to change.

Intervention participants completed the Physical Activity Behavior Change Scale (see Appendix B) and rated their readiness to change based on the Readiness Ruler (see Appendix B) 
every four weeks throughout the intervention (D’Onofrio, Bernstein, \& Rollnick, 1996; Marcus et al., 1992). If participants moved to a new stage of readiness for behavior change, they received a congratulatory message and were placed into the updated group.

Perceived barriers are defined as obstacles to acting; these perceived barriers can impede action and delay a person's behavior change and can be operationalized as cons of changing behavior. One of the key strategies for behavior change is to minimize the cons of physical activity behavior change if participants do not realize a full change in behavior a more sensitive measure of behavior change can be identified through a reduction of perceived cons (Prochaska, Velicer, \& Rossi, 1994). The survey question consisted of a list of the top ten barriers to physical activity identified by the CDC (Sallis \& Hovell, 1990). Using a four-point Likert scale from "rarely" to "often," parents were asked to identify: "how often do the following things prevent you from being physically active ?" Aggregation of these ten measures provided a score of perceived barriers.

Self-efficacy reflects the degree in which a person believes that they can take a positive action when confronted with a task related to changing their behavior, and is an underlying construct of behavior change (Johnson \& Cook, 2013). To measure perceived self-efficacy as it relates to making sustainable physical activity behavior change, a 12-item scale was adapted from the initial 17-item Physical activity self-efficacy scale (Ryckman, Robbins, \& Thornton, 1982). Parents were asked to rate their belief that they would be able to motivate themselves to engage in 12 physical activity behaviors on a 4-point Likert scale ranging from "I know I cannot" to "I know I can." Aggregation of these twelve measures will provide a score of perceived self-efficacy. 
Parent PA recall. Part one of the physical activity behavior change scale consisted of a 7day recall where parents' reported the number of days per week where they recorded at least thirty minutes of moderate to vigorous physical activity. Physical activity measures from the instrument have shown moderate levels of reliability as a tool to assess seven-day physical activity $(r=.29-.46)$ with higher levels of accuracy being demonstrated in women (Carlson, Sallis, Wagner, Calfas, Patrick, Groesz, et al., 2012). Results from the physical activity behavior change questionnaire part one was converted into a PA minutes per week. Active minutes were recorded at baseline, and posttest, to determine differences in daily PA habits before and after the intervention.

Parents also reported the amount of physical activity that their children received in each week. Parents were asked to recall how much time their child spent in moderate to vigorous physical activity over the last week. Again these values were compared at baseline and post-test to determine differences in daily PA habits for children before and after the intervention.

Parent attitudes questionnaire items. In the Theory of Reasoned Action and later refined in the Theory of Planned Behavior, researchers identified one of the most important determinants of physical activity behavior as behavioral intention. Behavioral intention is composed of a personal attitude toward physical activity and the subjective norm towards the activity (Ajzen \& Fishbein, 1977). Parent attitudes play a role not only on the physical activity behaviors of parents but also on the behaviors of the child (Kimiecik \& Horn, 1998).

Parents attitudes toward physical activity were assessed using 6-item scale adapted from the Physical Activity Attitude Questionnaire (Corbin, Lindsey, \& Welk, 2000). Aggregation of scores combined with a 1-item measure of enjoyment of physical activity provided a score of attitudes toward physical activity for parents (D’Onofrio et al., 1996). 
Home environment questionnaire items. Factors of the home environment have been shown to impact the physical activity habits of children. These factors include parental support for physical activity, parenting styles, and sedentary family behaviors (Davison \& Birch, 2001; Dempsey, Kimiecik, \& Horn, 1993; DiLorenzo, Stucky-Ropp, Vander Wal, \& Gotham, 1998; Golan, 2006).

Parental support for physical activity will be assessed using a 10-item family support scale developed for use in the activate! intervention by experts in family physical activity. This scale includes ten behaviors related to family support for physical activity. Parents use a Likerttype scale to select the frequency in which these behaviors occur within their home. An aggregate value of these scores will be created to generate an overall value for family support of physical activity.

The family health climate reflects upon the daily family life behaviors with respect to routines and interactions. A change in the family health climate can reflect the importance of physical activity as a part of daily life. For this study, the physical activity section of The Family Health Climate instrument was used, to assess changes in the home environment and consists of 10-items that describe the daily interactions and family values concerning physical activity. These items are assessed on a 4-point Likert scale ranging from "definitely false" - "definitely true." In a recent study, the perception of the family health climate demonstrated a strong correlation $(\mathrm{r}=.56)$ to physical activity outcomes in the family (Niermann, Krapf, \& Renner, 2014).

\section{Table 5}

Assessment Schedule 


\begin{tabular}{ll}
\hline Week & Instruments \\
\hline 1 (Baseline) & Questionnaire, SOC, Physical activity (2 weeks) \\
\hline 4 & SOC, Readiness Ruler \\
\hline 8 & SOC, Readiness Ruler \\
\hline 12 & Readiness Ruler, Physical activity (2 weeks) \\
\hline 16 & SOC, Readiness Ruler \\
\hline 19 (Final week of intervention) & Questionnaire, SOC, Readiness Ruler \\
\hline Note. SOC= Stage of Behavior Change Scale, Physical activity = Self-report days parents received \\
at least 30 minutes of PA.
\end{tabular}

Facebook analytical data and monitoring. Data from participant interactions with the Facebook group will be recorded to quantify participants level of engagement with social mediabased content. Engagement levels will be quantified for participants' interaction with core messaging content as well as stage-matched messaging.

Social media engagement. The hypothesis of this study suggests that parents who receive messaging targeted to improving components of parent physical activity, including the family home environment and parent's attitudes toward physical activity for themselves and for their children, will have improved outcomes in each of these areas. If this hypothesis is true, then parents' level of engagement with social media will mediate outcomes in these categories. Measures of engagement with the Facebook group will be assessed on two main outcomes: core messaging and stage-matched messaging. 
Core message engagement. Engagement with core messaging was analyzed using four main outcomes from Sociograph.io, a website analytics tool used to provide statistics on Facebook site interactions. Existing literature suggests that social media engagement is difficult to quantify as a standard score and should be considered individually for each social media site. High levels of engagement may look different for every type of Facebook page so engagement measures should be determined by site traffic (Sterne, 2010). Engagement scores for participants will be calculated by measuring the quantity of users' interactions with the Facebook core content and binning levels of engagement by quartile (see Table 6). Cut points for engagement level will be set for each of the quartile ranges and include categories for low, medium, high, and very-high engagement. Sociograph.io calculates engagement score by collecting data on Facebook interactions and summing values for total interactions across a defined date period. Additionally, participants' views with Facebook content were assessed and operationalized as a percentage of content viewed.

Stage-matched message engagement. Engagement with staged messaging content will be assessed by measuring participants' number of reads. Facebook allows group administrators to view message history and shows if and when users viewed messages. This data will be recorded for each participant. Participants will then be placed into one of four engagement categories. Table 6

Facebook Core/Staged Messaging Engagement Scoring

\begin{tabular}{llll}
\hline Engagement rating & No engagement & Low Engagement & High Engagement \\
\hline $\begin{array}{l}\text { Total engagement } \\
\text { percentile score }\end{array}$ & SME $=0$ & SME $<1$ & SME $>1$ \\
\hline
\end{tabular}

*Strategic Messaging engagement score $(\mathrm{SME})=$ Core Message Engagement $(\mathrm{CME})+$ Direct Message Engagement (DME) 


\section{Statistical Analysis}

Using data from the Project activate! pre and post survey, a repeated measures multivariate analysis of variance (MANOVA) was conducted to determine if there were significant differences between groups over time (two measurement periods, prior to the beginning of the intervention and at the completion of a 19-week intervention) in physical activity behavior change and family environment outcomes (Parents support, Home climate, SOC, Parent PA, Child PA, Parent Self-Efficacy, Parent Attitudes) based on participation in the intervention ("Control" coded as 0 "Intervention" coded as 1).

A secondary repeated measures MANOVA was conducted to determine if there were significant differences between levels of engagement over time, determined by how active a participant was with the Facebook group. Participants level of Core Message Engagement (CME) was calculated using sociography.io a $3^{\text {rd }}$ party analytics tool, engagement scores for participation in the group were summed by totaling interactions with content messaging by totaling, message views, reactions, comments and, shares. CME was then converted to a percentage by taking the actual score and dividing by the maximum score. Direct messaging engagement scores were calculated by taking the percentage of messages viewed. These percentages were then totaled to create a total score for both measures of Strategic Messaging Engagement (SME). SME was then coded into one of three values; no engagement, coded as a score of 0 , low engagement, coded as any value between 0 and 1 , and high engagement, any value greater than 1 . This would indicate that participants who engaged with over half of the intervention content would be considered high engagement, and participants who interacted with less than half of the content were considered low engagement. 
The analysis was designed to identify specific group differences in three main areas: 1) differences between the control and intervention groups 2) differences in the dependent variables based on the level of engagement in the Facebook group. 3) differences between levels of stagematched engagement and changes in stage of behavior change.

Dependent variables. The dependent variables for this study include stage of physical activity behavior change, parent attitudes toward physical activity, changes in the home environment, physical activity levels, and parent support for physical activity.

Independent variables. The 19-week stage-based intervention designed to increase participant's readiness to change physical activity behaviors, improve attitudes towards physical activity, and improve aspects of the home environment that contribute to increased physical activity served as the independent variable for this study. Within the intervention arm, there are two other independent variables broken down by engagement in the features of the Facebook site for core messaging and stage-matched messaging. Within the intervention independent variables, there are four levels determined by participant's level of engagement with the Facebook site, low engagement, moderate engagement, high engagement and very high engagement for each messaging type.

\section{Measures}

Outcome measures for this study came from the Parent Physical Activity Questionnaire developed for the activate! intervention, and analytic data that was recorded from participant's participation in the activate! Facebook group. The Parent Physical Activity Questionnaire consisted of five scale items for this study: Parent support for PA, Family Health Climate, Parent self-efficacy, Barriers to PA, Parent attitudes toward PA. Each of the scale items was analyzed using Cronbach's alpha for internal consistency before being used as scale variables. Results of 
the survey item reliability are presented in Table 6. Additional survey responses were collected using the Parent Physical Activity Questionnaire for Stage of behavior change; parent reported child PA, self-reported parent PA and demographic information.

\section{Table 6}

Parent Physical Activity Questionnaire Scale Items

\begin{tabular}{lcc}
\hline Scale & \multicolumn{2}{c}{ Cronbach's Alpha } \\
Measures & Pre & Post \\
\hline Parent Support & .856 & .869 \\
Family Health Climate & .91 & .875 \\
Parent Self Efficacy & .837 & .865 \\
Barriers to PA & .875 & .878 \\
Parent Attitudes & .778 & .848 \\
\hline
\end{tabular}

Note. Two items were removed from the parent attitude scale to bring the scale to acceptable levels of internal consistency

Group differences. Research question one is to determine if the addition of a Facebook group can have a significant difference in group mean outcome for the dependent variables. In this study, there are several dependent variables that can be influenced by membership in the intervention group (see Table 6). Multivariate analysis of variance (MANOVA) allowed for the evaluation of differences across composite means of the dependent variables between groups (Tabachnick, Fidell, \& Osterlind, 2001). Additionally, MANOVA analysis provides outputs of each of the univariate analysis for each dependent variable while reducing Type 1 error. The MANOVA analysis also detected interactions and main effects between independent and dependent variables, on the differences between the intervention and control variables for physical activity levels, physical activity attitudes and the home environment to answer the 
primary research questions related to engagement with content within the Facebook group (see

\section{$\underline{\text { Table 7). }}$}

Stage of change is a categorical variable so it cannot be included in the MANOVA analysis as a dependent variable to detect group differences. Instead, a separate analysis, the Kruskal-Wallis test was conducted on the nonparametric dependent variable of behavior change. The Kruskal-Wallis test is a non-parametric alternative to the one-way between groups ANOVA and will detect any significant group differences across stages of change for each of the groups (Pallant, 2013).

\section{Table 7}

Analysis of research questions

\begin{tabular}{ll}
\hline Research Question & Proposed Analysis \\
\hline $\begin{array}{l}\text { What impact does the inclusion of a strategic } \\
\text { messaging campaign within a Facebook group } \\
\text { have on parent's physical activity behaviors } \\
\text { (Family Health Climate (FHC), Stage of Change }\end{array}$ & $\begin{array}{l}\text { MANOVA- Main effects between the } \\
\text { control group and intervention group for } \\
\text { each level of engagement. }\end{array}$ \\
$\begin{array}{l}\text { (SOC), Parent Support for Physical Activity } \\
\text { (PSPA) and Physical Activity (PA) levels) and }\end{array}$ & \\
$\begin{array}{l}\text { attitudes in an existing family-based physical } \\
\text { activity intervention? }\end{array}$ & \\
\hline $\begin{array}{l}\text { Does parents' level of engagement in a Facebook } \\
\text { group affect their physical activity behaviors } \\
\text { (FHC, SOC, PSPA, and PA levels) and attitudes } \\
\text { in an existing family-based physical activity } \\
\text { intervention? }\end{array}$ & $\begin{array}{l}\text { MANOVA- Interaction effects between } \\
\text { attitudes. }\end{array}$ \\
\hline $\begin{array}{l}\text { Does the delivery of tailored messaging based on } \\
\text { the TTM and delivered through Facebook } \\
\text { influence a parent's readiness to change their PA } \\
\text { behaviors? }\end{array}$ & $\begin{array}{l}\text { Kruskal-Wallis - Analysis of statistically } \\
\text { significant median differences between } \\
\text { groups based on Stage-matched IV }\end{array}$ \\
\hline
\end{tabular}




\section{Results}

\section{Sample Characteristics}

A total of 101 parents completed pre and post survey instruments, 57 parents in the control group and 44 parents in the family intervention group. Seventeen participants failed to complete more than $50 \%$ of the survey items and were removed from the analysis. A total of 84 participants were included in the final analysis, 42 parents in the control group and 42 parents in the family intervention group. Across the sample, $87.4 \%$ of study parents used Facebook. There were no significant differences between the frequency of Facebook use $(p=.285)$, and neither group reported significantly higher use of any other social media site $(\mathrm{p}=.888)$. The majority of study participants reported that they accessed Facebook on a regular basis (see Table 8).

Table 8

Facebook Use

\begin{tabular}{lllllllllllll}
\hline & \multicolumn{2}{l}{$\begin{array}{l}\text { Multiple times per } \\
\text { day }\end{array}$} & & Daily & & Weekly & Monthly & \multicolumn{2}{l}{ Never } \\
\hline Control & $40.9 \%$ & $\mathrm{n}=18$ & $36.4 \%$ & $\mathrm{n}=16$ & $4.5 \%$ & $\mathrm{n}=2$ & $6.8 \%$ & $\mathrm{n}=3$ & $11.4 \%$ & $\mathrm{n}=5$ \\
& & & & & & & & & & \\
Intervention & $50.0 \%$ & $\mathrm{n}=21$ & $26.2 \%$ & $\mathrm{n}=11$ & $19.0 \%$ & $\mathrm{n}=8$ & $0.0 \%$ & $\mathrm{n}=0$ & $4.8 \%$ & $\mathrm{n}=2$ \\
\hline
\end{tabular}

Study participants were disproportionately female; $90.8 \%$ of participants were female between the ages of $30-40(69.6 \%)$, with $24.5 \%$ of parents reporting an age over forty years and only $6.7 \%$ reporting their age as under 30 years (see Table 9).

Table 9

Participant Characteristics

Age $\quad 30$ or under $\quad 30-40 \quad 40-45 \quad 46$ or older $\quad$ Total




\begin{tabular}{lllllllllll}
\hline Male & $0.0 \%$ & 0 & $71.4 \%$ & 5 & $14.3 \%$ & 1 & $14.3 \%$ & 1 & $100.0 \%$ & 7 \\
& & & & & & & & & & \\
Female & $6.7 \%$ & 5 & $70.7 \%$ & 53 & $10.7 \%$ & 8 & $12.0 \%$ & 9 & $100.0 \%$ & 75 \\
\hline
\end{tabular}

\section{Strategic Messaging Impact on Health Behaviors and Attitudes}

Research question one investigated what impact the inclusion of a strategic messaging campaign within a Facebook group had on parents' physical activity behaviors (i.e.,FHC, Parent Support, Parent SE, Barriers to PA, Parent PA, Child PA, and SOC) and attitudes in an existing family-based physical activity intervention.

The results from the repeated measures MANOVA demonstrated a significant difference between the time points depending on the group on the linear combination of dependent variables, Wilk's Lambda $=0.77, \mathrm{~F}=2.866, \mathrm{p}=0.01$, partial $\mathrm{eta}^{2}=0.23$. This indicates that the control and intervention groups differed based on the combination of dependent variables $(\mathrm{F}(8$, $75)=2.33, p=.027$, partial $\left.\eta^{2}=.199\right)$. Partial eta square suggested a large main effect for groups. Closer inspection of the univariate analysis showed that parents in the intervention group showed a greater level of improvement on measures of family health climate $[\mathrm{F}(1)=5.611, \mathrm{p}=$ 0.02, partial eta $\left.{ }^{2}=0.06\right]$, parents' support $\left[\mathrm{F}(1)=8.699, \mathrm{p}=0.00\right.$, partial eta $\left.{ }^{2}=0.10\right]$, and selfefficacy $\left[F(1)=4.623, p=0.03\right.$, partial eta $\left.^{2}=0.05\right]$ on the mean differences between baseline and posttest. The intervention group improved all three dimensions, while the control group showed no significant differences (see Table 10).

In order to assess the degree of change in scores between the family intervention participants and the control participants, the net change of each mean score for each group was calculated by subtracting the pretest score from the post-test score. Differences in means of 
scaled scores for each group are also included in Table 10 for each variable. These results indicate that strategic messaging has a positive effect on parents' health behaviors related to the development of the FHC, PSPA, and Parent Self-efficacy. Strategic messaging did not appear to have a significant effect on any other measures of health behaviors or attitudes.

\section{Table 10}

Mean Differences Between Groups

\begin{tabular}{|c|c|c|c|c|c|c|c|}
\hline & \multicolumn{2}{|c|}{ Control } & \multicolumn{2}{|c|}{ Family } & \multirow{2}{*}{$\begin{array}{l}\text { Sig } \\
p=\end{array}$} & \multirow{2}{*}{$\begin{array}{l}\text { Effect } \\
\eta^{2}=\end{array}$} \\
\hline & & Mean & SD & Mean & SD & & \\
\hline \multirow{3}{*}{$\begin{array}{l}\text { Family Health } \\
\text { Climate* }\end{array}$} & Pre & 31.5952 & 7.91744 & 27.0952 & 10.68806 & \multirow[t]{3}{*}{.02} & \multirow[t]{3}{*}{.064} \\
\hline & Post & 30.459 & 9.58687 & 31.2143 & 6.66822 & & \\
\hline & Change & -1.1362 & & 4.1191 & & & \\
\hline \multirow{3}{*}{$\begin{array}{l}\text { Parent } \\
\text { Support* }\end{array}$} & Pre & 41.1905 & 6.25568 & 32.2857 & 15.87802 & \multirow[t]{3}{*}{.004} & \multirow[t]{3}{*}{.096} \\
\hline & Post & 41.0714 & 9.32187 & 39.9762 & 6.38782 & & \\
\hline & Change & -0.1191 & & 7.6905 & & & \\
\hline \multirow{3}{*}{$\begin{array}{l}\text { Parent Self- } \\
\text { efficacy* }\end{array}$} & Pre & 31.4048 & 5.04642 & 26.3571 & 10.20478 & \multirow[t]{3}{*}{.034} & \multirow[t]{3}{*}{.053} \\
\hline & Post & 30.3571 & 6.89228 & 29.2381 & 4.89305 & & \\
\hline & Change & -1.0477 & & 2.881 & & & \\
\hline \multirow{3}{*}{$\begin{array}{l}\text { Stage of } \\
\text { change }\end{array}$} & Pre & 2.9524 & 1.41339 & 2.4286 & 1.06251 & \multirow[t]{3}{*}{.357} & \multirow[t]{3}{*}{.010} \\
\hline & Post & 3.119 & 1.27265 & 2.3333 & 1.00406 & & \\
\hline & Change & 0.1666 & & -0.0953 & & & \\
\hline \multirow{3}{*}{$\begin{array}{l}\text { Parent PA } \\
\text { (days per } \\
\text { week) }\end{array}$} & Pre & 3.0714 & 2.09986 & 2.7831 & 1.35283 & \multirow[t]{3}{*}{.143} & \multirow[t]{3}{*}{.026} \\
\hline & Post & 3.619 & 1.63726 & 2.7664 & 1.46291 & & \\
\hline & Change & 0.5476 & & -0.0167 & & & \\
\hline \multirow{3}{*}{$\begin{array}{l}\text { Child PA } \\
\text { (Weekend } \\
\text { Minutes) }\end{array}$} & Pre & 276.3652 & 209.50248 & 220.8682 & 178.72082 & \multirow[t]{3}{*}{697} & \multirow[t]{3}{*}{.002} \\
\hline & Post & 311.734 & 196.88632 & 274.8001 & 166.33376 & & \\
\hline & Change & 35.3688 & & 53.9319 & & & \\
\hline
\end{tabular}




\begin{tabular}{llllllll}
\hline PA Attitude & Pre & 16.2857 & 2.25341 & 15.6833 & 2.7798 & .678 & .002 \\
& Post & 16.3095 & 2.6085 & 16.2381 & 2.39725 & & \\
& Change & 0.0238 & & 0.5548 & & & \\
\hline Barriers & Pre & 20.0476 & 6.2076 & 22.119 & 10.48158 & .484 & .006 \\
& Post & 20.881 & 7.18468 & 24.2381 & 6.07999 & & \\
& Change & 0.8334 & & 2.1191 & & &
\end{tabular}

Note. Significant findings indicated with *

\section{Differences in Parent Outcomes Based on Social Media Engagement}

Research question two investigated how engagement in a Facebook group affected parents' physical activity behaviors ((Family Health Climate (FHC), Stage of Change (SOC), Parent Support for Physical Activity (PSPA) and Physical Activity (PA) levels)) and attitudes in an existing family-based physical activity intervention.

Overall, the model was significant for describing differences in the combination of dependent variables based on parent's level of engagement with the Facebook group $[\mathrm{F}(6,76)=$ $2.678, p=.021$, partial $\left.\eta^{2}=.175\right]$. A significant interaction effect between parent social media engagement and time for family health climate $(\mathrm{F}(2,39)=5.347, p=.009)$, and parent selfefficacy $(\mathrm{F}(2,39)=4.562, p=.017)$ was found dependent upon a person's level of engagement. This finding indicates that participants' family health climate and level of self-efficacy differed significantly dependent upon their level of engagement with the Facebook group during the intervention. Examination of the mean differences between pre and post for each level revealed a linear improvement in participant outcomes for both family health climate and self-efficacy by the level of engagement (see Table 11). The more a participant engaged with the strategic messaging delivered through the Facebook group, the more their reported self-efficacy $(\mathrm{p}=.017)$ 
and family health climate ratings increased $(\mathrm{p}=.049)$. The remaining interaction terms revealed no other significant interactions.

\section{Table 11}

Mean Differences by Engagement Level

\begin{tabular}{|c|c|c|c|c|c|c|c|}
\hline \multirow[b]{2}{*}{ Measures } & \multicolumn{3}{|c|}{ No Engagement } & \multicolumn{2}{|c|}{ Low Engagement } & \multicolumn{2}{|c|}{ High Engagement } \\
\hline & & Mean & SE & Mean & SE & Mean & SE \\
\hline \multirow{3}{*}{$\begin{array}{l}\text { *Family Health } \\
\text { Climate }\end{array}$} & Pre & 27.462 & 2.982 & 30.3 & 3.4 & 25.158 & 2.466 \\
\hline & Post & 31.769 & 1.706 & 35.7 & 1.945 & 28.474 & 1.411 \\
\hline & Change & 4.307 & & 5.4 & & 3.316 & \\
\hline \multirow[t]{3}{*}{ Parent Support } & Pre & 34.615 & 4.429 & 35.6 & 5.05 & 28.947 & 2.466 \\
\hline & Post & 38.846 & 1.758 & 42.8 & 2.004 & 39.263 & 1.411 \\
\hline & Change & 4.231 & & 7.2 & & 10.316 & \\
\hline \multirow{3}{*}{$\begin{array}{l}\text { *Parent Self- } \\
\text { efficacy }\end{array}$} & Pre & 30.769 & 2.703 & 28 & 3.081 & 22.474 & 2.235 \\
\hline & Post & 31.154 & 1.28 & 30.7 & 1.459 & 27.158 & 1.059 \\
\hline & Change & 0.385 & & 2.7 & & 4.684 & \\
\hline \multirow[t]{3}{*}{ SOC } & Pre & 2.385 & 0.302 & 2.5 & 0.344 & 2.421 & 0.25 \\
\hline & Post & 2.154 & 0.279 & 2.7 & 0.318 & 2.263 & 0.231 \\
\hline & Change & -0.231 & & 0.2 & & -0.158 & \\
\hline \multirow{3}{*}{$\begin{array}{l}\text { Parent PA (days } \\
\text { per week) }\end{array}$} & Pre & 3 & 0.382 & 2.6 & 0.436 & 2.731 & 0.316 \\
\hline & Post & 2.385 & 0.409 & 3.019 & 0.467 & 2.895 & 0.338 \\
\hline & Change & -0.615 & & 0.419 & & 0.164 & \\
\hline \multirow{3}{*}{$\begin{array}{l}\text { Child PA } \\
\text { (Weekend } \\
\text { Minutes) }\end{array}$} & Pre & 170.737 & 39.917 & 164.459 & 45.513 & 123.673 & 33.019 \\
\hline & Post & 218.301 & 30.397 & 216.783 & 34.658 & 99.57 & 25.143 \\
\hline & Change & 47.564 & & 52.324 & & -24.103 & \\
\hline \multirow[t]{3}{*}{ PA Attitude } & Pre & 23.543 & 0.776 & 22.5 & 0.884 & 21.768 & 0.641 \\
\hline & Post & 23.385 & 0.83 & 23.9 & 0.946 & 22.401 & 0.687 \\
\hline & Change & -0.158 & & 1.4 & & 0.633 & \\
\hline
\end{tabular}




\begin{tabular}{llrrrrrr}
\hline Barriers & Pre & 23.154 & 2.969 & 20.7 & 3.386 & 22.158 & 2.456 \\
& Post & 22.385 & 1.574 & 21.5 & 1.795 & 26.947 & 1.302 \\
& Change & -0.769 & & 0.8 & & 4.789 &
\end{tabular}

Note. Significant findings indicated with *

\section{Effectiveness of Tailored Messaging on SOC}

The third research question investigated the effectiveness of delivering a stage-matched physical activity behavior change intervention using Facebook as the delivery mode.

Distributions of SOC scores were not similar, as assessed by visual inspection of a boxplot (see Figure 3). The mean rank of SOC scores was not statistically significantly different between groups $[\chi 2(1)=0.082, p=.774]$. These results indicate that there were no statistically significant differences between the two conditions. A secondary Friedman test was run to determine if there were differences in SOC over time. The control group median SOC increased from pre (Mdn = $2)$, to post-intervention $(\mathrm{Mdn}=3)$, but the differences were not statistically significant $\left[\chi^{2}(1)=\right.$ $1.471, \mathrm{p}=.225]$. The tailored message groups medians did not differ from pre $(\mathrm{Mdn}=2)$ to postintervention $(\mathrm{Mdn}=2)$. 


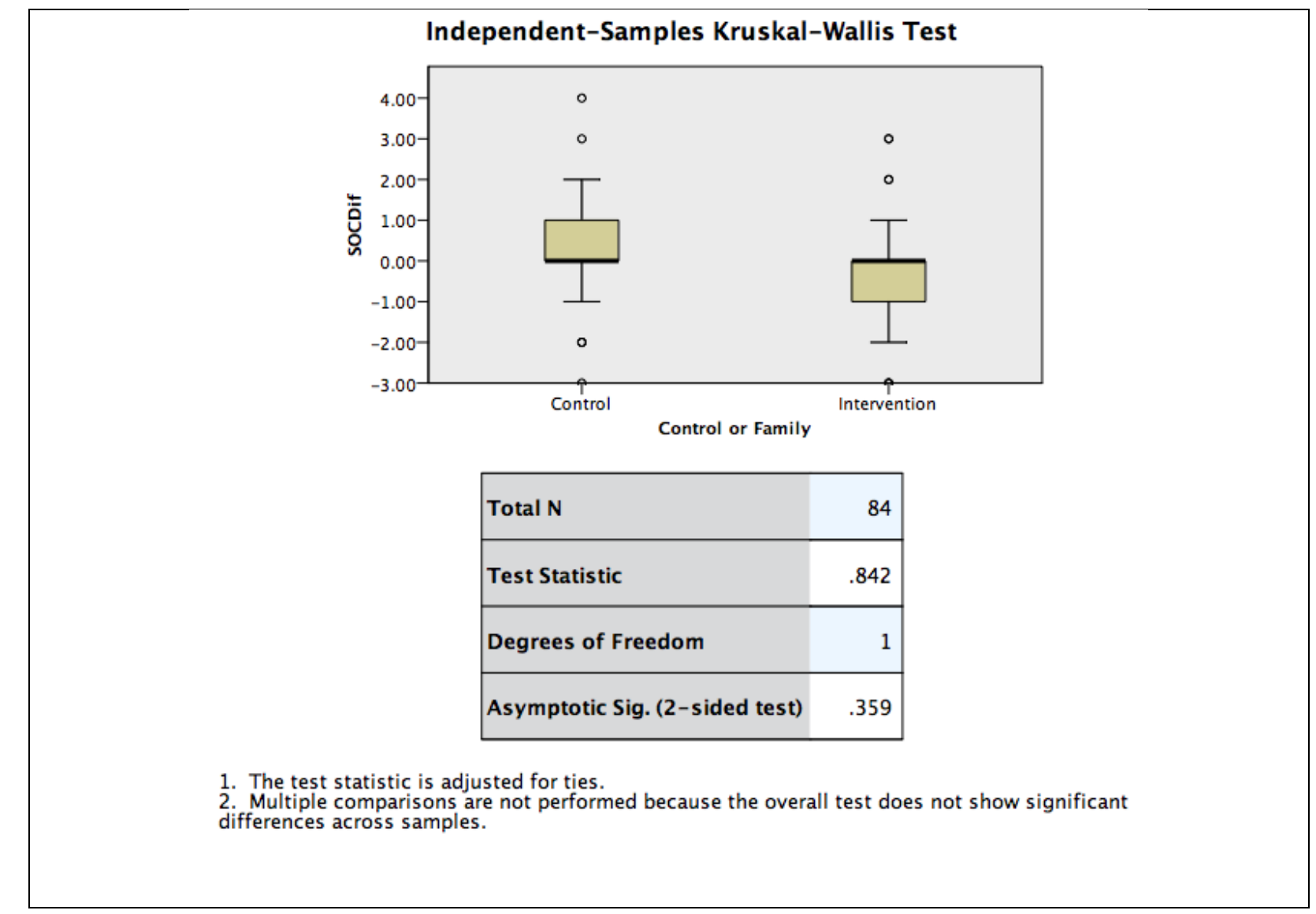

Figure 3. Kruskal-Wallis Test boxplot

\section{Discussion}

In an effort to combat physical inactivity, the home and family are important areas of concern, and have led to the development of a large number of programs designed to educate and to change physical activity behaviors within the family unit (Beech \& Klesges, 2003;

Kitzman-Ulrich, Hampson, Wilson, Presnell, Brown, \& O 'Boyle, 2009; Welk, 1999). This study sought to investigate how to best structure programs that incorporate strategic messaging campaigns of this type within the context of social media.

The initial research question of this study sought to explore what impact the inclusion of a strategic messaging campaign within a Facebook group can have on parents' physical activity 
behaviors including Family Health Climate, Stage Of Change, Parent Support for Physical Activity, Physical Activity levels and attitudes in an existing family-based physical activity intervention. Analysis of the data from the Parent Physical Activity Questionnaire and analytical data from the activate! Facebook group indicated statistically significant positive outcomes for family health climate, parent support for physical activity and parent self-efficacy.

The Family Health Climate reflects upon the daily family life behaviors with respect to routines and interactions. A positive Family Health Climate reflects families' values towards being physically active as an important part of their daily life. Parent value for physical activity has been tied to an improvement in physical activity behaviors in children (Beets \& Cardinal, 2010). The outcomes from this study showed significant improvements for parents FHC, which demonstrates some potential in the use of social media to help to develop value for physical activity with families and parents using social media as the delivery channel.

The main strategy that was used to influence the FHC was derived from the core messaging content developed for this study. The primary strategies used to influence FHC were messaging geared towards emphasizing the benefits and values of physical activity for parents and their children, as well as the influence of the home environment in promoting physical activity. These strategies used Facebook delivery to show parents how the home and family can be an important area of influence in their child's PA habits, sample messages from this strategy can be found in appendix E.

In this study Parents' didn't change their attitude towards physical activity related to their own participation, nor did they significantly change their existing stage of change from pre-topost. Participants in the intervention group may have had more positive attitudes towards physical activity at baseline, because of an overestimation of their own physical activity habits. 
Weinstein and colleagues (1998) caution researchers to take care when interpreting stage of change studies as often participants initial stage of change and estimation of initial physical activity levels do not match their subjective estimation. Anecdotal evidence from the Facebook group suggests that this may have been the case within our study. Parents who took the monthly stage of change measure delivered through the Facebook site showed an immediate reduction in stage of change from their baseline scores after just one week of tailored messaging. Part of the educational messaging delivered through the intervention informed parents of the minimum daily recommendations for physical activity; parents' who had not understood how much physical activity they needed to get may have been overestimating their initial physical activity levels which may have influenced their attitude towards physical activity and their perception of their existing stage of change.

Additionally, the nature of the TTM allows for a fluid stage of change where often participants relapse as they become comfortable with their current stage of change. To get a better sense of how a person is moving through the stages of change it may be beneficial to look at sub-constructs of the SOC instead of trying to see full-scale changes. Self-efficacy has been shown to be a good indicator of progress in SOC and may better represent changes in participants PA behaviors (Berry, Naylor, \& Wharf-Higgins, 2005). Future studies should consider looking at assessing decisional balance and parent self-efficacy as indicators of behavior change and consider assessing baseline levels after providing initial education on minimum recommendations for daily physical activity to avoid problems of overestimation and the natural relapse of SOC measures.

Parents' support is a major correlate of child physical activity related to increasing physical activity in the home environment (Sallis, Prochaska, \& Taylor, 2000). Parent support 
was highly influenced by participation in the intervention. Tailored messaging delivered through the Facebook group provided consistent education on the importance of parent support throughout the 19-week intervention. The education delivered through this messaging improved parent support for their children's physical activity and provides support for the use of Facebook groups in collaboration with an existing intervention as a tool for improving parent support for physical activity. Parents in the group seemed to be much more responsive when content focused specifically on supporting or influencing the PA of their children. Messaging delivered through direct messaging, and the group page had more interactions when the content was specific to PA within the family than content that focused on the parent's PA habits. These indications emphasize the importance of the family as a component of the intervention.

The use of activity tracker wearables (i.e. Fitbits) for the study was intended to provide objective physical activity data of participants' daily PA behaviors. However, because of insufficient wear time and data loss there was not sufficient PA data to compare baseline and post PA levels using this data. Over the nineteen-week period parents seemed to lose interest in the use of the Fitbit device or had technical issues syncing the device, leading many parents to abandon regular wear of their device. Instead subjective measures of parents weekly physical activity were derived from the PA recall questions on the Parent Physical Activity Questionnaire. Parents indicated how many days per week they achieved more than thirty minutes of moderate to vigorous physical activity. There were no significant changes in self-reported physical activity data over the intervention period. Again, the results of our physical activity self-reported data may indicate an overestimation of parent's initial physical activity levels. Ideally interventions should look for objective measures of physical activity to quantify physical activity levels. The 
use of wearable technology such as Fitbits in this study are not recommended, given the reliance on study participant's to regularly sync their device for researchers to be able to access data.

Research question two was designed to explore how the level of engagement influenced physical activity behaviors within an existing intervention. Similarly, family health climate and parent self-efficacy outcomes improved significantly dependent upon a person's level of engagement with the Facebook group, while all other study variables were not significant.

The ability of this intervention to influence parents' perceptions of the value of physical activity within the home was dependent upon how they interacted with the Facebook group. Parents who showed at least low levels of engagement in the Facebook group significantly improved their outcomes related to their family health environment. However, this relationship did not follow a linear path, low levels of engagement were actually more beneficial to influencing the home environment than the higher levels of engagement, which may indicate that the level of engagement has a saturation point where content begins to become less effective. Another interesting point to note was the differences between baseline scores for FHC and SE, participants who had the highest levels of engagement also had the lowest scores at baseline. Additional research is needed to qualitatively investigate how parents at each level of engagement interpret content messaging and participant characteristics as well as to understand more about a potential saturation point for intervention messaging. While there is some question related to how much engagement is needed to make Facebook a useful tool, these findings did indicate that Facebook is a useful tool for communicating tailored health messaging and that intervention designers should look for unique ways to encourage engagement in Facebook groups to improve measures of the family home environment. 
Parent self-efficacy was significantly influenced by participant's level of engagement with the Facebook group. The more interaction parents had with the Facebook group, the higher their level of physical activity-related self-efficacy. Self-efficacy is related to physical activity behavior change and may be an important indicator of the overall effectiveness of using social media to influence parent physical activity behavior change (Bess H. Marcus, Selby, Niaura, \& Rossi, 1992). However, within this study engagement actually negatively influenced participants SOC, though these findings were not significant, they are interesting to note given the increase in levels of SE that occurred opposite to SOC. SE has been shown to be a predictor of SOC and is often used as a proxy variable for determining changes in PA behaviors (Berry et al., 2005). The fluid nature of SOC as well as potential overestimation at baseline may have caused this irregularity within the SOC relationship. Future studies should include multiple constructs of SOC and consider giving baseline survey content during the initial PA data collection period to ensure parents have a grasp on their PA behaviors.

The third research question was to explore the effectiveness of providing physical activity behavior change tailored messaging through Facebook on parents' readiness to change their physical activity behavior. The goal of this component of the project was to use a tailored approach for each participant designed to move a participant from one stage of change to the next. This study found no significant effect of the direct message engagement in influencing the participants' readiness to change. Again, part of the inability to detect change may have been caused by participant's overestimation of their initial stage of change. However, overall stage of change may be too broad of a measure for use with social media delivered interventions. It may then be more useful to measure the sub contexts of stage of behavior change, measures like self- 
efficacy and decisional balance may be better suited to detect a less drastic change in short-term web-based interventions like these.

This study provides evidence that Facebook can be used effectively within family physical activity interventions to improve parents physical activity values, support for physical activity in the family, as well as parent self-efficacy. These findings agree with existing research that shows a great potential for the use of social media within physical activity interventions (David N. Cavallo, Tate, Ries, Brown, Devellis, \& Ammerman, 2012; Maher et al., 2014). There is still a great deal of potential that has not been uncovered when using social media-based tools with interventions, and it is still unclear if social media can be used as the exclusive delivery tool for physical activity interventions. What is clear is that the addition of social media can provide an effective communication channel to existing interventions. Researchers conducting modern family-based physical activity intervention programs should consider available social media tools as a way to enhance the delivery of their programs.

\section{Comparison to Previous Work}

The existing body of literature on the use of social media as a tool to improve physical activity behaviors, has investigated strategies to increase social support, MVPA, and PA Self efficacy (Cavallo, Tate, Ward, DeVellis, Thayer, \& Ammerman, 2014; Maher, et al., 2015; Napolitano, Hayes, Bennett, Ives, \& Foster, 2013). These studies have all made recommendations for the need for additional work to understand the potential of social media as a tool for health communications. This study makes important contributions to the body of literature as the first tailored messaging approach used in a Facebook PA intervention. While tailored messaging using Facebook has been effective in smoking cessation literature, this study was the first to apply tailored messaging strategies to a PA intervention (Thrul, Klein, \& Ramo, 
2015b). And while this study was unable to detect significant differences in paticipants readiness to change their PA behaviors, it's notable that participants self-efficacy for PA was significantly improved by participation in the Facebook group, this study is the first Facebook based study to demonstrate significance in this area (Maher et al., 2014).

To our knowledge no other Social media based PA study has been specifically targeted towards parents to date. This study was able to establish a precedent for future work, by establish significant improvements in the Family Health Climate and Parent support for PA. Future study's should consider these factors when creating strategies to target parents using social media based approaches.

Core messaging was linked to FHC and PSPA, through the messaging based on Benefits and values of physical activity for their child and themselves as well as messaging geared toward demonstrating the influences of the home environment on child physical activity (see Appendix E).

\section{Practical Implications}

This study provides researchers and health promotion profesionals insight into effective strategies for social media based physical activity promotion. Messaging that was related to parents influence on their child physical activity behaviors were effective in making changes related to participants perceptions of the family health climate and factors of parent support. Health professionals that are considering Facebook as a delivery tool for PA messaging should consider incorporating factors related to the influence parents can have on their childrens PA habits. 
Additionally parent self efficacy was positively influenced using direct tailored messaging, delivered through Facebook. This study is the first social media based intervention to demonstrate improvements in participants PA self efficacy levels. Researchers that are attempting to advance PA behavior change should utilize messaging that is specifically tailored to participants SOC in order to make improvements in levels of PA self efficacy.

While this study demonstrated that engagement levels play a role in how successful participants are in improving health behaviors. It was difficult to determine if there was a threshold for engagement levels. Participants who at least engaged somewhat were certainly more succecful in changing health related baheviors however higher levels of engagement did not continuely improve these outcomes. This may be due to an oversaturation of intervention content that made the prospect of changing behavior seem too daunting for participants who may have not been ready for that level of lifestyle change. Further studies should look into how this effect influences participants success in Facebook based PA interventions.

\section{Strengths and Limitations}

The primary strength of this study is that it was one of the first of its kind to use social media as the delivery system to provide direct tailored messaging to intervention participants through Facebook using the Stage of Change Model. This provides future researchers with a starting point for the continued development of tailored messaging delivered through popular social media platforms.

This study did suffer from several limitations as well, participants' responses to baseline Stage of Change measures may have been overestimated as many participants did not accurately assess their existing physical activity habits and levels. Additionally, this study lacked an accurate objective measure of parent physical activity. The physical activity tracker wearable and 
platform chosen were heavily reliant on participants to record data consistently over the course of 19-weeks. Researchers should take care to structure data collection periods at regular intervals throughout the intervention period and incorporate checks to verify that participants have taken the time to sync their devices. Additionally, if participants are going to be issued a device from the intervention, it is recommended that participants be required to complete an in-person or web-based training on operation and care of their devices.

Another major limitation of this study was the relatively low sample size within each group, initial estimates placed over 100 participants per cell for the MANOVA analysis. However, the number of participants who completed both baseline and post assessments reduced the actual number to less than half of that projection.

\section{Future Directions}

This study used Facebook as the delivery system for the intervention messaging based on how frequently parents used Facebook as their preferred social media platform. Tools like Hootsuite, a social media management tool, allows users to deliver messaging through multiple different social media channels simultaneously. A continued investigation into the effectiveness of a variety of social media tools on physical activity intervention outcomes would be beneficial to intervention designers. Future studies should also investigate the details related to stages of behavior change when using tailored messaging. Specific measurement of decisional balance, self-efficacy, physical activity and the behavior change stages should all be considered as important measurement variables for future studies.

While this study found significant results for family health climate, parent support for physical activity and parent self-efficacy behaviors, mean differences indicated that there may be 
additional evidence to support social media as an effective intervention delivery tool. Future studies should seek larger samples to provide adequate power to detect smaller effects.

\section{References}

Ajzen, I., \& Fishbein, M. (1977). Attitude-behavior relations: A theoretical analysis and review of empirical research. Psychological Bulletin. Retrieved from http://psycnet.apa.org/journals/bul/84/5/888/

Andriani, H., Liao, C. Y., \& Kuo, H. W. (2015). Parental weight changes as key predictors of child weight changes. BMC Public Health, 15, 645. http://doi.org/10.1186/s12889-0152005-X

Armitage, C. J., \& Arden, M. A. (2008). How useful are the stages of change for targeting interventions? Randomized test of a brief intervention to reduce smoking. Health Psychology. Retrieved from http://psycnet.apa.org/journals/hea/27/6/789/

Bandura, A. (1971). Social learning theory. Social Learning Theory. http://doi.org/10.1111/j.1460-2466.1978.tb01621.x

Bandura, A. (1994). Self-efficacy. Retrieved from http://onlinelibrary.wiley.com/doi/10.1002/9780470479216.corpsy0836/full

Barlow, S. E., Dietz, W. H., Epstein, L. H., Gidding, S. S., Himes, J. H., Jonides, L., ... Story, M. (1998). Obesity Evaluation and Treatment: Expert Committee Recommendations. Pediatrics, 102(3).

Baughcum, A. E., Burklow, K. A., Deeks, C. M., Powers, S. W., \& Whitaker, R. C. (1998). Maternal Feeding Practices and Childhood Obesity. Archives of Pediatrics \& Adolescent 
Medicine, 152(10), 1010-1014. http://doi.org/10.1001/archpedi.152.10.1010

Beech, B., \& Klesges, R. (2003). Child-and parent-targeted interventions: the Memphis GEMS pilot study. Ethnicity and .... Retrieved from https://www.researchgate.net/profile/Lisa_Klesges/publication/10789403_Childand_parenttargeted_Interventions_The_Memphis_GEMS_pilot_study/links/0c960527162cf2f1990000 00.pdf

Beets, M., \& Cardinal, B. (2010). Parental social support and the physical activity-related behaviors of youth: a review. Health Education \&. Retrieved from http://heb.sagepub.com/content/early/2010/08/19/1090198110363884.abstract

Berlin, J., \& Colditz, G. (1990). A meta-analysis of physical activity in the prevention of coronary heart disease. American Journal of Epidemiology. Retrieved from http://aje.oxfordjournals.org/content/132/4/612.short

Berry, T., Naylor, P. J., \& Wharf-Higgins, J. (2005). Stages of change in adolescents: an examination of self-efficacy, decisional balance, and reasons for relapse. Journal of Adolescent Health, 37(6), 452-459. http://doi.org/10.1016/j.jadohealth.2004.09.019

Blair, S., Cheng, Y., \& Holder, J. (2001). Is physical activity or physical fitness more important in defining health benefits? Medicine and Science in Sports and .... Retrieved from http://www.iub.edu/ k562/articles/role/fitness or activity Blair 2001.pdf

Blair, S. N. (2009). Physical inactivity: the biggest public health problem of the 21 st century. British Journal of Sports Medicine, 43(1), 1-2. Retrieved from http://www.ncbi.nlm.nih.gov/pubmed/19136507 
Blitstein, J. L., Cates, S. C., Hersey, J., Montgomery, D., Shelley, M., Hradek, C., ... Singh, A. (2016). Adding a Social Marketing Campaign to a School-Based Nutrition Education Program Improves Children's Dietary Intake: A Quasi-Experimental Study. Journal of the Academy of Nutrition and Dietetics, 1-10. http://doi.org/10.1016/j.jand.2015.12.016

Bock, B. C., Marcus, B. H., Pinto, B. M., \& Forsyth, L. H. (2001). Maintenance of Physical Activity Following an Individualized Motivationally Tailored Intervention. Ann Behav Med, 23(2), 79-87.

Borg, G. (1998). Borg's perceived exertion and pain scales. Retrieved from http://psycnet.apa.org/psycinfo/1998-07179-000

Brindal, E., Freyne, J., Saunders, I., Berkovsky, S., Smith, G., \& Noakes, M. (2012). Features predicting weight loss in overweight or obese participants in a web-based intervention: randomized trial. Journal of Medical Internet Research, 14(6), e173. http://doi.org/10.2196/jmir.2156

Brouwer W, Kroeze W, Crutzen R, de NJ, de Vries NK, Brug J, O. A. (2011). Which intervention characteristics are related to more exposure to internet-delivered healthy lifestyle promotion interventions? A systematic review. Journal of Medical Internet Research, 13(1). Retrieved from http://www.jmir.org/2011/1/e2/

Brown, H. E., Atkin, A. J., Panter, J., Wong, G., Chinapaw, M. J. M., \& van Sluijs, E. M. F. (2016). Family-based interventions to increase physical activity in children: a systematic review, meta-analysis and realist synthesis. Obesity Reviews, 17(4), 345-360. http://doi.org/10.1111/obr.12362

Buxton, K., Wyse, J., \& Mercer, T. (1996). How applicable is the stages of change model to 
exercise behaviour? A review. Health Education Journal. Retrieved from http://hej.sagepub.com/content/55/2/239.short

Calfas, K. J., Sallis, J. F., Oldenburg, B., \& Ffrench, M. (1997). Mediators of change in physical activity following an intervention in primary care: PACE. Preventive Medicine, 26(3), 297304. http://doi.org/10.1006/pmed.1997.0141

Carlson, S., \& Fulton, J. (2008). Physical education and academic achievement in elementary school: data from the early childhood longitudinal study. ... Journal of Public .... Retrieved from http://ajph.aphapublications.org/doi/abs/10.2105/AJPH.2007.117176

Cavallo, D. N., Tate, D. F., Ries, A. V., Brown, J. D., Devellis, R. F., \& Ammerman, A. S. (2012). A social media-based physical activity intervention: A randomized controlled trial. American Journal of Preventive Medicine, 43(5), 527-532. http://doi.org/10.1016/j.amepre.2012.07.019

Cavallo, D. N., Tate, D. F., Ries, A. V, Brown, J. D., DeVellis, R. F., \& Ammerman, A. S. (2012a). A social media-based physical activity intervention: a randomized controlled trial. Am J Prev Med, 43(5), 527-532. http://doi.org/10.1016/j.amepre.2012.07.019

Cavallo, D. N., Tate, D. F., Ries, A. V, Brown, J. D., DeVellis, R. F., \& Ammerman, A. S. (2012b). A social media-based physical activity intervention: a randomized controlled trial. Am J Prev Med, 43(5), 527-532. http://doi.org/10.1016/j.amepre.2012.07.019

Cavallo, D. N., Tate, D. F., Ward, D. S., DeVellis, R. F., Thayer, L. M., \& Ammerman, A. S. (2014). Social support for physical activity-role of Facebook with and without structured intervention. Translational Behavioral Medicine, 4(4), 346-54. http://doi.org/10.1007/s13142-014-0269-9 
Cavallo, D. N., Tate, D. F., Ward, D. S., DeVellis, R. F., Thayer, L. M., \& Ammerman, A. S. (2014). Social support for physical activity—role of Facebook with and without structured intervention. Translational Behavioral Medicine, 4(4), 346-354.

http://doi.org/10.1007/s13142-014-0269-9

CDC. (2008). Physical activity guidelines advisory committee report, 2008. Washington, DC: US Department .... Retrieved from https://scholar.google.com/scholar?q=Physical+activity+guidelines+advisory+committee+r eport, $+2008 \# 0$

CDC. (2014). State Indicator Report on Physical Activity. Retrieved from http://www.cdc.gov/physicalactivity/resources/reports.html

Centers for Disease Control and Prevention. (2011). The health communicator's social media toolkit.

Centers for Disease Control and Prevention. (2012). Parent engagement: Strategies for involving parents in school health. (CDC, Ed.). Atlanta, Ga: US Department of Health and Human Services.

Centers for Disease Control and Prevention. (2015). US Department of Health and Human Services. Physical Activity and Health: A Report of the Surgeon General. Atlanta, Georgia Google Scholar. Washington, DC. Retrieved from https://scholar.google.com/scholar?q=US+Department+of+Health+and+Human+Services.+ Physical+Activity+and+Health\%3A+A+Report+of+the+Surgeon+General.+Atlanta\%2C+G eorgia\&btnG=\&hl=en\&as_sdt=0\%2C49

Christakis, N., \& Fowler, J. (2007). The spread of obesity in a large social network over 32 
years. New England Journal of Medicine. Retrieved from

http://www.nejm.org/doi/full/10.1056/nejmsa066082

Cobb, N. K., \& Graham, A. L. (2012). Health behavior interventions in the age of facebook. Am J Prev Med, 43(5), 571-572. http://doi.org/10.1016/j.amepre.2012.08.001

Constine, J. (2013). Facebook's Q2: Monthly Users Up 21\% YOY To 1.15B, Dailies Up 27\% To 699M, Mobile Monthlies Up 51\% To 819M. Retrieved March 12, 2016, from http://techcrunch.com/2013/07/24/facebook-growth-2/

Corbin, C., Lindsey, R., \& Welk, G. (2000). Concepts of physical fitness: Active lifestyles for wellness. Retrieved from http://novellaqalive2.mhhe.com/sites/dl/free/0072843748/123956/corbin12e111403sup.doc

D’Onofrio, G., Bernstein, E., \& Rollnick, S. (1996). Motivating patients for change: a brief strategy for negotiation. Case Studies in Emergency Medicine and the Health of the Public. Boston, MA: Jones and Bartlett.

Dagkas, S., \& Quarmby, T. (2012). Young People's Embodiment of Physical Activity: The Role of the "Pedagogized" Family. Sociology of Sport Journal, 29(2), 210-226.

Dalton, W. T., \& Kitzmann, K. (2008). Broadening Parental Involvement in Family-based Interventions for Pediatric Overweight: Implications From Family Systems and Child Health. Family \& Community Health. Retrieved from http://journals.lww.com/familyandcommunityhealth/Abstract/2008/10000/Broadening_Pare ntal_Involvement_in_Family_based.3.aspx

Davison, K., \& Birch, L. (2001). Childhood overweight: a contextual model and 
recommendations for future research. Obesity Reviews. Retrieved from http://onlinelibrary.wiley.com/doi/10.1046/j.1467-789x.2001.00036.x/full

Davison, K., Cutting, T., \& Birch, L. (2003). Parents' activity-related parenting practices predict girls' physical activity. Medicine and Science in Sports. Retrieved from http://www.ncbi.nlm.nih.gov/pmc/articles/pmc2530913/

Davison, K. K., \& Birch, L. L. (2001). Childhood overweight: a contextual model and recommendations for future research. Obesity Reviews : An Official Journal of the International Association for the Study of Obesity, 2(3), 159-71. http://doi.org/10.1046/j.1467-789x.2001.00036.x

Dempsey, J. M., Kimiecik, J. C., \& Horn, T. S. (1993). Parental influence on children's moderate to vigorous physical activity participation: An expectancy-value approach. Pediatric Exercise Science, 5, 151-167.

Dietz, W. H., \& Gortmaker, S. L. (1985). Do We Fatten Our Children At the Tv Set.Pdf. Pediatrics, 75(5), 807-812.

DiLorenzo, T. M., Stucky-Ropp, R. C., Vander Wal, J. S., \& Gotham, H. J. (1998). Determinants of Exercise among Children. II. A Longitudinal Analysis. Preventive Medicine, 27(3), 470477. http://doi.org/10.1006/pmed.1998.0307

Dishman, R. (1988). Agenda ." Exercise Adherence Research : Future Directions. American Journal of Health Promotion, 3(1), 52-56.

Duggan, M., Lenhart, A., Lampe, C., \& Ellison, N. (2015). Parents and Social Media. Pew Research Center. Retrieved from http://www.pewinternet.org/2015/07/16/parents-and- 
social-media/

Epstein, L. H., Myers, M., Raynor, H., \& Saelens, B. (1998). Treatment of Pediatric Obesity. Pediatrics, 101, 1123-1129.

Epstein, L., Paluch, R., Roemmich, J., \& Beecher, M. (2007). Family-based obesity treatment, then and now: twenty-five years of pediatric obesity treatment. Health .... Retrieved from http://psycnet.apa.org/journals/hea/26/4/381/

Eysenbach, G. (2005). The law of attrition. Journal of Medical Internet Research. Retrieved from http://www.jmir.org/article/citations/402

Field, T., Diego, M., \& Sanders, C. (2001). Exercise is positively related to adolescents' relationships and academics. ADOLESCENCE-SAN DIEGO-. Retrieved from http://search.proquest.com/openview/ad7a403d0bb1ec2481bb2c965d89915a/1.pdf?pqorigsite $=$ gscholar $\& \mathrm{cbl}=41539$

Foster, D., Linehan, C., \& Lawson, S. (2010). Motivating physical activity at work: using persuasive social media extensions for simple mobile devices. Retrieved from http://eprints.lincoln.ac.uk/3153

Fox, K. R. (1999). The influence of physical activity on mental well-being. Public Health Nutrition, 2(3a), 411-418. http://doi.org/10.1017/S1368980099000567

Fuemmeler, B. F., Anderson, C. B., \& Masse, L. C. (2011a). Parent-child relationship of directly measured physical activity. Int J Behav Nutr Phys Act, 8, 17. http://doi.org/10.1186/1479$5868-8-17$

Fuemmeler, B. F., Anderson, C. B., \& Masse, L. C. (2011b). Parent-child relationship of directly 
measured physical activity. Int J Behav Nutr Phys Act, 8, 17. http://doi.org/10.1186/14795868-8-17

Golan, M. (2006). Parents as agents of change in childhood obesity--from research to practice. International Journal of Pediatric Obesity : IJPO : An Official Journal of the International Association for the Study of Obesity, 1(December 2005), 66-76. http://doi.org/10.1080/17477160600644272

Gorely, T., Nevill, M. E., Morris, J. G., Stensel, D. J., \& Nevill, A. (2009). Effect of a schoolbased intervention to promote healthy lifestyles in 7-11 year old children. International Journal of Behavioral Nutrition and Physical Activity, 6(5). http://doi.org/10.1186/14795868-6-5

Gustafson, S. L., \& Rhodes, R. E. (2006). Parental Correlates of Physical Activity in Children and Early Adolescents. Sports Medicine, 36(1), 79-97. http://doi.org/10.2165/00007256200636010-00006

Gustafson, S., \& Rhodes, R. (2006). Parental correlates of physical activity in children and early adolescents. Sports Medicine. Retrieved from http://link.springer.com/article/10.2165/00007256-200636010-00006

Hales, S. B., Davidson, C., \& Turner-McGrievy, G. M. (2014). Varying social media post types differentially impacts engagement in a behavioral weight loss intervention. Translational Behavioral Medicine, 4(4), 355-62. http://doi.org/10.1007/s13142-014-0274-z

Hillman, C. H., Erickson, K. I., \& Kramer, A. F. (2008). Be smart, exercise your heart: exercise effects on brain and cognition. Nature, 9, 58-65. http://doi.org/10.1038/nrn2298 
Hilton, S., Doherty, S., \& Kendrick, T. (1999). Promotion of healthy behaviour among adults at increased risk of coronary heart disease in general practice: methodology and baseline data from the Change of. Health Education .... Retrieved from http://hej.sagepub.com/content/58/1/3.short

Hu, Y., \& Shyam Sundar, S. (2010). Effects of Online Health Sources on Credibility and Behavioral Intentions. Communication Research, 37(1), 105-132. http://doi.org/10.1177/0093650209351512

Hutchison, A. J., Breckon, J. D., \& Johnston, L. H. (2009a). Physical activity behavior change interventions based on the transtheoretical model: a systematic review. Health Education and Behavior, 36(5), 829-845. http://doi.org/10.1177/1090198108318491

Hutchison, A. J., Breckon, J. D., \& Johnston, L. H. (2009b). Physical activity behavior change interventions based on the transtheoretical model: a systematic review. Health Education and Behavior, 36(5), 829-845. http://doi.org/10.1177/1090198108318491

HW Kohl. (2001). Physical activity and cardiovascular disease: evidence for a dose response. Medicine and Science in Sports and Exercise. Retrieved from http://europepmc.org/abstract/med/11427773

Israel, A., Stolmaker, L., \& Andrian, C. (1985). The effects of training parents in general child management skills on a behavioral weight loss program for children. Behavior Therapy. Retrieved from http://www.sciencedirect.com/science/article/pii/S0005789485800435

Jang, J., \& Dworkin, J. (2014a). Does social network site use matter for mothers? Implications for bonding and bridging capital. Computers in Human Behavior, 35, 489-495. http://doi.org/10.1016/j.chb.2014.02.049 
Jang, J., \& Dworkin, J. (2014b). Does social network site use matter for mothers? Implications for bonding and bridging capital. Computers in Human Behavior, 35, 489-495. http://doi.org/10.1016/j.chb.2014.02.049

Jawad, M., Abass, J., Hariri, A., \& Akl, E. A. (2015). Social Media Use for Public Health Campaigning in a Low Resource Setting : The Case of Waterpipe Tobacco Smoking, 2015.

Jeon, D. J., Kim, K. J., \& Heo, M. (2014). Factors related to stages of exercise behavior change among university students based on the transtheoretical model. Journal of Physical Therapy Science, 26(12), 1929-1932. http://doi.org/10.1589/jpts.26.1929

Johnson, S., \& Birch, L. (1994). Parents' and children's adiposity and eating style. Pediatrics. Retrieved from http://pediatrics.aappublications.org/content/94/5/653.short

Johnson, S., \& Cook, B. (2013). Building Motivation: How Ready Are You? Aspects of Physical Activity and Exercise. Retrieved from https://books.google.com/books?hl=en\&lr=\&id=pFueAgAAQBAJ\&oi=fnd\&pg=PA103\&d q=Building+motivation:+how+ready+are+you\%3F\&ots=uxIZ84VCJv\&sig=1lfjgGyIFrtqFj m-E-wjLcftpbo

Kimiecik, J. C., \& Horn, T. S. (1998). Parental Beliefs and Children's Moderate-to-Vigorous Physical Activity. Research Quarterly for Exercise and Sport, 69(2), 163-175. http://doi.org/10.1080/02701367.1998.10607681

Kitzman-Ulrich, H., Hampson, R., Wilson, D. K., Presnell, K., Brown, A., \& O ’boyle, M. (2009). An Adolescent Weight-Loss Program Integrating Family Variables Reduces Energy Intake. YJADA, 109, 491-496. http://doi.org/10.1016/j.jada.2008.11.029 
Kitzmann, K., Dalton, W., \& Buscemi, J. (2008). Beyond Parenting Practices: Family Context and the Treatment of Pediatric Obesity*. Family Relations. Retrieved from http://onlinelibrary.wiley.com/doi/10.1111/j.1741-3729.2007.00479.x/full

Korda, H., \& Itani, Z. (2013). Harnessing social media for health promotion and behavior change. Health Promotion Practice, 14(1), 15-23.

Krebs, P., Prochaska, J., \& Rossi, J. (2010). A meta-analysis of computer-tailored interventions for health behavior change. Preventive Medicine. Retrieved from http://www.sciencedirect.com/science/article/pii/S0091743510002318

Kreuter, M. W., \& Skinner, C. S. (2000). Tailoring: what's in a name? Health Education Research, 15(1), 1-4. http://doi.org/10.1093/her/15.1.1

Kriemler, S., Meyer, U., Martin, E., Van Sluijs, E., Andersen, L., \& Martin, B. (2011). Effect of School-Based Interventions On Physical Activity and Fitness in Children and Adolescents: A Review of Reviews and Systematic Update. Br J Sports Med, 45(11). http://doi.org/10.1136/bjsports-2011-090186

Kumar, P., \& Schoenebeck, S. (2015). The modern day baby book: Enacting good mothering and stewarding privacy on facebook. Proceedings of the 18th ACM Conference on .... Retrieved from http://dl.acm.org/citation.cfm?id=2675149

Lee, I., Hsieh, C., \& Paffenbarger, R. (1995). Exercise intensity and longevity in men: the Harvard Alumni Health Study. Jama. Retrieved from http://jama.jamanetwork.com/article.aspx ?articleid=387973

Lee, I., \& Paffenbarger, R. (2000). Associations of light, moderate, and vigorous intensity 
physical activity with longevity The Harvard Alumni Health Study. American Journal of Epidemiology. Retrieved from http://aje.oxfordjournals.org/content/151/3/293.short

Leonard H. Epstein, Valoski, A. M., Vara, L. S., McCurley, J., Wisniewski, L., Kalarchian, M. A., ... Shrager, L. R. (1995). Effects of decreasing sedentary behavior and increasing activity on weight change in obese children. Health Psychology, 14(2), 109-115. Retrieved from http://psycnet.apa.org/journals/hea/14/2/109/

Lewallen, T. C., Hunt, H., Potts-Datema, W., Zaza, S., \& Giles, W. (2015). The Whole School, Whole Community, Whole Child Model: A New Approach for Improving Educational Attainment and Healthy Development for Students. Journal of School Health, 85(11), 729739. http://doi.org/10.1111/josh.12310

Lindner, K. (2002). The physical activity participation-academic performance relationship revisited: perceived and actual performance and the effect of banding (academic. Pediatric Exercise Science. Retrieved from https://scholar.google.com/scholar?q=Lindner\%2C+K.+J.+The+physical+activity+participa tion+academic+performance+relationship+revisited $\% 3 \mathrm{~A}+$ perceived+and+actual+performance+ and + the + effect + of + banding $\& b \operatorname{bth}=\& h l=e n \&$ as_sdt $=0 \% 2 \mathrm{C} 49 \# 0$

Lindsay, A. C., Sussner, K. M., Kim, J., \& Gortmaker, S. L. (2006). The Role of Parents in Preventing Childhood Obesity. The Future of Children, 16(1), 169-186. http://doi.org/10.1353/foc.2006.0006

Lobstein, T., Baur, L., \& Uauy, R. (2004). Obesity in children and young people: a crisis in public health. Obesity Reviews. Retrieved from 
http://onlinelibrary.wiley.com/doi/10.1111/j.1467-789X.2004.00133.x/full

Ma, X., Chen, G., \& Xiao, J. (2010). Analysis of an online health social network. Proceedings of the 1st ACM International Health .... Retrieved from http://dl.acm.org/citation.cfm?id=1883035

Maher, C. (2010). An internet-based computer-tailored physical activity intervention has short term positive effects on physical activity levels among adolescents. Journal of Physiotherapy, 56(2), 132. http://doi.org/10.1016/s1836-9553(10)70043-6

Maher, C., Ferguson, M., Vandelanotte, C., Plotnikoff, R., De Bourdeaudhuij, I., Thomas, S., ... Olds, T. (2015). A Web-Based, Social Networking Physical Activity Intervention for Insufficiently Active Adults Delivered via Facebook App: Randomized Controlled Trial. $J$ Med Internet Res, 17(7), e174. http://doi.org/10.2196/jmir.4086

Maher, C., Ryan, J., Kernot, J., Podsiadly, J., \& Keenihan, S. (2015). Social Media and Applications to Health Behavior. Current Opinion in Psychology, 9, 50-55. http://doi.org/10.1016/j.copsyc.2015.10.021

Maher, Lewis, L. K., Ferrar, K., Marshall, S., De Bourdeaudhuij, I., \& Vandelanotte, C. (2014). Are health behavior change interventions that use online social networks effective? A systematic review. J Med Internet Res, 16(2), e40. http://doi.org/10.2196/jmir.2952

Marcus, B., Emmons, K. M., Simkin-Silverman, L. R., Linnan, L. A., Taylor, E. R., \& Brock, B. C. (1998). Evaluation of Motivationally Tailored vs Standard Self-Help Physical Activity Interventions at the Workplace. American Journal of Health Promotion, 12, 246-253.

Marcus, B., Forsyth, L., \& Stone, E. (2000). Physical activity behavior change: issues in 
adoption and maintenance. Health Psychology, 19(1), 32-41. http://doi.org/10.1037//02786133.19.1(Suppl.).32

Marcus, B. H., Banspach, S. W., Lefebvre, R. C., Rossi, J. S., Carleton, R. A., Abrams, D. B., ... Prochaska, J. O. (1992). Using the Stages of Change model to increase the adoption of physical activity among community participants. American Journal of Health Promotion, 6(6), 424-429.

Marcus, B. H., Bock, B. C., Pinto, B. M., Forsyth, L. A. H., Roberts, M. B., \& Traficante, R. M. (1998). Efficacy of an individualized, motivationally-tailored physical activity intervention, 20(3), 174-180. http://doi.org/10.1007/BF02884958

Marcus, B. H., Forsyth, L. A. H., \& Stone, E. J. (2000). Physical activity behavior change: issues in adoption and maintenance. Health Psychology, 19(1), 32-41. http://doi.org/10.1037//0278-6133.19.1(Suppl.).32

Marcus, B. H., Selby, V. C., Niaura, R. S., \& Rossi, J. S. (1992). Self-Efficacy and the Stages of Exercise Behavior Change. Research Quarterly for Exercise and Sport, 63(1), 60-66. http://doi.org/10.1080/02701367.1992.10607557

Marcus, B. H., Selby, V. C., Niaura, R. S., \& Rossi, J. S. (1992). Self-Efficacy and the Stages of Exercise Behavior Change. Research Quarterly for Exercise and Sport, 63(1), 60-66. http://doi.org/10.1080/02701367.1992.10607557

Marcus, B., \& Simkin, L. (1994). The transtheoretical model: applications to exercise behavior. Medicine and Science in Sports and Exercise, 26(11), 1400-1404. http://doi.org/10.1249/00005768-199411000-00016 
Marshall, S., \& Biddle, S. (2001). The transtheoretical model of behavior change: a metaanalysis of applications to physical activity and exercise. Annals of Behavioral Medicine. Retrieved from http://link.springer.com/article/10.1207/S15324796ABM2304_2

McClure, J. B., Shortreed, S. M., Bogart, A., Derry, H., Riggs, K., St John, J., ... An, L. (2013). The effect of program design on engagement with an internet-based smoking intervention: randomized factorial trial. Journal of Medical Internet Research, 15(3), e69. http://doi.org/10.2196/jmir.2508

McFarlane, A. (1995). Family Structure, Family Functioning and Adolescent Well-Being: the Transcendent Influence of Parental Style. Journal of Child .... Retrieved from http://onlinelibrary.wiley.com/doi/10.1111/j.1469-7610.1995.tb01333.x/abstract

Meeks, L., Heit, P., \& Page, R. (2009). Comprehensive school health education: Totally awesome strategies for teaching health. Retrieved from http://112.72.97.196:8080/dspace/handle/123456789/9026

Moore, L. L., Gao, D., Bradlee, M. L., Cupples, L. A., Sundarajan-Ramamurti, A., Proctor, M. H., ... Ellison, R. C. (2003). Does early physical activity predict body fat change throughout childhood? Preventive Medicine, 37(1), 10-17. http://doi.org/10.1016/S00917435(03)00048-3

Moore, L. L., Lombardi, D. A., White, M. J., Campbell, J. L., Oliveria, S. A., Ellison, R. C., \& Lynn L. Moore, MS David A. Lombardi, Mary Jo White, James L. Campbell, Susan A. Oliveria, C. E. (1991). Influence of parents' physical activity levels on activity levels of young children. Journal of Pediatrics, 118(2), 215-219. http://doi.org/10.1016/S00223476(05)80485-8 
Moore, M., Highstein, G., \& Tschannen-Moran, B. (2010). Coaching behavior change. Coaching: Psychology. Retrieved from http://www.academia.edu/download/7736581/mooresampchap3.pdf

Morris, M. R. (2014). Social networking site use by mothers of young children. In Proceedings of the 17th ACM conference on Computer supported cooperative work \& social computing CSCW'14 (pp. 1-11). http://doi.org/10.1145/2531602.2531603

Napolitano, M., Hayes, S., Bennett, G., Ives, A. K., \& Foster, G. D. (2013). Using Facebook and text messaging to deliver a weight loss program to college students. Obesity Journal, 21(1), 25-31. Retrieved from http://onlinelibrary.wiley.com/doi/10.1002/oby.20232/full

Naylor, P.-J., Macdonald, H. M., Zebedee, J. A., Reed, K. E., \& Mckay, H. A. (2006). Lessons learned from Action Schools! BC_—An "active school" model to promote physical activity in elementary schools. Journal of Science and Medicine in Sport, 9, 413-423. http://doi.org/10.1016/j.jsams.2006.06.013

Nemet, D., Barzilay-Teeni, N., \& Eliakim, A. (2008). Treatment of childhood obesity in obese families. Journal of Pediatric. Retrieved from http://www.degruyter.com/view/j/jpem.2008.21.5/jpem.2008.21.5.461/jpem.2008.21.5.461. $\mathrm{xml}$

Niermann, C., Krapf, F., \& Renner, B. (2014). Family health climate scale (FHC-scale): development and validation. International. Retrieved from http://ijbnpa.biomedcentral.com/articles/10.1186/1479-5868-11-30

Niermann, C., Krapf, F., Renner, B., Reiner, M., \& Woll, A. (2014). Family health climate scale (FHC-scale): development and validation. The International Journal of Behavioral 
Nutrition and Physical Activity, 11(1), 30. http://doi.org/10.1186/1479-5868-11-30

Noar, S. M., Benac, C. N., \& Harris, M. S. (2007). Does tailoring matter? Meta-analytic review of tailored print health behavior change interventions. Psychological Bulletin, 133(4), 673693. http://doi.org/10.1037/0033-2909.133.4.673

O’Connor, T. M., Jago, R., \& Baranowski, T. (2009). Engaging parents to increase youth physical activity a systematic review. American Journal of Preventive Medicine, 37(2), 141-9. http://doi.org/10.1016/j.amepre.2009.04.020

O’Flahavan, L., \& Goulet, A. (2012). CDC'S GUIDE TO Writing for Social Media.

Oguma, Y., \& Sesso, H. (2002). Physical activity and all cause mortality in women: a review of the evidence. British Journal of Sports .... Retrieved from http://bjsm.bmj.com/content/36/3/162.short

Ostbye, T., Malhotra, R., Stroo, M., Lovelady, C., Brouwer, R., Zucker, N., \& Fuemmeler, B. (2013). The effect of the home environment on physical activity and dietary intake in preschool children. Int J Obes (Lond), 37(10), 1314-1321. http://doi.org/10.1038/ijo.2013.76

Paffenbarger JR, R., \& Hale, W. (1975). Work activity and coronary heart mortality. New England Journal of Medicine. Retrieved from http://www.nejm.org/doi/full/10.1056/NEJM197503132921101

Pallant, J. (2013). SPSS survival manual. Retrieved from https://books.google.com/books $?$ hl=en\&lr=\&id=fZZTBgAAQBAJ\&oi=fnd\&pg=PR7\&dq= spss+survival+manual+pallant\&ots=KUNtiKUVzT\&sig=xIxsdH60luLqsf7wk7MtSSS2Kt 
$\mathrm{U}$

Perrin, A. (2015). Social Media Usage 2005-2015. Pew Research Center. Retrieved from http://www.pewinternet.org/files/2015/10/PI_2015-10-08_Social-Networking-Usage-20052015_FINAL.pdf

Perry, C. L., Luepker, R. V, Murray, D. M., Kurth, C., Mullis, R., Crockett, S., \& Jacobs, D. R. (1988). Parent Involvement with Children's Health Promotion: The Minnesota Home Team. American Journal of Public Health, 78(9). Retrieved from https://www.ncbi.nlm.nih.gov/pmc/articles/PMC1349385/pdf/amjph00248-0022.pdf

Peterson, T. R., \& Aldana, S. G. (1999a). Improving exercise behavior: An application of the stages of change model in a worksite setting. American Journal of Health Promotion, 13(4), 229-232. http://doi.org/10.4278/0890-1171-13.4.229

Peterson, T. R., \& Aldana, S. G. (1999b). Improving exercise behavior: An application of the stages of change model in a worksite setting. American Journal of Health Promotion, 13(4), 229-232. http://doi.org/10.4278/0890-1171-13.4.229

Pinto, B. M., Goldstein, M. G., DePue, J. D., \& Milan, F. B. (1998). Acceptability and feasibility of physician-based activity counseling. American Journal of Preventive Medicine, 15(2), 95-102. http://doi.org/10.1016/S0749-3797(98)00043-9

Plantin, L., \& Daneback, K. (2009). Parenthood, information and support on the internet. A literature review of research on parents and professionals online. BMC Family Practice, 10(1), 34. http://doi.org/10.1186/1471-2296-10-34

Powell, K. (1987). Physical activity and the incidence of coronary heart disease. Annual Review 
of .... Retrieved from

http://www.annualreviews.org/doi/pdf/10.1146/annurev.pu.08.050187.001345

Prochaska, J. O., Redding, C. A., Evers, K. E., Glanz, K., Lewis, F. M., \& Rimer, B. K. (2002). The transtheoretical model and stages of change. In Health behavior and health education: Theory, research, and practice. (pp. 60-84). Retrieved from http://www.sciencedirect.com/science/article/pii/S107772299980025X

Prochaska, J. (2013). Transtheoretical model of behavior change. Encyclopedia of Behavioral Medicine, 62(24), 2342-2343. http://doi.org/10.1016/j.jacc.2013.11.008

Prochaska, J., \& Marcus, B. (1994). The transtheoretical model: Applications to exercise. Retrieved from http://psycnet.apa.org/psycinfo/1994-98849-004

Prochaska, J. O., \& DiClemente, C. C. (1982). Transtheoretical therapy: Toward a more integrative model of change. Psychotherapy: Theory, Research and Practice, 19(3), 276288. http://doi.org/10.1037/h0088437

Prochaska, J. O., \& Velicer, W. F. (1997). The Transtheoretical Change Model of Health Behavior. American Journal of Health Promotion, 12(1), 38-48. http://doi.org/10.4278/0890-1171-12.1.38

Prochaska, J. O., Velicer, W. F., DiClemente, C. C., \& Fava, J. (1988a). Measuring processes of change: Applications to the cessation of smoking. Journal of Consulting and Clinical Psychology, 56(4), 520-528. http://doi.org/10.1037/0022-006X.56.4.520

Prochaska, J. O., Velicer, W. F., DiClemente, C. C., \& Fava, J. (1988b). Measuring processes of change: Applications to the cessation of smoking. Journal of Consulting and Clinical 
Psychology, 56(4), 520-528. http://doi.org/10.1037/0022-006X.56.4.520

Prochaska, J., Redding, C., \& Evers, K. (2002). Health behavior and health education: theory, research, and practice. Health Behavior and Health .... Retrieved from https://scholar.google.com/scholar?oi=gsb40\&q=Prochaska\%2C 2002\&lookup=0\&hl=en\#0

Prochaska, J., Velicer, W., \& Rossi, J. (1994). Stages of change and decisional balance for 12 problem behaviors. Health. Retrieved from http://psycnet.apa.org/journals/hea/13/1/39/

Ramo, D. E., Thrul, J., Delucchi, K. L., Ling, P. M., Hall, S. M., \& Prochaska, J. J. (2015). The Tobacco Status Project (TSP): Study protocol for a randomized controlled trial of a Facebook smoking cessation intervention for young adults. BMC Public Health, 15(1), 897. http://doi.org/10.1186/s12889-015-2217-0

Ryckman, R., Robbins, M., \& Thornton, B. (1982). Development and validation of a physical self-efficacy scale. Journal of Personality. Retrieved from http://psycnet.apa.org/journals/psp/42/5/891/

Safko, L. (2010). The social media bible: Tactics, tools, and strategies for business success. Retrieved from https://books.google.com/books?hl=en\&lr=\&id=2c0Yrp1Xo8C\&oi=fnd\&pg=PR5\&dq=what+is+social+media\&ots=VdwyRe5LA9\&sig=7X622bHKdtrmsCD26V3HDzAmwg

Sallis, J. F., Prochaska, J. J., \& Taylor, W. C. (2000). A review of correlates of physical activity of children and adolescents. Medicine \& Science in Sports \& Exercise, (JUNE 2000), 963975. http://doi.org/10.1097/00005768-200005000-00014

Sallis, J., \& Hovell, M. (1990). Determinants of exercise behavior. Exercise and Sport Sciences 
Reviews. Retrieved from http://journals.lww.com/acsm-

essr/Citation/1990/01000/Determinants_of_Exercise_Behavior.14.aspx

Sallis, J., McKenzie, T., \& Kolody, B. (1999). Effects of health-related physical education on academic achievement: Project SPARK. ... Quarterly for Exercise .... Retrieved from http://www.tandfonline.com/doi/abs/10.1080/02701367.1999.10608030

Sallis, J., Prochaska, J., \& Taylor, W. (2000). A review of correlates of physical activity of children and adolescents. ... in Sports and Exercise. Retrieved from https://www.researchgate.net/profile/Judith_Prochaska/publication/12521182_'A_Review_ of_Correlates_of_Physical_Activity_of_Children_and_Adolescents'/links/0fcfd509495ae32 123000000.pdf

Salmon, J., Ball, K., Hume, C., Booth, M., \& Crawford, D. (2008). Outcomes of a grouprandomized trial to prevent excess weight gain, reduce screen behaviours and promote physical activity in 10-year-old children: Switch-Play. International Journal of Obesity, 32, 601-612. http://doi.org/10.1038/sj.ijo.0803805

Shelton, D., Gros, K. Le, \& Norton, L. (2007). Randomised controlled trial: A parent-based group education programme for overweight children. Paediatrics and Child .... Retrieved from http://onlinelibrary.wiley.com/doi/10.1111/j.1440-1754.2007.01150.x/full

Sterne, J. (2010). Social media metrics: How to measure and optimize your marketing investment. Retrieved from https://books.google.com/books ?hl=en\&lr=\&id=OkkZhB2Yw7IC\&oi=fnd\&pg=PR10\&dq= $\% 09 \%$ ASocial+media+metrics+++how+to+measure+and+optimize+your+marketing+inve stment\&ots=1FlZtxOLHX\&sig=MvQ2KEfspdqwXrJrfii7EGXmJSo 
Strauss \& Knight, J., R. S. (1999). Influence of the home environment on the development of obesity in children. . Pediatrics, 103(6), e85-e85.

Stroup, D., Johnson, V., Proctor, D., \& Hahn, R. (2009). Reversing the trend of childhood obesity. Prev Chronic Dis. Retrieved from http://origin.glb.cdc.gov/pcd/issues/2009/jul/08_0255.htm

Swift, D., Johannsen, N., Lavie, C., \& Earnest, C. (2014). The role of exercise and physical activity in weight loss and maintenance. Progress in. Retrieved from http://www.sciencedirect.com/science/article/pii/S0033062013001655

Tabachnick, B., Fidell, L., \& Osterlind, S. (2001). Using multivariate statistics. Retrieved from https://www.ulb.tu-darmstadt.de/tocs/135813948.pdf

Taras, H. (2005). Physical activity and student performance at school. Journal of School Health. Retrieved from http://onlinelibrary.wiley.com/doi/10.1111/j.17461561.2005.tb06675.x/abstract

Thackeray, R., Neiger, B., \& Hanson, C. (2008). Enhancing promotional strategies within social marketing programs: use of Web 2.0 social media. Health Promotion. Retrieved from http://hpp.sagepub.com/content/9/4/338.short

Thrul, J., Klein, A. B., \& Ramo, D. E. (2015a). Smoking Cessation Intervention on Facebook: Which Content Generates the Best Engagement? Journal of Medical Internet Research, 17(11), e244. http://doi.org/10.2196/jmir.4575

Thrul, J., Klein, A. B., \& Ramo, D. E. (2015b). Smoking Cessation Intervention on Facebook: Which Content Generates the Best Engagement? Journal of Medical Internet Research, 
17(11), e244. http://doi.org/10.2196/jmir.4575

Trost, S. G., Sallis, J. F., Pate, R. R., Freedson, P. S., Taylor, W. C., \& Dowda, M. (2003). Evaluating a model of parental influence on youth physical activity. American Journal of Preventive Medicine, 25(4), 277-282. http://doi.org/10.1016/S0749-3797(03)00217-4

Valle, C., Tate, D., \& Mayer, D. (2013). A randomized trial of a Facebook-based physical activity intervention for young adult cancer survivors. Journal of Cancer .... Retrieved from http://link.springer.com/article/10.1007/s11764-013-0279-5

Vandelanotte, C., Kirwan, M., Rebar, A., Alley, S., Short, C., Fallon, L., ... Duncan, M. J. (2014). Examining the use of evidence-based and social media supported tools in freely accessible physical activity intervention websites. Int J Behav Nutr Phys Act, 11, 105. http://doi.org/10.1186/s12966-014-0105-0

Velicer, W. F., Prochaska, J. O., Rossi, J. S., \& Snow, M. G. (1992a). Assessing outcome in smoking cessation studies. Psychological Bulletin, 111(1), 23-41. http://doi.org/10.1037/0033-2909.111.1.23

Velicer, W. F., Prochaska, J. O., Rossi, J. S., \& Snow, M. G. (1992b). Assessing outcome in smoking cessation studies. Psychological Bulletin, 111(1), 23-41. http://doi.org/10.1037/0033-2909.111.1.23

Wannamethee, S., Shaper, A., \& Walker, M. (1998). Changes in physical activity, mortality, and incidence of coronary heart disease in older men. The Lancet. Retrieved from http://www.sciencedirect.com/science/article/pii/S0140673697123558

Warschburger, P., Kroeller, K., Haerting, J., Unverzagt, S., \& van Egmond-Fröhlich, A. (2016). 
Empowering Parents of Obese Children (EPOC): A Randomized Controlled Trial on Additional Long-Term Weight Effects of Parent Training. Appetite. http://doi.org/10.1016/j.appet.2016.04.007

Welk, G. J. (1999). Promoting Physical Activity in Children: Parental Influences.

Whitaker, R., \& Wright, J. (1997). Predicting obesity in young adulthood from childhood and parental obesity. ... England Journal of .... Retrieved from http://www.nejm.org/doi/full/10.1056/NEJM199709253371301

WHO, W. H. organization. (2015). Global Health Risks-Mortality and burden of disease attributable to selected major risks. The Lancet. Retrieved from http://obesity.thehealthwell.info/node/9612

Wing, R. R., \& Jeffery, R. W. (1999). Benefits of recruiting participants with friends and increasing social support for weight loss and maintenance. Journal of Consulting and Clinical Psychology, 67(1), 132-8. Retrieved from http://www.ncbi.nlm.nih.gov/pubmed/10028217

Wofford, L. G. (2008). Systematic Review of Childhood Obesity Prevention. Journal of Pediatric Nursing, 23(1), 5-19. http://doi.org/10.1016/j.pedn.2007.07.006

Yu, C., Chan, S., \& Cheng, F. (2006). Are physical activity and academic performance compatible? Academic achievement, conduct, physical activity and self-esteem of Hong Kong Chinese primary. Educational Studies. Retrieved from http://www.tandfonline.com/doi/abs/10.1080/03055690600850016 


\section{Appendix A}

\section{Extended Review of Literature}

\section{A Healthy Lifestyle}

Living a healthy lifestyle is dependent upon a number of different lifestyle characteristics, which directly influence a person's health and well-being. A healthy lifestyle is comprised of three main domains: family social health, mental-emotional health, and physical health (Meeks, Heit, \& Page, 2009). The major influences on a person's physical health include nutrition, sleep, risky behaviors (alcohol, tobacco, and drug use), and physical activity. An area of primary concern for this review is the area of physical health. A 2008 task force of experts from the CDC identified physical activity as one of the five primary target areas for interventions to reverse the obesity trend and improve health and well-being (Stroup, Johnson, Proctor, \& Hahn, 2009).

Benefits of a Healthy Lifestyle. There is an extensive body of literature supporting the concept of physical activity as an essential component of a healthy lifestyle. Regular physical activity has been positively associated with many significant health benefits. These benefits include a lower risk of premature death, obesity, depression, cardiovascular disease, type 2 diabetes, ischemic stroke, and colon and breast cancers (CDC, 2008). Benefits of physical activity, however, extend beyond just the prevention of chronic disease. Regular healthenhancing levels of physical activity have been linked to improving cognitive functioning across a variety of age groups (Hillman, Erickson, \& Kramer, 2008). In addition to the cognitive benefits of regular physical activity, regular exercise has been shown to have a moderate effect on reducing anxiety as well as improving self-esteem (Fox, 1999). A more tangible benefit of 
regular physical activity is the maintenance of normal weight status (Swift, Johannsen, Lavie, \& Earnest, 2014).

In the past 50 years, there has been a great deal of literature highlighting the benefits of a physically active lifestyle. In 1953, Morris and Heady discovered a significant difference in mortality rates of middle-aged men when controlling for occupation and cause of death. They found a general relationship between health and disease associated with the nature of occupations regarding physical exertion. Paffenbarger JR \& Hale (1975) reinforced this concept of physical activities threshold influencing mortality rates. Their follow up work looked into the mortality rates of dockworkers who were categorized into three categories of high, medium, and low, related to the caloric output of their assigned job. Workers who worked in the high caloric output category were significantly less likely to suffer a premature death than those in the medium or light categories. These foundational discoveries set a precedent for an investigation into physical activity as a primary cornerstone of a healthy lifestyle. Since these studies, there has been a significant body of literature investigating the link between physical activity and mortality (WHO, 2015; Berlin \& Colditz, 1990; Blair, Cheng, \& Holder, 2001; HW Kohl, 2001; Lee, Hsieh, \& Paffenbarger, 1995; Lee \& Paffenbarger, 2000; Oguma \& Sesso, 2002; Powell, 1987; Wannamethee, Shaper, \& Walker, 1998).

Early physical activity has been shown to predict body fat change throughout childhood and into adolescence (L. L. Moore, Gao, Bradlee, Cupples, Sundarajan-Ramamurti, Proctor, et al., 2003). If children are inadequately physically active during this childhood age range, they are at increased risk of becoming obese during childhood putting them at a higher risk level for adult obesity and at risk for a number of related chronic diseases and negative psychosocial factors. 
Wofford (2008) conducted a systematic review of childhood obesity literature and identified prevention as the dominant recommendation across the childhood obesity literature. Prevention, as opposed to correction, was continually emphasized. One reason is the damaging psychosocial effects obesity can have that make it difficult to reverse negative behaviors. Lobstein, Baur, \& Uauy (2004) cited the cost and effort required to control the current obesity trend and indicated prevention as the only realistic option of reversing the obesity epidemic. Preventive interventions have a heavy focus on introducing healthy levels of physical activity at an early age and reinforcing these behaviors throughout childhood and adolescence using both school and home-based interventions as the ideal setting for these interventions.

Physical activity and aerobic physical activity specifically have been shown to enhance multiple aspects of cognitive functioning. In a 2008 study, Hillman and colleagues examined the impact of physical activity at the molecular level of brain function. Using electroencephalograms (EEG) to measure electrocortical activity to indicate brain activity, researchers indicated that physical activity resulted in higher levels of activation and more efficient cognitive processing (Hillman et al., 2008). There is additional research to support that an improvement in cognitive achievement is related to the biological reaction of the brain to physical activity. Field, Diego, \& Sanders (2001) found a positive relationship between high school students' academic performance and self-reported physical activity habits. A number of additional literature sources provides added support to the connection between academic performance and physical activity levels throughout adolescence (Carlson \& Fulton, 2008; Field et al., 2001; Lindner, 2002; J. Sallis, McKenzie, \& Kolody, 1999; Taras, 2005; Yu, Chan, \& Cheng, 2006). 
National recommendations. Current national recommendations for daily physical activity call for at least 60 minutes per day for children between 6 and 17 years of age (CDC, 2008). Most of the active minutes should come in the form of moderate to vigorous aerobic activities. Activities in the moderate zone would be rated between 12-14 on the Borg Rating of Perceived Exertion (RPE) scale and would consist of activities like brisk walking, riding a bike or playing doubles tennis (Borg, 1998). At least three days per week children should participate in vigorous physical activities consisting of these activities would be rated as hard to very hard on the Borgs scale and include activities like jumping rope or running (CDC, 2008). As part of the daily 60 minutes of physical activity muscle strengthening activities, which include activities causing the muscles to hold against an applied force, should be included at least three days of the week. Bone-strengthening activities, which produce a force applied to the skeletal system such as high impact jumping or running, should also be included at least three times per week. Encouraging a wide variety of physical activities is important for children as they learn to develop lifelong physical fitness skills.

Current recommendations suggest that adults need at least 150 minutes of moderateintensity aerobic activity per day or 75 minutes of vigorous aerobic activity per week or an equal combination of the two (CDC, 2008). More extensive health benefits can be gained by increasing these daily recommendations. It is also important to include strength training exercises on at least two days per week (CDC, 2008).

\section{Current physical activity trends.}

In the US. According to the Center for Disease control currently, 51.6\% of Americans are meeting the minimum recommendation for physical activity by meeting the recommended 150 minutes per week of aerobic activity. With only $31.8 \%$ of Americans performing physical 
activity at a level to achieve substantial health benefits by performing 300 minutes per week of aerobic physical activity. $25.4 \%$ of Americans reported that they had no leisure time activity and did not perform any aerobic activity throughout the week. Only $27.1 \%$ of children met the minimum recommendations for aerobic physical activity while $15.2 \%$ reported no physical activity. Daily physical education was only offered to $29.4 \%$ of $9^{\text {th }}$ to $12^{\text {th }}$-grade students nationally (CDC, 2014).

$\boldsymbol{W V}$. According to the CDC state indicator report currently, $43.0 \%$ of West Virginians are meeting the minimum recommendation for physical activity by meeting the recommended 150 minutes per week of aerobic activity. Another $26.1 \%$ of West Virginians performed physical activity at a level to achieve substantial health benefits by performing 300 minutes per week of aerobic physical activity. 35.1\% of West Virginians reported that they had no leisure time activity and did not perform any aerobic activity throughout the week (CDC, 2014). Only $31 \%$ of children met the minimum recommendations for aerobic physical activity while $15 \%$ reported no physical activity. Daily physical education was only offered to $30.7 \%$ of children (CDC, 2014).

\section{School-Based Physical Activity to Influence Children's Health. Physical activity} promotion in schools and families have become an important target area for health and physical activity interventions; both settings have been recommended as ideal locations to target children's health behavior and reverse the trend of childhood obesity (Stroup et al., 2009). While this study seeks to focus primarily on the families' role in influencing children's health, schoolbased strategies offer insight into the most effective intervention strategies.

Children spend most of their day in schools. Consequently, the school is an important area to target, and several studies have demonstrated effective improvements in child physical 
activity using school-based physical activity interventions (Kriemler, Meyer, Martin, Van Sluijs, Andersen, \& Martin, 2011).

In an intervention by Gorely, Nevill, Morris, Stensel, \& Nevill (2009), researchers were able to use a structured curriculum designed to integrate physical activity throughout the school to produce significant increases in MVPA and steps, both during the school day and outside of school. The Greatfun2run intervention ( $n=310$ intervention, $n=279$ control) utilized five specific strategies to increase physical activity in the schools. These strategies included parent involvement as an important component of the school-based intervention. Teachers within the intervention group were provided with a CD-ROM of teaching and learning resources that integrated physical activity breaks into the curriculum and were allowed to decide how they wanted to use the material. Students also participated in two annual 1-mile school run/walk events that encouraged them to improve upon their previous time. An interactive website was designed for students and connected with parents to reinforce key concepts provided through the teacher's materials. A local media initiative was formed to raise community excitement and awareness for the intervention. Finally, students were provided with activity wall planners to track their physical activity throughout the summer. Main outcomes from this study included child physical activity measured through ActiGraph GT1M accelerometers, fruit and vegetable intake, body composition psychosocial survey measures and parent and teacher qualitative feedback. Researchers found significant increases in child MVPA and step counts within the intervention group using the Greatfun2run program. Researchers acknowledged the need for a long-term follow-up to support the sustainability of the intervention.

The Action Schools! BC (AS!BC) model in British Colombia provides another valuable example of a school-based intervention strategy which has been effective at increasing child 
physical activity (Naylor, Macdonald, Zebedee, Reed, \& Mckay, 2006). Using a 16-month cluster randomized comparison trial $(n=10)$ schools applied the AS!BC model. This model provided direct resources for teachers and schools to create individualized plans across six different action zones, with the intent on giving teachers the tools to facilitate 150 minutes of MVPA per week through a multi-dimensional approach. This strategy supported schools existing PE structure and offered support for additional PA opportunities throughout the school day by improving the school environment, and infusing physical activity into the curriculum. Additionally, family and community support was recruited by stabling parent-led PA opportunities and clubs with school spirit as the heart of the recruitment effort to engage parents. Both intervention groups demonstrated significant increases in weekly MVPA minutes compared to the control group. Teachers who received the intervention training provided additional 55-67 minutes of physical activity per/week more than control schools. Each school had varied strategies on engaging families using newsletters, workshops, and physical activity homework to engage families was indicated as an important component of the AS!BC model. More intensive outreach efforts to involve parents have been recommended as a way to increase the fidelity of the family component of the intervention.

A common theme of these school-based interventions was the inclusion of a home or family component, which is in line with the CDC's Whole School, Whole Community, Whole Child (WSCC) approach for health learning (Lewallen, Hunt, Potts-Datema, Zaza, \& Giles, 2015). Developing a continued understanding of how to best target families will lend support to not only family-based interventions but school-based interventions as well. A common concern across these interventions was the need for additional outreach efforts to engage family 
stakeholders. Parent PA behaviors and the related psychosocial variables are one way that may be useful in engaging families through a structured behavior change model intervention.

\section{Behavior Change}

Behavior change theory was initially conceptualized as a tool to combat smoking addiction (J. O. Prochaska, Velicer, DiClemente, \& Fava, 1988a; Velicer, Prochaska, Rossi, \& Snow, 1992a). However, in recent years with the consistent growth of the obesity epidemic, behavior change theory has been applied to physical activity and exercise behavior with moderate success (Hutchison, Breckon, \& Johnston, 2009b; B. H. Marcus et al., 1992; BH Marcus et al., 2000).

Physical activity behavior change. A consistent problem with physical activity interventions is the pattern of participant attrition, nearly $50 \%$ of participants in physical activity interventions drop out of intervention programs within the first three to six months (Dishman, 1988). Similarly, this attrition pattern is also shown in the smoking cessation literature. However, there is also evidence in this literature that behavior change has been an effective means of retaining participants in programs that utilize a behavior change model (Eysenbach, 2005). The strength of using the stages of behavior change model is the opportunity to offer participants more than an "all or nothing approach" to health intervention. In the stages of change, model participants may have very different levels of success dependent upon their initial stage of behavior change when they enter the program. This staged approach to influencing health behaviors has been suggested as a more effective model to understand the process of behavior change for physical activity and health behaviors (Bess H. Marcus et al., 1992).

A wide variety of physical activity interventions have been able to demonstrate a high level of success for encouraging exercise adoption; however, there has been little success 
monitoring the maintenance of these exercise behaviors. While there is no definitive line of understanding as to why people stop or start exercise maintenance behaviors; a major theme of interruption has stemmed from life events. Staged behavior change interventions provide participants with lifestyle behavior change that is more likely to withstand lifestyle factors than interventions that do not incorporate lifestyle behavior change (BH Marcus et al., 2000).

The Transtheoretical model (TTM) of behavior change has been recommended as an effective means of physical activity promotion when incorporating a staged approach to physical activity interventions (Buxton, Wyse, \& Mercer, 1996; Marshall \& Biddle, 2001).

Transtheoretical Model of Behavior Change. Borrowing from the smoking cessation literature this study seeks to use the Transtheoretical Model of behavior change as a tool to deliver the intervention (Armitage \& Arden, 2008; Ramo, Thrul, Delucchi, Ling, Hall, \& Prochaska, 2015; Thrul et al., 2015a; Velicer et al., 1992a). The Transtheoretical Model of behavior change was first established in the late 1970's as a way to aid people in smoking cessation ( Prochaska \& DiClemente, 1982). Before the development of the TTM, emphasis on understanding behaviors was primarily handled in the theoretical perspective with over 200 new behavioral theories to explain why behaviors occurred, where new theories were being developed for every behavioral condition rather than an effort to create a unifying theory. Prochaska was more concerned with the process of change than the reasons for behavior change. He organized the TTM by reviewing the 18 leading behavioral therapies and identifying the critical processes that allowed clients to reach their behavioral goals. This resulted in the discovery of what we refer to as the Transtheoretical Model of Behavior Change ( Prochaska \& DiClemente, 1982). 
The stages of behavior change initially developed by Prochaska \& DiClemente (1982), have been extensively studied since their development. The stages consist of four core constructs.

\section{First core construct: stages of behavior change.}

Precontemplation. The initial period of behavior change begins before a person has made the decision to change their behavior. During this phase of change, a person may not yet have any intention to change their behavior within the next six months. Individuals in this stage may not be aware that their behavior is a problem or may feel incapable of changing or defensive about the problem behavior. In this stage of behavior change, it is important to emphasize the pros of behavior change(J. Prochaska, 2013).

Contemplation. During the contemplation phase, a person becomes aware of the need for behavior change and intends to make a change to a targeted behavior within the next six months. While aware of the cons in this stage of behavior change, individuals are in tune to the pros of changing their behavior. According to Prochaska (2013), the mottos of a person in the contemplation phase of change may be "When in doubt, don't act" (p.1998).

Preparation. Individuals in the preparation stage of change intend to take action on their desired behavior change within the next thirty days. The emphasis on this phase is to make sure that the individual is well prepared to take on the behavior change. Prochaska (2013), noted the number one concern of someone in the preparation stage as "If I act, will I fail" (p.1998).

Action. The action stage of change is an overt and observable change in a person's behavior; this can be noted by a person's increase in physical activity or decrease in smoking. The action phase will last as long as six months of continued observable behavior change. 
During this stage of behavior change a person is at the highest risk to revert to previous behavior and must work the hardest to maintain behavior change (J. Prochaska, 2013).

Maintenance. The maintenance stage of behavior change is the period of six months up to five years after a behavior change was made. During this stage of change, the temptation to relapse on behavior is no longer as difficult to overcome, and individuals do not have to work as hard to avoid relapsing on behaviors. During this stage of change, the primary concern for relapse is distressing situations where a person may be abnormally anxious, bored, or depressed (J. Prochaska, 2013).

Termination. By the time, a person reaches the termination stage of behavior change they are no longer tempted to relapse to previous behavior. Some people will never reach this stage of change, only about $20 \%$ of alcoholics report reaching the termination stage after five years of maintenance (Velicer, Prochaska, Rossi, \& Snow, 1992b).

Second core construct: process of behavior change. The second core concept of the Transtheoretical Model is the processes of change; these processes involve strategies and coping mechanisms that are used to help a person change their behavior from one stage to the next (J. O. Prochaska, Velicer, DiClemente, \& Fava, 1988b). These processes work to help a person progress from one stage of behavior change to the next. Prochaska, Velicer, DiClemente and Fava (1988), identified ten critical processes of change, these were organized into two categories: experiential/cognitive processes and behavioral processes. Experiential/cognitive processes of change were characterized by passive processes, while behavioral processes of change involved some form of behavior manipulation (J. O. Prochaska et al., 1988b). 
There are five critical processes of change that fall into the category of experiential/cognitive (B. H. Marcus et al., 1992, p. 425):

1) Consciousness raising: efforts by an individual to seek information and gain an understanding of a problem behavior

2) Dramatic Relief: affective aspects of change, often involving intense emotional experiences related to problem behavior

3) Self-reevaluation: an emotional and cognitive reappraisal of values by the individual with respect to the problem behavior

4) Environmental reevaluation: Consideration of how problem behavior affects the physical and social environment

5) Social liberation: acceptance by the individual of an alternative problem free lifestyle

The five critical processes of change that fall into the behavioral category are:

1) Self-Liberation: an emotional and cognitive reappraisal of values by the individual with respect to the problem behavior

2) Counterconditioning: substitution of alternative behaviors for the problem behavior

3) Stimulus Control: control of stimulus and other causes which might trigger the problem behavior

4) Contingency Management: changing the contingencies that control or maintain the problem behavior

5) Helping Relationships: trusting accepting and utilizing the support of caring others during an attempt to change problem behavior 
Third core construct: decisional balance. The Decisional Balance construct of the Transtheoretical Model consists of a person's perceptions of the negative and positive aspects of behavior change (J. Prochaska, Redding, \& Evers, 2002). This balance is typically negative when a person is still in the precontemplation or contemplation stages of change; a person in this stage has trouble seeing past the potential sacrifices that they would have to make to change their current behavior. An individual in the later stages of change, action or maintenance will have a positive decisional balance; a person in this stage will view the benefits of the changed behavior and focus more on the positive effects of their behavior change (B. H. Marcus et al., 1992; J. O. Prochaska \& Velicer, 1997).

Fourth core construct: self-efficacy. Bandura, (1994) defined self-efficacy as "people's beliefs about their capabilities to produce designated levels of performance that exercise influence over events that affect their lives (pp. 71-81)." This theory postulates that as a person gains a higher sense of self-efficacy they then have a higher threshold for success and personal accomplishment (Bandura, 1971).

Behavior change and self-efficacy have a linear relationship, as a person begins to gain efficacy in their ability to change the desired behavior, they will then be able to perform the necessary behavior change. Likewise, the stages of behavior change work as the mediating device that helps to enhance a person's efficacy in changing the desired behavior (Marcus \& Simkin, 1994). An individual in the precontemplation stage of behavior change would have a very low level of self-efficacy in their ability to change their physical activity behavior, while someone in the maintenance or termination stage would likely have a very high level of efficacy (Bess H. Marcus et al., 1992; J. Prochaska \& Marcus, 1994). 
Review of intervention studies focused on behavior change. One of the more challenging components of creating an effective physical activity intervention is determining how to appropriately tailor the intervention program specifically for a population's readiness to make a behavior change based on the Transtheoretical model of behavior change (J. Prochaska \& Marcus, 1994). However, solving this problem has been proven to be very effective in delivering health and physical activity interventions.

In a six-week intervention with 610 residents in a small northeastern community, researchers sought to encourage participation in physical activity. Participants were targeted based on their readiness to change from three of the five stages of change, contemplation (39\%), preparation (37\%), and action (24\%), by receiving written material matched to their stage of change. After completion of the six-week program a Stuart-Maxwell test for correlational proportion showed that participants were significantly more active $\left(X^{2}=64.55, d f=2, p<.0001\right)$ participants in the contemplation stage significantly increased their physical activity $31.4 \%$ moving from contemplation to preparation, while $30.2 \%$ of participants in the preparation stage moved to the action stage at follow-up (B. H. Marcus et al., 1992).

Interventions using the Transtheoretical model (TTM) of behavior change have had varying levels of success with short-term effects being the principal area of success. Early evidence from the physician-based assessment and counseling for exercise (PACE) trials indicated that the effect of a TTM based intervention relied heavily on the initial stage of a person when entering into the intervention and indicated that TTM interventions had more potential to be effective in patients who were still in the contemplation stage of change (Calfas, Sallis, Oldenburg, \& Ffrench, 1997). 
The Physical Activity for Life (PAL) intervention applied the PACE model in a targeted population of individuals over 50 years of age and also incorporated a follow-up evaluation upon completion of the intervention. Initial physical activity changes showed promise for behavior change, however upon follow-up, there was no longer a significant difference in the group's physical activity behaviors indicating that behavior change was not sustained when the intervention was removed (Pinto, Goldstein, DePue, \& Milan, 1998).

The Change of Heart study was able to demonstrate significant levels of exercise adherence over and above generic counseling using the TTM approach. An important construct of the Change of Heart trial was the direct training to nurses on counseling patients using the TTM for all three high-risk behaviors (sedentary, high-fat diet and smoking) rather than focusing only on physical activity (Hilton, Doherty, \& Kendrick, 1999). These indications align with Adam's \& White's (2003) review of effective TTM interventions where they suggested that effective interventions should be delivered by trained personnel to ensure fidelity of the model.

Peterson \& Aldana (1999) applied the TTM to a workplace wellness in comparison to a generic delivered intervention program. The staged intervention group had their questionnaires analyzed and were placed into stages of change groups. Messaging for the staged group was tailored for each stage of change. The generic group received general recommendations on physical activity from the report of the Surgeon General on physical activity (Centers for Disease Control and Prevention, 2015). In the follow-up, participants in the staged group demonstrated a $13 \%$ increase in activity; while the generic group only increased activity by $1 \%$ and the control group saw an $8 \%$ decrease in physical activity over the six-week program. These findings are in agreement with Findings from the Physical Activity for Life project which found that utilizing 
stage-specific counseling for participants based on their perceived stage of behavior were more effective than generic behavior change counseling (Peterson \& Aldana, 1999b).

Bess, Bock, Pinto, Forsyth, Roberts, \& Traficante (1998), used an individually tailored intervention based on participant's motivational feedback, self-efficacy, decisional balance and cognitive readiness for physical activity adoption to place participants in one of three tailored groups (precontemplation, contemplation, preparation). Participants were placed into either the individually tailored intervention (IT, $\mathrm{n}=441$ ) or the standard intervention $(\mathrm{ST}, \mathrm{n}=462)$ and physical activity were monitored using self-assessment throughout the intervention period. Sixtyfive percent of precontemplation and $61.3 \%$ of contemplation group members in the IT group increased their stage designation through the intervention. Similarly, participants in the preparation and action stages increased their stage designation by $51.4 \%$ and $58.2 \%$ respectively. These stage increases were significantly higher at each stage of change for IT participants than for ST apart from the maintenance stage where both groups had similar results. IT Participants demonstrated significantly higher levels of physical activity consistently throughout the intervention. These results carried over to a 1-year follow-up, lending support to the effectiveness of interventions that target participants in their specific stage of change (Bock, Marcus, Pinto, \& Forsyth, 2001; Calfas et al., 1997).

In a meta-analysis, Marshall \& Biddle (2001) analyzed the findings from seventy-one published reports that presented data on at least one construct of using TTM. Their analysis was consistent with previous predictions that levels of physical activity increased as participants moved to a higher stage of change (Buxton et al., 1996; Salmon, Ball, Hume, Booth, \& Crawford, 2008). Specifically, findings identified that a change from the precontemplation to the contemplation stage showed evidence of moderate increases in physical activity in inactive 
participants (Marshall \& Biddle, 2001). These findings provide additional evidence that physical activity behavior change is related to the stage of change and participants should be targeted based on their existing behavioral readiness for change.

\section{Family}

The impact of caregivers and families on children's health is clearly demonstrated in the literature. Seventy-five percent of children who are obese between the ages of 6-9 and have obese parents will become obese adults (Blair et al., 2001; Moore, et al., 1991; Whitaker \& Wright, 1997). The home environment has consistently been identified as an area of emphasis for physical activity interventions that affect both children and adults. Parents' values, modeled behaviors, parenting styles, and physical activity habits have all been shown to impact the physical activity habits of children (Baughcum, Burklow, Deeks, Powers, \& Whitaker, 1998; K. Davison \& Birch, 2001; K. K. Davison \& Birch, 2001; SL Johnson \& Birch, 1994; McFarlane, 1995; L. L. Moore et al., 1991; O’Connor et al., 2009; Whitaker \& Wright, 1997). Numerous family-based health interventions have demonstrated that improving constructs of family behaviors affects positive physical activity behaviors and supports the need for more research to improve physical activity behaviors within the family (Dalton \& Kitzmann, 2008; Kitzmann, Dalton, \& Buscemi, 2008; Nemet, Barzilay-Teeni, \& Eliakim, 2008). The following sections provide an overview of the existing literature relevant to physical activity within the context of the family.

Parenting Behaviors and Their Children's Healthy Lifestyle Practices. The link between parent and child healthy lifestyle practices is influenced by a variety of different factors. The influence of the parent has a broad scope concerning child physical activity habits. Children look to their parents for modeling behaviors and values, parental support of physical activity, a 
home environment that supports a healthy lifestyle as well as authoritative parenting styles that establish expectations of healthy habits (Beets \& Cardinal, 2010; Dagkas \& Quarmby, 2012; K. Davison, Cutting, \& Birch, 2003; Fuemmeler et al., 2011a; S. Gustafson \& Rhodes, 2006; Ostbye et al., 2013).

\section{Parents' physical activity values and behaviors. Fuemmeler, Anderson, and Masse} (2011) investigated the relationship of directly measured physical activity between parents and children. Using a sample 57-parent child triads (Father, Mother, Child), researchers monitored physical activity 24 hours per day from Wednesday afternoon thru Monday morning with an average wear time of $90 \%$ across a 96 -hour period. Their findings suggest that increases in parent moderate to vigorous physical activity (MVPA) had a strong association with the MVPA of their children. Even more promising is that when both parents in the family had increased levels of MVPA, there was a greater association with child MVPA. The strongest association by the parent was found between mothers and their children. This indicates that mother's physical activity should be an area of emphasis when designing family interventions. The link between fathers and children's sedentary time was not associated in general, but when researchers adjusted for time, they found there was an association between sedentary time of fathers and children during weekends. This may help researchers to design interventions that focus on getting fathers active during the weekend and avoid long sedentary bouts during these time windows. To support the connection between parent-child PA, additional research is needed using longitudinal methods to assess PA decline with age and how that may be moderated by parent activity levels. Additionally, a larger sample size with a more diverse population may be effective in uncovering indicators, which this study was underpowered to demonstrate. 
To somewhat contrast these findings Dempsey, Kimiecik and Horn (1993) applied the expectancy-value approach to help understand the influence that parents have on their children's physical activity. While the Fuemmeler, Anderson, and Masse (2011) study provided evidence of a link between parent and child MVPA; this study did not identify a significant relationship between parent and child PA. The role modeling effect seen in existing literature may not have been seen in this study due to the subjective measure of MVPA Used in the study. Using selfreported measures of MVPA (Leisure Time Exercise Questionnaire) and a four-part questionnaire including measures of parent-child value, expectancies, perceived MVPA competence, and goal orientations, researchers took a sample of 71 child participants ( 35 girls, 36 boys) and 69 parent participants. Using a hierarchical regression analysis to examine the influence of these measures on child MVPA, researchers found only one significant outcome in the form of perceived PA competencies. These findings suggest that children's MVPA is more heavily influenced by parent's beliefs than their actual PA behaviors. These beliefs might include the value of exercise for their children, success expectancies, goals that they set for their children and perceived physical competence. While this study faced several limitations in the form of subjective MVPA measurement, and a lack of consideration for the complexity of parent-child PA beliefs they might explain how these beliefs influences one another; it still provides some indication that PA behavior between parents and children are more complex than simply role modeling a healthy lifestyle (Dempsey et al., 1993).

Dagkas and Quarmby (2012) added additional support for the complex nature of parentchild PA behaviors using a qualitative investigation they found that although children who came from homes with active parents had a positive outlook on PA, parent PA alone was not the only factor that contributed to children's PA dispositions. Using an interpretive research approach and 
conducting group interviews with children from similar family structures defined as two parent $(n=50)$, sole parent $(n=25)$, and stepparent families $(n=25)$. These authors found that the value that parents placed on physical activity played a bigger role in the values of the children than physical activity behavior itself did. In homes where parents placed a high value on physical activity and openly discussed health and fitness yet did not model that behavior, their children still placed a high value on physical activity. While families where parents were active yet did not support their child's physical activity, the children in these families looked at physical activity as something that their parents did that did not involve the child. It becomes necessary as a family to focus on setting an environment that encourages and supports physical activity in a variety of different ways. A potential limitation of this study was the parents not being involved in the interview process to substantiate and verify pedagogical practices within the home.

In a study by Andriani, Liao, and Kuo (2015), parent weight changes were identified as key indicators of weight changes within the child group. Using secondary analysis of the Indonesian Family Life Survey (IFLS) they were able to identify patterns by comparing BMI of parents and children between years on the survey across a fourteen-year span. Parents who maintained or reduced BMI during the period also had children with similar outcomes while parents who demonstrated an increase in BMI similarly had children that demonstrated similar increases. While this study did not attempt to determine any relevant causes for the potential weight changes, it does provide a representative sample to demonstrate some link between parent and child weight status across a very large population subset. Further exploration is needed to examine the behavioral characteristics related to parent and child weight fluctuation on a large scale. 
Genetics were originally believed to play a role in the relationship between parent and child weight relationships, and while there is evidence to support a genetic link, that evidence relies on factors that are believed to be mediated by an appropriate environment (Wardle, et al., 2008). Garn, Cole, and Bailey, (1976) dismissed the genetic notion as they found similar relationships between adoptive and biological parents. For both adoptive and biological parents, there was an association at each tier of weight gain and parents from low weight middleweight and overweight all had relative levels of BMI (Garn, Cole, \& Bailey, 1976). Epstein et al. (1980) observed that when parents and children are both involved in a behavior modification program that focuses on creating healthy eating habits, there is a greater effect on student BMI than if the child had completed the behavior modification program independently of their parent.

Evidence supporting the connection between weight variability in parents and children leave the question of what components of lifestyles influence this connection. There is a multitude of factors that contribute to a person's physical health and specifically a person's body weight. Most notably physical activity and diet play a huge role in the fluctuation of body weight (Ogden, Yanovski, Carroll, \& Flegal, 2007). This existing literature highlights parents PA behavior and values as recommendations for interventions to target when combating physical inactivity through the family.

Parenting style. Parenting styles differ from culture to culture and even across socioeconomic groups within the same cultural setting. In a study by Arrendondo, Elder, Ayala, Campbell, Baquero and Duerksen (2006), parent-child dyads $(\mathrm{n}=812)$ were recruited to complete a variety of subscales to assess parenting style, family nutritional patterns, child PA, and parent PA support to make associations between parenting styles and both healthy eating and physical activity. The study found that parents who implemented an authoritative parenting style by 
monitoring their child's healthy eating and physical activity (PA) had a positive correlation with healthier eating habits in their children $(r=.45, \mathrm{p}<.001)$ and increased levels of physical activity $(\mathrm{r}=.19, \mathrm{p}<.001)$. Parents who provided positive reinforcement for their children saw improved outcomes in healthy eating and physical activity behaviors. While parents who used a more controlling style of parenting had children with a diet that consisted of unhealthy, foods and consumed fewer fruits and vegetables. Parents who monitored and reinforced healthy behaviors had children who were more likely to eat healthy foods and were more physically active compared with the children of parents who did not use these parenting styles. These findings suggest that interventions should inform parents of the importance of monitoring behaviors above rigid policy on physical activity and eating habits. These findings are consistent with previous research in the field lending to the idea that parents who use positive reinforcement and appropriate discipline may have children with healthier lifestyle habits (Faith, Berkowitz, \& Stallings, 2004; Stark, Collins Jr., Osnes, \& Stokes, 1986).

The forms of cultural exchanges and production of cultural values within the family context constitute a set of informal pedagogy practices (Tinning, 2010). Many parenting styles are underpinned by a set of pedagogies within the family. These informal practices influenced by personal family histories and social circumstances heavily influence the child's behaviors. Through the home environment, these circumstances play a major role in childrens' learned health behaviors, attitudes, and beliefs towards healthy behaviors (Ball, 2010 ). Dagkas and Qaurmby (2012) examined how these underlying informal pedagogies within the culture of the family worked to develop health and physical activity behaviors for the children within the families. While many families want to lead lifestyles that encourage their children to be healthy and active this is not done through structured physical education lessons in the home, instead the 
parents must rely on their parenting styles, behaviors and attitudes to encourage physical activity in the family. Participants in the study highlighted their parent's attitudes and perceptions of physical activity as a reason why they found physical activity as important. For instance, one participant cited their mother's value by describing the home environment as his mother would “always banging on about how it's [physical activity] good for life... like health and that." (Dagkas \& Quarmby, 2012, p. 216). These examples associate the necessity for a well-rounded intervention that encompasses not only role modeling behaviors but also the family's PA value and a home environment that promotes PA.

An important indication from the literature on family has consistently been to target parental training as a key area when influencing child health (Barlow, Dietz, Epstein, Gidding, Himes, Jonides, et al., 1998; L. H. Epstein, Myers, Raynor, \& Saelens, 1998; Golan, 2006; Israel, Stolmaker, \& Andrian, 1985). Barlow and Dietz (1998) convened a committee of pediatric obesity experts, which identified key parenting principles that should be emphasized when managing physical activity and health behaviors, including role modeling, praise/correction that focuses on the behavior, not the child, and consistent responses to behavior from parents. These target areas can all be addressed through parental education and support within the home environment.

Home environment. The environment of the home itself is a major area of the informal home pedagogy and one that can have a profound effect on the values that children place on health and physical activity (Tinning, 2010). Evidence suggest that simple things like the groceries parents buy or the neighborhood environment may play a major role in how children perceive and value health, nutrition and physical activity (Ostbye, et al., 2013). Ostbye and colleagues (2013) investigated this role by monitoring the physical activity and food 
environment habits of children $(n=208)$ within families of overweight and obese mothers. They found that parent role modeling and limiting unhealthy food environment had a significant negative relationship $(r=-.44, p<.05)$ with "junk" food intake scores while parental policies that support PA had a positive relationship $(\mathrm{r}=.26, \mathrm{p}<.05)$ with MVPA time. The home environment is one area where parents can make small changes to improve the health habits of their children without overt behavior modeling. Some parents who have a low sense of behavior control in their ability to improve physical activity may be able to start introducing healthy behaviors by making small modifications in the home environment.

Decreasing sedentary behavior through the home environment is another key area where parents can make changes to improve children's health. In a study by Dietz \& Gortmaker (1985) evidence of sedentary behavior, specifically television (TV) watching in the home shows significant associations with the prevalence of child obesity. In this study, researchers used data from the National Health Examination Survey (NHES) to conduct simple regression and F statistic associations, with the prevalence of obesity and time spent watching tv. Children who watched more TV experienced a greater level of obesity $(\mathrm{p}<.01)$ than children watching less TV. These relationships were dependent upon the time spent watching TV; obesity prevalence increased between 1.2 and $2.9 \%$ for each hour that a child spent watching TV.

Epstein and colleagues (1995) investigated the effectiveness of interventions that use strategies to reinforce the reduction of sedentary behaviors. Using three groups families were randomized to one of three conditions: condition 1 (sedentary) targeted training to reduce sedentary behaviors in the family, Condition 2 (exercise) targeted training to increase exercise in the family, and condition 3 (combination) receiving both targeted training. Significant group differences $(\mathrm{p}<.05)$ were detected between groups receiving the sedentary condition and the 
exercise condition. Children who were reinforced for reducing sedentary behaviors showed changes over and above the exercise group for percentage overweight $(\mathrm{p}=.026)$ and percentage body fat changes $(p=.037)$. Children in all three groups increased fitness at the end of the study These findings suggest that implementing strategies to reduce sedentary time are useful additions to physical activity interventions and the reduction of sedentary behavior is an important tool in the treatment of obesity (Epstein et al., 1995).

The environment and family factors are a major area of concern to consider when investigating how to design interventions to impact family behaviors and health habits. Epstein, Paluch, Roemmich, and Beecher (2007) investigated how the design of interventions today compared to the design of family-based health interventions from twenty-five years ago, with a primary concern on the effectiveness and differences of interventions being used today. While there has been a massive change in the prevalence of obesity over the past twenty-five years, the effectiveness of family interventions has remained similar based on z-BMI score outcomes between study groups within family-based interventions. What has changed over the last 25 years is the prevalence of obesity and the obesogenic environments where children are raised (L. Epstein, Paluch, Roemmich, \& Beecher, 2007). Suggestions in the literature for designing effective family interventions related to the environment include parental education programs that work to improve cognitive stimulation for children in the home (Strauss \& Knight, J., 1999). Additionally, Otsbye \& colleagues (2013) recommend parental education to promote active play in the home by encouraging parental modeling of active behaviors.

Family-Based Health Interventions. The indications from the previous literature suggest several key factors that should be considered when creating a family health intervention, these key factors include parental support, behavior modeling, parenting style and the home 
environment (Andriani, Liao, \& Kuo, 2015; Barlow et al., 1998; K. Davison et al., 2003; L. H. Epstein et al., 1998; Fuemmeler, Anderson, \& Masse, 2011b; Kitzman-Ulrich et al., 2009;

Ostbye et al., 2013; J. F. Sallis et al., 2000). Interventions demonstrated that parents who utilized skills such as modeling, reinforcement, and monitoring often saw better outcomes than parents who did not use these skills (McFarlane, Bellissimo, \& Norman, 1995). Modeling of effective health and exercise behaviors has a positive impact on children's health outcomes, so it is important to emphasize this to parents when designing interventions (Anderssen, Wold, \& Torsheim, 2006). When designing health initiatives, that utilize the family as a focal point to improve PA behaviors it is important to draw on these findings, to structure interventions that focus on facilitating behavior change across each component (K. Davison et al., 2003; K. K. Davison \& Birch, 2001; Warschburger, Kroeller, Haerting, Unverzagt, \& van Egmond-Fröhlich, 2016).

Family-based interventions have been identified as an effective way to improve health behaviors in parents and their children (Beets \& Cardinal, 2010; Dalton \& Kitzmann, 2008; Kitzmann et al., 2008). However, at present, there is little evidence to support effective ways of influencing these areas in parents. This study will seek to identify an effective means of influencing parent's attitudes and behaviors related to PA using modern social media. Additionally, the current study will attempt to address a significant methodological limitation of existing family-based research by using objective measures of physical activity to track parent's activity throughout the intervention.

\section{Social Media}

Social media is a term that encompasses all the digital media resources that a person uses to connect socially with others. Using social media sites, humans have the ability to create and 
maintain relationships and build trust with others using a digital platform to communicate (Safko, 2010).

Social media has shown early promise that it may be an effective tool to help communicate health and physical activity interventions (Maher et al., 2014). The social support component of an effective physical activity intervention is often an area of concern for researchers (Blitstein, Cates, Hersey, Montgomery, Shelley, Hradek, et al., 2016; D N Cavallo, Tate, Ries, Brown, DeVellis, \& Ammerman, 2012a). However, social media now provides a way to mediate this concern by connecting intervention participants directly and allowing researchers a direct means of communication to participants.

Social Media Engagement. The prevalence of social media has grown exponentially over the past decade. In 2005 only twelve percent of young adults between the ages of eighteen and nineteen used social media; by 2015 that number had increased to ninety percent. Adults ages thirty to forty-nine have increased social media use from eight percent to seventy-seven percent over the same time period (Perrin, 2015). Social media has become an integral part of most Americans everyday life; social media users rely on this connectivity to stay in touch with friends and loved ones, learn about current events and share their experiences with the world (Duggan et al., 2015). The reach of social media is not limited to an observatory role but instead has become an interactive space where users can share, contribute to, and collaborate on a wide variety of topics. Pew research centers have documented social media's reach into influencing things such as work life, politics, communication, and most notably for the purpose of this review, health and physical activity (Perrin, 2015).

Parents are among the largest consumers of social media; Pew Research Center estimates seventy-five percent of all parents use social media in one form or another (Duggan et al., 2015). 
Many parents use social media as a source for parental advice; half of all mothers on social media say that they have turned to social media for parenting advice at one time or another. Onethird of mothers surveyed has posted a parenting question to social media in the last thirty days. Facebook was among the most widely used of all of the popular social media sites with about seventy-five percent of all social media using parents describing Facebook as one avenue of social media that they used; including eighty-one percent of mothers (Duggan et al., 2015). Parental advice, is a primary concern for parent users, fifty-nine percent of parents and sixty-six percent of mothers have said that they have found helpful parenting information on Facebook. Another forty-two percent of parents and fifty percent of mothers believed that Facebook was a place where they have received social and/or emotional support on parenting issues. Additionally, thirty-one percent of parents and thirty-six percent of mothers have openly asked parenting questions on Facebook (Duggan et al., 2015).

Facebook. Duggan and colleagues (2015), took a deeper look into Facebook as the dominant social media platform for parents; their research uncovered a few interesting things about parents and Facebook. Parents' friendships on Facebook are made up of more people whom they would consider "actual friends" than non-parents on Facebook. This distinction may be important to consider when utilizing social media for health interventions, as it is less likely that a parent will join a group or "like" a page from an unknown source. Another important discovery to consider is the demographics of the parent users; mothers were more active on social media for nearly every metric, it may then be useful to consider tailoring messages towards mothers as they will be the most likely recipients of these messages (Duggan et al., 2015). 
Parents use social media for a variety of different reasons. Information sharing is among the primary reasons for connecting to social media. Mothers use the Internet to seek information, advice and support a form of social capital for mothers by sharing information and communicating about their children (Jang \& Dworkin, 2014a; Morris, 2014; Plantin \& Daneback, 2009). This information sharing creates a community of trust and helps develop online relationships where mothers can feel supported through the exchange of information (Jang \& Dworkin, 2014b). Many mothers also turn to social media as a form of validation for their parenting. Kumar \& Schoenebeck (2015), found that mothers share photographs online as a way of validating their parenting; the social and emotional support that they receive by way of comments and likes on their Facebook photos serves as a form of validation to many mothers. This sense of social support and validation makes social media an ideal setting to provide mothers and parents in general with quality health information.

Impact of Social Media Interventions. Research into social media as a health information communication tool is still in its infancy, as researchers strive to find utility in the many features and connections made available by digital social networks. Vandelanotte, Spathonis, Eakin and Owen (2007), conducted a structured review of existing web-based physical activity interventions and found that half of web-based interventions have been shown to provide positive physical activity behavior outcomes in the short term. While there is still not a clear framework that provides best practices when conducting social media-based health interventions, there is lots of promise in much of the existing work.

Jawad, Abass, Hariri, \& Akl (2015), investigated the utility of social media health campaigns in low resource settings with the intent on raising awareness of the adverse effects of waterpipe tobacco smoking. The project was an unfunded grassroots campaign named 
ShishAware that relied solely on the utility of social media to deliver their campaign. They used a variety of different social media outlets including Facebook, Twitter, and YouTube. Their research found great utility in all three forms of social media they utilized in the project. Facebook was more useful and had higher levels of interactions when short intermittent (14.4 posts per month) health messages were given. Conversely, Twitter posts were more efficient in the short term (1.4 posts per day) and with a more constant flow of information that consisted primarily of external links or current affairs news. ShishAware gathered 520 unique Facebook users over the course of the nine-month project and delivered 130 status updates. After analyzing user engagement, they found that users were more engaged with facts, which they termed "shishafacts" about water pipe tobacco then they were with current affairs posting. This idea mirrors the CDC's recommendations for providing scientifically accurate Quick Facts as a way to engage users (Centers for Disease Control and Prevention, 2011).

The type of posting seems to be an important variable to consider when creating a social media delivery strategy. Hales, Davidson, \& Turner-McGrievy (2014), investigated how the participants responded to different posting types in a behavioral weight loss intervention $(\mathrm{n}=$ 63). This study used website analytics as a measure of engagement in the form of likes, comments, or poll responses to measure the engagement or effectiveness of the post type. Using this method, they found that polls were the most engaging form of interaction, followed by posts that provided quick tips or suggestions for weight loss and the least engaging posts provided news or recipe suggestion posts. There were no significant differences between groups in age, BMI, gender, ethnicity, education, or marital status. This seems to align with previous research on effective Facebook messaging as well (CDC, 2012; Jawad et al., 2015; Maher, Ryan, Kernot, Podsiadly, \& Keenihan, 2015; O'Flahavan \& Goulet, 2012). However, at the end of the study, 
researchers asked users to rate postings in order of most to least preferred; participants rated news and recipes as their most preferred message followed by polling and then suggestions. These results are counter to the analytical user engagement levels used in most all of the previous research. Another important discovery from this study was user engagement generated from counselor-delivered posting compared to user-generated content; users were much more likely to engage in the post when the post was initiated by a counselor instead of another user $(7.5 \pm 5.0$ per post for counselors, $0.7 \pm 1.0$ per post for participants; $\mathrm{P}<0.001)$ (Hales et al., 2014). This significant difference in post engagement may be related to the concept that posts delivered from people who are considered health experts are viewed as more credible (Hu \& Shyam Sundar, 2010). This study had several limitations that need to be considered when incorporating post engagement strategies; the authors note that randomization was not possible since joining the Facebook group was an optional component of the intervention. This makes it impossible to determine the direction of the relationship between engagement and weight loss.

Engagement is critical to the success of any health intervention and finding ways to engage participants is an essential component to creating effective health interventions (Maher et al., 2014). Current information on the internet-delivered health intervention suggests that peer and counselor support, email/telephone contact, and regular updates to the website improve participant engagement (Brouwer W, Kroeze W, Crutzen R, de NJ, de Vries NK, Brug J, 2011). Additionally, the results of a Web-based smoking cessation intervention found that a prescriptive message enhanced engagement of participants more than a motivational message tone (McClure, Shortreed, Bogart, Derry, Riggs, St John, et al., 2013). The translation of these engagements strategies from Internet-based interventions to social media-based interventions is still not clear. Social media is an engaging platform that $61 \%$ of users check on a daily basis, so additional 
research is needed to target specific engagement strategies for social media-based interventions (Constine, 2013).

Review of Social Media Interventions. Maher et al., (2014), reviewed the existing field of literature on strictly social media-based interventions and the effectiveness of these interventions of the initial 2040 articles reviewed only ten articles met the criteria for inclusion into the effectiveness of social media.

Brindal, Freyne, Saunders, Berkovsky, Smith, \& Noakes (2012), sought to show that web-based programs offer real potential for delivery of weight loss programs. They studied whether the 12-week Internet-delivered lifestyle intervention program and supportive features could affect retention and weight loss. This design included three different groups; informationbased (eligible, $n=183$, completers $n=16$ ), supportive (eligible, $n=3994$, completers $n=213$ ), or personalized-supportive (eligible, $n=3935$, completers $n=206$ ). Participants were overwhelmingly female which may be a symptom of the voluntary nature of the study; participants were on average 45 years of age \pm 11.9 and had a BMI over 25 . Both supportive sites included tools, such as a weight tracker, meal planner, and social networking platform. All data was collected online with no face-to-face contact. The information group only received one level of the intervention as only the diet and exercise information was given to that group. The supportive groups received interactive planning features, compliance feedback, social support system, and diet \& weight self-monitoring. The personalized support group received additional personalized planning tailored specifically for each participant. The results of the study did not show a weight loss or retention effect for the study; however, the social networking component did increase the average number of days that a user logged into the website (Brindal et al., 2012). A common issue with web-based health interventions has been the retention rates of participants, 
while many studies delivered through the web have shown great potential for recruitment often the retention rates of these studies fall between $6 \%$ - 35\% this study suffered the same issue with only $16.3 \%$ of participants who provided an initial entry completing the program. However, there was a statistically significant difference between sites that offered information only and those that offered social support at the 12 -week retention point $(\mathrm{p}<.01)$.

Interventions that use popular social media have been shown to be more efficient in early studies as users typically already use one form of social media or another (Maher et al., 2014). Cavallo, Tate, Ries, Brown, DeVellis, \& Ammerman (2012), tested the impact of an intervention with the use of an online physical activity-focused website, physical activity self-monitoring, and access to a Facebook group for social support. Participants were randomly assigned to one of two groups; the education-only control group $(n=67)$ or the intervention group $(n=67)$. The education-only control group received limited access to a dedicated physical activity website INSHAPE, with educational materials. The intervention group which had access to the website also participated in online self-monitoring of physical activity habits and an additional physical activity themed Facebook group. Participants in the intervention group were provided social support related to increasing physical activity through the Facebook group. Reported measures were perceived social support for physical activity and self-reported physical activity. Results did not indicate any significant differences in main effects between the two groups. However, the level of engagement in the program was much higher for intervention participants. Participant in the intervention group logged into the INSHAPE website once every two weeks compared to control participants who only logged in twice over the course of the intervention. This study did not find an increase in perceived social support $(F(1,127.28)=1.57, \mathrm{p}=0.21)$ or physical activity $(F(1,127.75)=0.42, \mathrm{p}=0.52)$ over time between groups. However, a high level of 
participant satisfaction and engagement with the intervention group may indicate that social media is, in fact, a useful platform for the delivery of health interventions. Recommendations from the authors suggest that it may be helpful to include subsets of current friends within the intervention to maximize social support options and maximize participant motivation (Wing \& Jeffery, 1999). Additionally, the use of objective data collection measures for Facebook engagement should be utilized (D N Cavallo et al., 2012b).

Foster, Linehan, \& Lawson (2010), focused on the use of competition to drive behavior change using social media in their recent study. Participants were nurses working in a UK hospital that were randomly assigned to one of two groups. The control group received a pedometer and logged their daily steps using a non-socially enabled version of Step Matron. The intervention group used the socially enabled version of Step Matron to log their daily step counts. Participants in the intervention group also were given access to a Facebook group where they could view and compare each other's step data and make comments. The experiment was counterbalanced to ensure effect and participant conditions were switched halfway through the intervention so that every participant experienced both conditions. The primary measure for this study was participant step count. Nine out of ten of the participants walked significantly more steps in the social condition ( $M=42004.4)$ than in the nonsocial condition ( $M=38132.1)(Z=-$ 2.5, $\mathrm{N}=10, \mathrm{p}=0.013$ ). While this sample is quite small, it does help to support the notion of competition as a useful tool in motivating behavior change within a social media delivered health intervention as well as using a robust study design powerful enough to detect differences within a small population. The participants in this study were all well acquainted and were all current "friends" on Facebook; which may have helped to drive the competition and the increase in 
steps. Researchers suggest that additional research is needed to understand the full effects of motivational and competitive tools within a social media environment (Foster et al., 2010).

Ma, Chen, \& Xiao (2010), tested the idea of how online social influence impacts weight gain of users through an online social network. Similar research of this kind had been done in face-to-face settings, demonstrating that the health status of an individual is heavily influenced by the health status of those in your social circle. For example, a person would be more likely to become obese if one or more of their friends were to become obese (Christakis \& Fowler, 2007). Ma \& colleagues (2010), wanted to see if this concept would also apply to an online social network setting. To do this, the researchers analyzed the data of an existing weight loss social networking site. Fat Secret (www.fatsecret.com) is a site designed to allow users to set and track weight loss goals in a socially connected environment. An analysis of user data yielded significant correlation between users and friends weight loss $(\mathrm{r}=.94, \mathrm{p}<.001)$. When user's friends met significant weight loss, goals the user became more likely to make considerable progress on weight loss. These results could be seen as far as four degrees away from the initial user and provide further evidence that online social groupings are critical to health interventions. Using existing social settings may be an important consideration when designing health interventions using social media (Ma et al., 2010).

While engagement seems to be a common thread across most studies, social support is also an important theme to consider. Napolitano, Hayes, Bennett, Ives, \& Foster (2013), conducted a randomized control trial using a social media group aided with the support of a text messaging service providing a direct connection to a qualified mentor. In this study, 52 participants were randomly assigned to one of three conditions. The control/waiting list condition ( $\mathrm{n}=17)$, Facebook condition $(\mathrm{n}=17)$, and Facebook Plus condition $(\mathrm{n}=18)$, 
participants in the Facebook group were given access to a closed group Facebook support account and provided with health information content and invited to campus physical activity or nutrition events. The Facebook Plus group receives the same components via social media but also had the additional support of a wellness coach who kept in contact with participants on a daily basis using text messaging. Participants in the Facebook Plus group received personalized and tailored messaging that was adjusted to fit the needs of the goals of the participants. Text messages were sent to support participants on their progress and offer support for activity if necessary to assist participants in achieving their goals. The Facebook Plus group produced significantly higher weight loss outcome $(-2.4 \mathrm{~kg} \pm 2.5)$ than either the Facebook $(-0.63 \mathrm{~kg} \pm 2.4)$ ( $\mathrm{P}<0.05 ; 95 \%$ confidence interval: -7.70 and -0.04$)$ or the control group $(-0.24 \mathrm{~kg} \pm 2.6)(\mathrm{P}<$ 0.05; 95\% confidence interval: -8.46 and -0.77) (Napolitano et al., 2013). While engagement levels were high across both the Facebook and Facebook Plus groups, the tailored messaging of the Facebook plus group had the most significant effect on participant weight loss. This may indicate that a generic health intervention may not be sufficient to affect behavior change without specifically tailoring messages based on participant's current health behaviors.

Valle, Tate, \& Mayer (2013), attempted to utilize a social media-based intervention to increase PA among young adult cancer survivors. Over half of young adult cancer survivors are not sufficiently active to meet daily PA recommendations; there has been little research to identify effective physical activity interventions within this population. The authors of this study sought to evaluate the feasibility of delivering a PA intervention using Facebook. Two private Facebook groups were created (FITNET and SC) and participants were randomly assigned to one of the two groups. The FITNET group participants $(n=45)$ would receive moderated support and a structured 12-week behavioral strategy based on social cognitive theory, with a 
primary focus on improving self-efficacy, behavioral capability, self-monitoring and social support through Facebook, as well as access to a companion site where they could log their daily steps and get additional information related to increasing physical activity. The self-help comparison site (SC) would receive 12-week messages that provided general information on PA the Facebook group moderators would post weekly information related to PA, but the discussion was to be facilitated through the participants. The results of this trial showed significant increases in daily PA for both groups and a significantly higher level of light PA for the FITNET group. Light duty PA such as walking is a common recommendation for physical activity for recovering cancer survivors so that may explain why the level of light lifestyle PA saw the highest increases. This study provides another example of the potential for social media to contribute to health and physical activity interventions and is among the first PA interventions to incorporate the use of behavioral theories into the social media intervention strategy. However had several limitations that prohibit large-scale dissemination including, sample size/demographics, and a common problem among web-based interventions a self-reported measure of PA. Future research should seek to utilize objective measures of physical activity to determine significant changes in PA over time (Valle et al., 2013).

One of the major threads of the social media health intervention literature is the link between participant engagement to the social media site and health outcomes, studies with higher levels of participant engagement typically have provided outcomes that are more effective. Thrul, Klein, \& Ramo (2015), attempted to harness user engagement to assist them in implementing a strategic behavior change strategy within a smoking cessation intervention. Operationalizing the common-sense idea that participants will be more likely to be engaged if the content is relevant to them and compartmentalizing this idea into the Transtheoretical model of 
behavior change utilizing the process of change for to develop content for participants based on their stage of behavior change. Participants were assigned to tailored Facebook groups based on their stage of change; Precontemplation $(n=33)$, Contemplation $(n=36)$, or Preparation $(n=$ 10). Participants then received tailored messaging designed around the process of change framework for each group. Precontemplation and Contemplation group participants demonstrated higher levels of engagement, operationalized as the number of interactions with each content area through Facebook comments when decision balance posts were used, which emphasized the pros of quitting smoking. A change in decisional balance consistent with the literature has been shown to be associated with transitions from the precontemplation to contemplations stage of change (Jeon et al., 2014). While Preparation group participants' saw a greater level of engagement for consciousness raising posts, these posts were more informative in nature and provide facts and tips about behavior change. Engagement was associated favorably with abstinence at three-month follow-up, participants who had been abstinent for seven days at follow-up had higher engagement scores $(M=22.4$ Comments, $S D=21.9)$ than participants who had not been abstinent $(M=8.3$ Comments, $\mathrm{SD}=13.9)$ however, these results were only borderline significant $(\mathrm{z}=2.0 ; \mathrm{P}=.04)$ and additional research is needed with larger sample sizes to achieve a more powerful effect size (Thrul et al., 2015a).

The reoccurring theme that seems to be present in these studies is the recommendation that social media does have the potential to serve as a viable method of performing health or physical activity interventions. The missing piece to this seems to be the intervention itself; there is much disparity in the types of interventions that are being offered throughout the social media based literature, and evidence-based interventions have not been a strong point of many of these web and social media delivered interventions. The proposed study seeks to close that gap, by 
using a strategic messaging plan based on the TTM to drive participant engagement as measured by a person's interaction with web delivered content, which has been a consistent predictor of outcomes throughout the literature. Another major limitation in existing social media delivered intervention research has been the lack of objective measures of PA; many studies have relied on self-reported PA given the lack of a face-to-face setting, this study looks to close that gap by issuing participants consumer friendly accelerometers (Fitbit's) to wear throughout the intervention.

Much of the research into social media-based health interventions have utilized websites that were specifically designed for the study, which may not be practical for large-scale dissemination (Maher et al., 2014). By using Facebook as the primarily delivery tool of the intervention, this research will contribute to researchers' understanding of the feasibility of largescale dissemination.

Conclusion. Much of the evidence from existing literature involves the use of intervention specific websites to disseminate intervention materials. Enrolling parents to a specific website to deliver health interventions is not practical and sustainability for health professionals (Maher et al., 2014). Developing material and strategies that can be used to deliver health interventions through parents existing social networks will make wide-scale dissemination more practical.

It will also be important to understand the value of studies offered through popular social media websites like Facebook, given the site's proven ability to attract participants and potential for intervention dissemination with little or no physical equipment (Maher et al., 2014). Much of the existing literature suggests a need for more information about the cost, benefits, and 
effectiveness of social media as a health promotion tool (Cobb \& Graham, 2012; Korda \& Itani, 2013; Maher et al., 2014).

While there is still a wide gap in the literature in the area of social media-delivered health interventions, early evidence suggests that strategies using the behavior change model have the potential to be effective in the initial stages of research (Carol Maher et al., 2015; Thrul et al., 2015a). Given what we know about parents social media habits (e.g. Perrin, 2015) and the influence of parents health behavior on children's physical activity (e.g. Fuemmeler, Anderson, \& Masse, 2011), creating a social media based health intervention to modify parents health behavior has the potential to have a positive impact on both parent and child physical activity. If it is possible to impact parent physical activity behaviors using social media, then the implications of this study could have a profound effect on combatting the obesity epidemic on a national scale.

\section{References}

Ajzen, I., \& Fishbein, M. (1977). Attitude-behavior relations: A theoretical analysis and review of empirical research. Psychological Bulletin. Retrieved from http://psycnet.apa.org/journals/bul/84/5/888/

Andriani, H., Liao, C. Y., \& Kuo, H. W. (2015). Parental weight changes as key predictors of child weight changes. BMC Public Health, 15, 645. http://doi.org/10.1186/s12889-0152005-x

Armitage, C. J., \& Arden, M. A. (2008). How useful are the stages of change for targeting interventions? Randomized test of a brief intervention to reduce smoking. Health Psychology. Retrieved from http://psycnet.apa.org/journals/hea/27/6/789/ 
Bandura, A. (1971). Social learning theory. Social Learning Theory. http://doi.org/10.1111/j.1460-2466.1978.tb01621.x

Bandura, A. (1994). Self-efficacy. Retrieved from http://onlinelibrary.wiley.com/doi/10.1002/9780470479216.corpsy0836/full

Barlow, S. E., Dietz, W. H., Epstein, L. H., Gidding, S. S., Himes, J. H., Jonides, L., ... Story, M. (1998). Obesity Evaluation and Treatment: Expert Committee Recommendations. Pediatrics, 102(3).

Baughcum, A. E., Burklow, K. A., Deeks, C. M., Powers, S. W., \& Whitaker, R. C. (1998). Maternal Feeding Practices and Childhood Obesity. Archives of Pediatrics \& Adolescent Medicine, 152(10), 1010-1014. http://doi.org/10.1001/archpedi.152.10.1010

Beech, B., \& Klesges, R. (2003). Child-and parent-targeted interventions: the Memphis GEMS pilot study. Ethnicity and .... Retrieved from https://www.researchgate.net/profile/Lisa_Klesges/publication/10789403_Childand_parenttargeted_Interventions_The_Memphis_GEMS_pilot_study/links/0c960527162cf2f1990000 00.pdf

Beets, M., \& Cardinal, B. (2010). Parental social support and the physical activity-related behaviors of youth: a review. Health Education \&. Retrieved from http://heb.sagepub.com/content/early/2010/08/19/1090198110363884.abstract

Berlin, J., \& Colditz, G. (1990). A meta-analysis of physical activity in the prevention of coronary heart disease. American Journal of Epidemiology. Retrieved from http://aje.oxfordjournals.org/content/132/4/612.short 
Berry, T., Naylor, P. J., \& Wharf-Higgins, J. (2005). Stages of change in adolescents: an examination of self-efficacy, decisional balance, and reasons for relapse. Journal of Adolescent Health, 37(6), 452-459. http://doi.org/10.1016/j.jadohealth.2004.09.019

Blair, S., Cheng, Y., \& Holder, J. (2001). Is physical activity or physical fitness more important in defining health benefits? Medicine and Science in Sports and .... Retrieved from http://www.iub.edu/ k562/articles/role/fitness or activity Blair 2001.pdf

Blair, S. N. (2009). Physical inactivity: the biggest public health problem of the 21 st century. British Journal of Sports Medicine, 43(1), 1-2. Retrieved from http://www.ncbi.nlm.nih.gov/pubmed/19136507

Blitstein, J. L., Cates, S. C., Hersey, J., Montgomery, D., Shelley, M., Hradek, C., ... Singh, A. (2016). Adding a Social Marketing Campaign to a School-Based Nutrition Education Program Improves Children's Dietary Intake: A Quasi-Experimental Study. Journal of the Academy of Nutrition and Dietetics, 1-10. http://doi.org/10.1016/j.jand.2015.12.016

Bock, B. C., Marcus, B. H., Pinto, B. M., \& Forsyth, L. H. (2001). Maintenance of Physical Activity Following an Individualized Motivationally Tailored Intervention. Ann Behav Med, 23(2), 79-87.

Borg, G. (1998). Borg's perceived exertion and pain scales. Retrieved from http://psycnet.apa.org/psycinfo/1998-07179-000

Brindal, E., Freyne, J., Saunders, I., Berkovsky, S., Smith, G., \& Noakes, M. (2012). Features predicting weight loss in overweight or obese participants in a web-based intervention: randomized trial. Journal of Medical Internet Research, 14(6), e173. http://doi.org/10.2196/jmir.2156 
Brouwer W, Kroeze W, Crutzen R, de NJ, de Vries NK, Brug J, O. A. (2011). Which intervention characteristics are related to more exposure to internet-delivered healthy lifestyle promotion interventions? A systematic review. Journal of Medical Internet Research, 13(1). Retrieved from http://www.jmir.org/2011/1/e2/

Brown, H. E., Atkin, A. J., Panter, J., Wong, G., Chinapaw, M. J. M., \& van Sluijs, E. M. F. (2016). Family-based interventions to increase physical activity in children: a systematic review, meta-analysis and realist synthesis. Obesity Reviews, 17(4), 345-360. http://doi.org/10.1111/obr.12362

Buxton, K., Wyse, J., \& Mercer, T. (1996). How applicable is the stages of change model to exercise behaviour? A review. Health Education Journal. Retrieved from http://hej.sagepub.com/content/55/2/239.short

Calfas, K. J., Sallis, J. F., Oldenburg, B., \& Ffrench, M. (1997). Mediators of change in physical activity following an intervention in primary care: PACE. Preventive Medicine, 26(3), 297304. http://doi.org/10.1006/pmed.1997.0141

Carlson, S., \& Fulton, J. (2008). Physical education and academic achievement in elementary school: data from the early childhood longitudinal study. ... Journal of Public .... Retrieved from http://ajph.aphapublications.org/doi/abs/10.2105/AJPH.2007.117176

Cavallo, D. N., Tate, D. F., Ries, A. V., Brown, J. D., Devellis, R. F., \& Ammerman, A. S. (2012). A social media-based physical activity intervention: A randomized controlled trial. American Journal of Preventive Medicine, 43(5), 527-532. http://doi.org/10.1016/j.amepre.2012.07.019

Cavallo, D. N., Tate, D. F., Ries, A. V, Brown, J. D., DeVellis, R. F., \& Ammerman, A. S. 
(2012a). A social media-based physical activity intervention: a randomized controlled trial. Am J Prev Med, 43(5), 527-532. http://doi.org/10.1016/j.amepre.2012.07.019

Cavallo, D. N., Tate, D. F., Ries, A. V, Brown, J. D., DeVellis, R. F., \& Ammerman, A. S. (2012b). A social media-based physical activity intervention: a randomized controlled trial. Am J Prev Med, 43(5), 527-532. http://doi.org/10.1016/j.amepre.2012.07.019

Cavallo, D. N., Tate, D. F., Ward, D. S., DeVellis, R. F., Thayer, L. M., \& Ammerman, A. S. (2014). Social support for physical activity-role of Facebook with and without structured intervention. Translational Behavioral Medicine, 4(4), 346-54. http://doi.org/10.1007/s13142-014-0269-9

Cavallo, D. N., Tate, D. F., Ward, D. S., DeVellis, R. F., Thayer, L. M., \& Ammerman, A. S. (2014). Social support for physical activity—role of Facebook with and without structured intervention. Translational Behavioral Medicine, 4(4), 346-354. http://doi.org/10.1007/s13142-014-0269-9

CDC. (2008). Physical activity guidelines advisory committee report, 2008. Washington, DC: US Department .... Retrieved from https://scholar.google.com/scholar?q=Physical+activity+guidelines+advisory+committee+r eport, $+2008 \# 0$

CDC. (2014). State Indicator Report on Physical Activity. Retrieved from http://www.cdc.gov/physicalactivity/resources/reports.html

Centers for Disease Control and Prevention. (2011). The health communicator's social media toolkit. 
Centers for Disease Control and Prevention. (2012). Parent engagement: Strategies for involving parents in school health. (CDC, Ed.). Atlanta, Ga: US Department of Health and Human Services.

Centers for Disease Control and Prevention. (2015). US Department of Health and Human Services. Physical Activity and Health: A Report of the Surgeon General. Atlanta, Georgia Google Scholar. Washington, DC. Retrieved from https://scholar.google.com/scholar?q=US+Department+of+Health+and+Human+Services.+ Physical+Activity+and+Health\%3A+A+Report+of+the+Surgeon+General.+Atlanta\%2C+G eorgia\&btnG=\&hl=en\&as_sdt=0\%2C49

Christakis, N., \& Fowler, J. (2007). The spread of obesity in a large social network over 32 years. New England Journal of Medicine. Retrieved from http://www.nejm.org/doi/full/10.1056/nejmsa066082

Cobb, N. K., \& Graham, A. L. (2012). Health behavior interventions in the age of facebook. Am J Prev Med, 43(5), 571-572. http://doi.org/10.1016/j.amepre.2012.08.001

Constine, J. (2013). Facebook's Q2: Monthly Users Up 21\% YOY To 1.15B, Dailies Up 27\% To 699M, Mobile Monthlies Up 51\% To 819M. Retrieved March 12, 2016, from http://techcrunch.com/2013/07/24/facebook-growth-2/

Corbin, C., Lindsey, R., \& Welk, G. (2000). Concepts of physical fitness: Active lifestyles for wellness. Retrieved from http://novellaqalive2.mhhe.com/sites/dl/free/0072843748/123956/corbin12e111403sup.doc

D’Onofrio, G., Bernstein, E., \& Rollnick, S. (1996). Motivating patients for change: a brief strategy for negotiation. Case Studies in Emergency Medicine and the Health of the Public. 


\section{Boston, MA: Jones and Bartlett.}

Dagkas, S., \& Quarmby, T. (2012). Young People's Embodiment of Physical Activity: The Role of the "Pedagogized" Family. Sociology of Sport Journal, 29(2), 210-226.

Dalton, W. T., \& Kitzmann, K. (2008). Broadening Parental Involvement in Family-based Interventions for Pediatric Overweight: Implications From Family Systems and Child Health. Family \& Community Health. Retrieved from http://journals.lww.com/familyandcommunityhealth/Abstract/2008/10000/Broadening_Pare ntal_Involvement_in_Family_based.3.aspx

Davison, K., \& Birch, L. (2001). Childhood overweight: a contextual model and recommendations for future research. Obesity Reviews. Retrieved from http://onlinelibrary.wiley.com/doi/10.1046/j.1467-789x.2001.00036.x/full

Davison, K., Cutting, T., \& Birch, L. (2003). Parents' activity-related parenting practices predict girls' physical activity. Medicine and Science in Sports. Retrieved from http://www.ncbi.nlm.nih.gov/pmc/articles/pmc2530913/

Davison, K. K., \& Birch, L. L. (2001). Childhood overweight: a contextual model and recommendations for future research. Obesity Reviews : An Official Journal of the International Association for the Study of Obesity, 2(3), 159-71. http://doi.org/10.1046/j.1467-789x.2001.00036.x

Dempsey, J. M., Kimiecik, J. C., \& Horn, T. S. (1993). Parental influence on children's moderate to vigorous physical activity participation: An expectancy-value approach. Pediatric Exercise Science, 5, 151-167. 
Dietz, W. H., \& Gortmaker, S. L. (1985). Do We Fatten Our Children At the Tv Set.Pdf. Pediatrics, 75(5), 807-812.

DiLorenzo, T. M., Stucky-Ropp, R. C., Vander Wal, J. S., \& Gotham, H. J. (1998). Determinants of Exercise among Children. II. A Longitudinal Analysis. Preventive Medicine, 27(3), 470477. http://doi.org/10.1006/pmed.1998.0307

Dishman, R. (1988). Agenda ." Exercise Adherence Research : Future Directions. American Journal of Health Promotion, 3(1), 52-56.

Duggan, M., Lenhart, A., Lampe, C., \& Ellison, N. (2015). Parents and Social Media. Pew Research Center. Retrieved from http://www.pewinternet.org/2015/07/16/parents-andsocial-media/

Epstein, L. H., Myers, M., Raynor, H., \& Saelens, B. (1998). Treatment of Pediatric Obesity. Pediatrics, 101, 1123-1129.

Epstein, L., Paluch, R., Roemmich, J., \& Beecher, M. (2007). Family-based obesity treatment, then and now: twenty-five years of pediatric obesity treatment. Health .... Retrieved from http://psycnet.apa.org/journals/hea/26/4/381/

Eysenbach, G. (2005). The law of attrition. Journal of Medical Internet Research. Retrieved from http://www.jmir.org/article/citations/402

Field, T., Diego, M., \& Sanders, C. (2001). Exercise is positively related to adolescents' relationships and academics. ADOLESCENCE-SAN DIEGO-. Retrieved from http://search.proquest.com/openview/ad7a403d0bb1ec2481bb2c965d89915a/1.pdf?pqorigsite $=$ gscholar $\& \mathrm{cbl}=41539$ 
Foster, D., Linehan, C., \& Lawson, S. (2010). Motivating physical activity at work: using persuasive social media extensions for simple mobile devices. Retrieved from http://eprints.lincoln.ac.uk/3153

Fox, K. R. (1999). The influence of physical activity on mental well-being. Public Health Nutrition, 2(3a), 411-418. http://doi.org/10.1017/S1368980099000567

Fuemmeler, B. F., Anderson, C. B., \& Masse, L. C. (2011a). Parent-child relationship of directly measured physical activity. Int J Behav Nutr Phys Act, 8, 17. http://doi.org/10.1186/14795868-8-17

Fuemmeler, B. F., Anderson, C. B., \& Masse, L. C. (2011b). Parent-child relationship of directly measured physical activity. Int J Behav Nutr Phys Act, 8, 17. http://doi.org/10.1186/14795868-8-17

Golan, M. (2006). Parents as agents of change in childhood obesity--from research to practice. International Journal of Pediatric Obesity : IJPO : An Official Journal of the International Association for the Study of Obesity, 1(December 2005), 66-76. http://doi.org/10.1080/17477160600644272

Gorely, T., Nevill, M. E., Morris, J. G., Stensel, D. J., \& Nevill, A. (2009). Effect of a schoolbased intervention to promote healthy lifestyles in 7-11 year old children. International Journal of Behavioral Nutrition and Physical Activity, 6(5). http://doi.org/10.1186/14795868-6-5

Gustafson, S. L., \& Rhodes, R. E. (2006). Parental Correlates of Physical Activity in Children and Early Adolescents. Sports Medicine, 36(1), 79-97. http://doi.org/10.2165/00007256200636010-00006 
Gustafson, S., \& Rhodes, R. (2006). Parental correlates of physical activity in children and early adolescents. Sports Medicine. Retrieved from http://link.springer.com/article/10.2165/00007256-200636010-00006

Hales, S. B., Davidson, C., \& Turner-McGrievy, G. M. (2014). Varying social media post types differentially impacts engagement in a behavioral weight loss intervention. Translational Behavioral Medicine, 4(4), 355-62. http://doi.org/10.1007/s13142-014-0274-z

Hillman, C. H., Erickson, K. I., \& Kramer, A. F. (2008). Be smart, exercise your heart: exercise effects on brain and cognition. Nature, 9, 58-65. http://doi.org/10.1038/nrn2298

Hilton, S., Doherty, S., \& Kendrick, T. (1999). Promotion of healthy behaviour among adults at increased risk of coronary heart disease in general practice: methodology and baseline data from the Change of. Health Education .... Retrieved from http://hej.sagepub.com/content/58/1/3.short

Hu, Y., \& Shyam Sundar, S. (2010). Effects of Online Health Sources on Credibility and Behavioral Intentions. Communication Research, 37(1), 105-132. http://doi.org/10.1177/0093650209351512

Hutchison, A. J., Breckon, J. D., \& Johnston, L. H. (2009a). Physical activity behavior change interventions based on the transtheoretical model: a systematic review. Health Education and Behavior, 36(5), 829-845. http://doi.org/10.1177/1090198108318491

Hutchison, A. J., Breckon, J. D., \& Johnston, L. H. (2009b). Physical activity behavior change interventions based on the transtheoretical model: a systematic review. Health Education and Behavior, 36(5), 829-845. http://doi.org/10.1177/1090198108318491 
HW Kohl. (2001). Physical activity and cardiovascular disease: evidence for a dose response. Medicine and Science in Sports and Exercise. Retrieved from http://europepmc.org/abstract/med/11427773

Israel, A., Stolmaker, L., \& Andrian, C. (1985). The effects of training parents in general child management skills on a behavioral weight loss program for children. Behavior Therapy. Retrieved from http://www.sciencedirect.com/science/article/pii/S0005789485800435

Jang, J., \& Dworkin, J. (2014a). Does social network site use matter for mothers? Implications for bonding and bridging capital. Computers in Human Behavior, 35, 489-495. http://doi.org/10.1016/j.chb.2014.02.049

Jang, J., \& Dworkin, J. (2014b). Does social network site use matter for mothers? Implications for bonding and bridging capital. Computers in Human Behavior, 35, 489-495. http://doi.org/10.1016/j.chb.2014.02.049

Jawad, M., Abass, J., Hariri, A., \& Akl, E. A. (2015). Social Media Use for Public Health Campaigning in a Low Resource Setting : The Case of Waterpipe Tobacco Smoking, 2015.

Jeon, D. J., Kim, K. J., \& Heo, M. (2014). Factors related to stages of exercise behavior change among university students based on the transtheoretical model. Journal of Physical Therapy Science, 26(12), 1929-1932. http://doi.org/10.1589/jpts.26.1929

Johnson, S., \& Birch, L. (1994). Parents' and children's adiposity and eating style. Pediatrics. Retrieved from http://pediatrics.aappublications.org/content/94/5/653.short

Johnson, S., \& Cook, B. (2013). Building Motivation: How Ready Are You? Aspects of Physical Activity and Exercise. Retrieved from 
https://books.google.com/books ?hl=en\&lr=\&id=pFueAgAAQBAJ\&oi=fnd\&pg=PA103\&d q=Building+motivation:+how+ready+are+you\%3F\&ots=uxIZ84VCJv\&sig=11fjgGyIFrtqFj m-E-wjLcftpbo

Kimiecik, J. C., \& Horn, T. S. (1998). Parental Beliefs and Children's Moderate-to-Vigorous Physical Activity. Research Quarterly for Exercise and Sport, 69(2), 163-175. http://doi.org/10.1080/02701367.1998.10607681

Kitzman-Ulrich, H., Hampson, R., Wilson, D. K., Presnell, K., Brown, A., \& O 'boyle, M. (2009). An Adolescent Weight-Loss Program Integrating Family Variables Reduces Energy Intake. YJADA, 109, 491-496. http://doi.org/10.1016/j.jada.2008.11.029

Kitzmann, K., Dalton, W., \& Buscemi, J. (2008). Beyond Parenting Practices: Family Context and the Treatment of Pediatric Obesity*. Family Relations. Retrieved from http://onlinelibrary.wiley.com/doi/10.1111/j.1741-3729.2007.00479.x/full

Korda, H., \& Itani, Z. (2013). Harnessing social media for health promotion and behavior change. Health Promotion Practice, 14(1), 15-23.

Krebs, P., Prochaska, J., \& Rossi, J. (2010). A meta-analysis of computer-tailored interventions for health behavior change. Preventive Medicine. Retrieved from http://www.sciencedirect.com/science/article/pii/S0091743510002318

Kreuter, M. W., \& Skinner, C. S. (2000). Tailoring: what's in a name? Health Education Research, 15(1), 1-4. http://doi.org/10.1093/her/15.1.1

Kriemler, S., Meyer, U., Martin, E., Van Sluijs, E., Andersen, L., \& Martin, B. (2011). Effect of School-Based Interventions On Physical Activity and Fitness in Children and Adolescents: 
A Review of Reviews and Systematic Update. Br J Sports Med, 45(11). http://doi.org/10.1136/bjsports-2011-090186

Kumar, P., \& Schoenebeck, S. (2015). The modern day baby book: Enacting good mothering and stewarding privacy on facebook. Proceedings of the 18th ACM Conference on .... Retrieved from http://dl.acm.org/citation.cfm?id=2675149

Lee, I., Hsieh, C., \& Paffenbarger, R. (1995). Exercise intensity and longevity in men: the Harvard Alumni Health Study. Jama. Retrieved from http://jama.jamanetwork.com/article.aspx ?articleid=387973

Lee, I., \& Paffenbarger, R. (2000). Associations of light, moderate, and vigorous intensity physical activity with longevity The Harvard Alumni Health Study. American Journal of Epidemiology. Retrieved from http://aje.oxfordjournals.org/content/151/3/293.short

Leonard H. Epstein, Valoski, A. M., Vara, L. S., McCurley, J., Wisniewski, L., Kalarchian, M. A., ... Shrager, L. R. (1995). Effects of decreasing sedentary behavior and increasing activity on weight change in obese children. Health Psychology, 14(2), 109-115. Retrieved from http://psycnet.apa.org/journals/hea/14/2/109/

Lewallen, T. C., Hunt, H., Potts-Datema, W., Zaza, S., \& Giles, W. (2015). The Whole School, Whole Community, Whole Child Model: A New Approach for Improving Educational Attainment and Healthy Development for Students. Journal of School Health, 85(11), 729739. http://doi.org/10.1111/josh.12310

Lindner, K. (2002). The physical activity participation-academic performance relationship revisited: perceived and actual performance and the effect of banding (academic. Pediatric Exercise Science. Retrieved from 
https://scholar.google.com/scholar?q=Lindner\%2C+K.+J.+The+physical+activity+participa tion-

+academic+performance+relationship+revisited $\% 3 \mathrm{~A}+$ perceived+and+actual+performance+ and +the+effect+of+banding \&btnG $=\& h \mathrm{hl}=$ en\&as_sdt $=0 \% 2 \mathrm{C} 49 \# 0$

Lindsay, A. C., Sussner, K. M., Kim, J., \& Gortmaker, S. L. (2006). The Role of Parents in Preventing Childhood Obesity. The Future of Children, 16(1), 169-186. http://doi.org/10.1353/foc.2006.0006

Lobstein, T., Baur, L., \& Uauy, R. (2004). Obesity in children and young people: a crisis in public health. Obesity Reviews. Retrieved from http://onlinelibrary.wiley.com/doi/10.1111/j.1467-789X.2004.00133.x/full

Ma, X., Chen, G., \& Xiao, J. (2010). Analysis of an online health social network. Proceedings of the 1st ACM International Health .... Retrieved from http://dl.acm.org/citation.cfm?id=1883035

Maher, C. (2010). An internet-based computer-tailored physical activity intervention has short term positive effects on physical activity levels among adolescents. Journal of Physiotherapy, 56(2), 132. http://doi.org/10.1016/s1836-9553(10)70043-6

Maher, C., Ferguson, M., Vandelanotte, C., Plotnikoff, R., De Bourdeaudhuij, I., Thomas, S., ... Olds, T. (2015). A Web-Based, Social Networking Physical Activity Intervention for Insufficiently Active Adults Delivered via Facebook App: Randomized Controlled Trial. $J$ Med Internet Res, 17(7), e174. http://doi.org/10.2196/jmir.4086

Maher, C., Ryan, J., Kernot, J., Podsiadly, J., \& Keenihan, S. (2015). Social Media and Applications to Health Behavior. Current Opinion in Psychology, 9, 50-55. 
http://doi.org/10.1016/j.copsyc.2015.10.021

Maher, Lewis, L. K., Ferrar, K., Marshall, S., De Bourdeaudhuij, I., \& Vandelanotte, C. (2014). Are health behavior change interventions that use online social networks effective? A systematic review. J Med Internet Res, 16(2), e40. http://doi.org/10.2196/jmir.2952

Marcus, B., Emmons, K. M., Simkin-Silverman, L. R., Linnan, L. A., Taylor, E. R., \& Brock, B. C. (1998). Evaluation of Motivationally Tailored vs Standard Self-Help Physical Activity Interventions at the Workplace. American Journal of Health Promotion, 12, 246-253.

Marcus, B., Forsyth, L., \& Stone, E. (2000). Physical activity behavior change: issues in adoption and maintenance. Health Psychology, 19(1), 32-41. http://doi.org/10.1037//02786133.19.1(Suppl.).32

Marcus, B. H., Banspach, S. W., Lefebvre, R. C., Rossi, J. S., Carleton, R. A., Abrams, D. B., ... Prochaska, J. O. (1992). Using the Stages of Change model to increase the adoption of physical activity among community participants. American Journal of Health Promotion, $6(6), 424-429$.

Marcus, B. H., Bock, B. C., Pinto, B. M., Forsyth, L. A. H., Roberts, M. B., \& Traficante, R. M. (1998). Efficacy of an individualized, motivationally-tailored physical activity intervention, 20(3), 174-180. http://doi.org/10.1007/BF02884958

Marcus, B. H., Forsyth, L. A. H., \& Stone, E. J. (2000). Physical activity behavior change: issues in adoption and maintenance. Health Psychology, 19(1), 32-41. http://doi.org/10.1037//0278-6133.19.1(Suppl.).32

Marcus, B. H., Selby, V. C., Niaura, R. S., \& Rossi, J. S. (1992). Self-Efficacy and the Stages of 
Exercise Behavior Change. Research Quarterly for Exercise and Sport, 63(1), 60-66. http://doi.org/10.1080/02701367.1992.10607557

Marcus, B. H., Selby, V. C., Niaura, R. S., \& Rossi, J. S. (1992). Self-Efficacy and the Stages of Exercise Behavior Change. Research Quarterly for Exercise and Sport, 63(1), 60-66. http://doi.org/10.1080/02701367.1992.10607557

Marcus, B., \& Simkin, L. (1994). The transtheoretical model: applications to exercise behavior. Medicine and Science in Sports and Exercise, 26(11), 1400-1404. http://doi.org/10.1249/00005768-199411000-00016

Marshall, S., \& Biddle, S. (2001). The transtheoretical model of behavior change: a metaanalysis of applications to physical activity and exercise. Annals of Behavioral Medicine. Retrieved from http://link.springer.com/article/10.1207/S15324796ABM2304_2

McClure, J. B., Shortreed, S. M., Bogart, A., Derry, H., Riggs, K., St John, J., ... An, L. (2013). The effect of program design on engagement with an internet-based smoking intervention: randomized factorial trial. Journal of Medical Internet Research, 15(3), e69. http://doi.org/10.2196/jmir.2508

McFarlane, A. (1995). Family Structure, Family Functioning and Adolescent Well-Being: the Transcendent Influence of Parental Style. Journal of Child .... Retrieved from http://onlinelibrary.wiley.com/doi/10.1111/j.1469-7610.1995.tb01333.x/abstract

Meeks, L., Heit, P., \& Page, R. (2009). Comprehensive school health education: Totally awesome strategies for teaching health. Retrieved from http://112.72.97.196:8080/dspace/handle/123456789/9026 
Moore, L. L., Gao, D., Bradlee, M. L., Cupples, L. A., Sundarajan-Ramamurti, A., Proctor, M. H., ... Ellison, R. C. (2003). Does early physical activity predict body fat change throughout childhood? Preventive Medicine, 37(1), 10-17. http://doi.org/10.1016/S00917435(03)00048-3

Moore, L. L., Lombardi, D. A., White, M. J., Campbell, J. L., Oliveria, S. A., Ellison, R. C., \& Lynn L. Moore, MS David A. Lombardi, Mary Jo White, James L. Campbell, Susan A. Oliveria, C. E. (1991). Influence of parents' physical activity levels on activity levels of young children. Journal of Pediatrics, 118(2), 215-219. http://doi.org/10.1016/S0022$3476(05) 80485-8$

Moore, M., Highstein, G., \& Tschannen-Moran, B. (2010). Coaching behavior change. Coaching: Psychology. Retrieved from http://www.academia.edu/download/7736581/mooresampchap3.pdf

Morris, M. R. (2014). Social networking site use by mothers of young children. In Proceedings of the 17th ACM conference on Computer supported cooperative work \& social computing CSCW '14 (pp. 1-11). http://doi.org/10.1145/2531602.2531603

Napolitano, M., Hayes, S., Bennett, G., Ives, A. K., \& Foster, G. D. (2013). Using Facebook and text messaging to deliver a weight loss program to college students. Obesity Journal, 21(1), 25-31. Retrieved from http://onlinelibrary.wiley.com/doi/10.1002/oby.20232/full

Naylor, P.-J., Macdonald, H. M., Zebedee, J. A., Reed, K. E., \& Mckay, H. A. (2006). Lessons learned from Action Schools! BC_ — An "active school" model to promote physical activity in elementary schools. Journal of Science and Medicine in Sport, 9, 413-423. http://doi.org/10.1016/j.jsams.2006.06.013 
Nemet, D., Barzilay-Teeni, N., \& Eliakim, A. (2008). Treatment of childhood obesity in obese families. Journal of Pediatric. Retrieved from http://www.degruyter.com/view/j/jpem.2008.21.5/jpem.2008.21.5.461/jpem.2008.21.5.461. $\mathrm{xml}$

Niermann, C., Krapf, F., \& Renner, B. (2014). Family health climate scale (FHC-scale): development and validation. International. Retrieved from http://ijbnpa.biomedcentral.com/articles/10.1186/1479-5868-11-30

Niermann, C., Krapf, F., Renner, B., Reiner, M., \& Woll, A. (2014). Family health climate scale (FHC-scale): development and validation. The International Journal of Behavioral Nutrition and Physical Activity, 11(1), 30. http://doi.org/10.1186/1479-5868-11-30

Noar, S. M., Benac, C. N., \& Harris, M. S. (2007). Does tailoring matter? Meta-analytic review of tailored print health behavior change interventions. Psychological Bulletin, 133(4), 673693. http://doi.org/10.1037/0033-2909.133.4.673

O’Connor, T. M., Jago, R., \& Baranowski, T. (2009). Engaging parents to increase youth physical activity a systematic review. American Journal of Preventive Medicine, 37(2), 141-9. http://doi.org/10.1016/j.amepre.2009.04.020

O’Flahavan, L., \& Goulet, A. (2012). CDC'S GUIDE TO Writing for Social Media.

Oguma, Y., \& Sesso, H. (2002). Physical activity and all cause mortality in women: a review of the evidence. British Journal of Sports .... Retrieved from http://bjsm.bmj.com/content/36/3/162.short

Ostbye, T., Malhotra, R., Stroo, M., Lovelady, C., Brouwer, R., Zucker, N., \& Fuemmeler, B. 
(2013). The effect of the home environment on physical activity and dietary intake in preschool children. Int J Obes (Lond), 37(10), 1314-1321.

http://doi.org/10.1038/ijo.2013.76

Paffenbarger JR, R., \& Hale, W. (1975). Work activity and coronary heart mortality. New England Journal of Medicine. Retrieved from http://www.nejm.org/doi/full/10.1056/NEJM197503132921101

Pallant, J. (2013). SPSS survival manual. Retrieved from https://books.google.com/books ?hl=en\&lr=\&id=fZZTBgAAQBAJ\&oi=fnd\&pg=PR7\&dq= spss+survival+manual+pallant\&ots=KUNtiKUVzT\&sig=xIxsdH60luLqsf7wk7MtSSS2Kt $\mathrm{U}$

Perrin, A. (2015). Social Media Usage 2005-2015. Pew Research Center. Retrieved from http://www.pewinternet.org/files/2015/10/PI_2015-10-08_Social-Networking-Usage-20052015_FINAL.pdf

Perry, C. L., Luepker, R. V, Murray, D. M., Kurth, C., Mullis, R., Crockett, S., \& Jacobs, D. R. (1988). Parent Involvement with Children's Health Promotion: The Minnesota Home Team. American Journal of Public Health, 78(9). Retrieved from https://www.ncbi.nlm.nih.gov/pmc/articles/PMC1349385/pdf/amjph00248-0022.pdf

Peterson, T. R., \& Aldana, S. G. (1999a). Improving exercise behavior: An application of the stages of change model in a worksite setting. American Journal of Health Promotion, 13(4), 229-232. http://doi.org/10.4278/0890-1171-13.4.229

Peterson, T. R., \& Aldana, S. G. (1999b). Improving exercise behavior: An application of the stages of change model in a worksite setting. American Journal of Health Promotion, 13(4), 
229-232. http://doi.org/10.4278/0890-1171-13.4.229

Pinto, B. M., Goldstein, M. G., DePue, J. D., \& Milan, F. B. (1998). Acceptability and feasibility of physician-based activity counseling. American Journal of Preventive Medicine, 15(2), 95-102. http://doi.org/10.1016/S0749-3797(98)00043-9

Plantin, L., \& Daneback, K. (2009). Parenthood, information and support on the internet. A literature review of research on parents and professionals online. BMC Family Practice, 10(1), 34. http://doi.org/10.1186/1471-2296-10-34

Powell, K. (1987). Physical activity and the incidence of coronary heart disease. Annual Review of .... Retrieved from http://www.annualreviews.org/doi/pdf/10.1146/annurev.pu.08.050187.001345

Prochaska, J. O., Redding, C. A., Evers, K. E., Glanz, K., Lewis, F. M., \& Rimer, B. K. (2002). The transtheoretical model and stages of change. In Health behavior and health education: Theory, research, and practice. (pp. 60-84). Retrieved from http://www.sciencedirect.com/science/article/pii/S107772299980025X

Prochaska, J. (2013). Transtheoretical model of behavior change. Encyclopedia of Behavioral Medicine, 62(24), 2342-2343. http://doi.org/10.1016/j.jacc.2013.11.008

Prochaska, J., \& Marcus, B. (1994). The transtheoretical model: Applications to exercise. Retrieved from http://psycnet.apa.org/psycinfo/1994-98849-004

Prochaska, J. O., \& DiClemente, C. C. (1982). Transtheoretical therapy: Toward a more integrative model of change. Psychotherapy: Theory, Research and Practice, 19(3), 276288. http://doi.org/10.1037/h0088437 
Prochaska, J. O., \& Velicer, W. F. (1997). The Transtheoretical Change Model of Health Behavior. American Journal of Health Promotion, 12(1), 38-48. http://doi.org/10.4278/0890-1171-12.1.38

Prochaska, J. O., Velicer, W. F., DiClemente, C. C., \& Fava, J. (1988a). Measuring processes of change: Applications to the cessation of smoking. Journal of Consulting and Clinical Psychology, 56(4), 520-528. http://doi.org/10.1037/0022-006X.56.4.520

Prochaska, J. O., Velicer, W. F., DiClemente, C. C., \& Fava, J. (1988b). Measuring processes of change: Applications to the cessation of smoking. Journal of Consulting and Clinical Psychology, 56(4), 520-528. http://doi.org/10.1037/0022-006X.56.4.520

Prochaska, J., Redding, C., \& Evers, K. (2002). Health behavior and health education: theory, research, and practice. Health Behavior and Health .... Retrieved from https://scholar.google.com/scholar?oi=gsb40\&q=Prochaska\%2C 2002\&lookup=0\&hl=en\#0

Prochaska, J., Velicer, W., \& Rossi, J. (1994). Stages of change and decisional balance for 12 problem behaviors. Health. Retrieved from http://psycnet.apa.org/journals/hea/13/1/39/

Ramo, D. E., Thrul, J., Delucchi, K. L., Ling, P. M., Hall, S. M., \& Prochaska, J. J. (2015). The Tobacco Status Project (TSP): Study protocol for a randomized controlled trial of a Facebook smoking cessation intervention for young adults. BMC Public Health, 15(1), 897. http://doi.org/10.1186/s12889-015-2217-0

Ryckman, R., Robbins, M., \& Thornton, B. (1982). Development and validation of a physical self-efficacy scale. Journal of Personality. Retrieved from http://psycnet.apa.org/journals/psp/42/5/891/ 
Safko, L. (2010). The social media bible: Tactics, tools, and strategies for business success. Retrieved from https://books.google.com/books?hl=en\&lr=\&id=2c0Yrp1Xo8C\&oi=fnd\&pg=PR5\&dq=what+is+social+media\&ots=VdwyRe5LA9\&sig=7X622bHKdtrmsCD26V3HDzAmwg

Sallis, J. F., Prochaska, J. J., \& Taylor, W. C. (2000). A review of correlates of physical activity of children and adolescents. Medicine \& Science in Sports \& Exercise, (JUNE 2000), 963975. http://doi.org/10.1097/00005768-200005000-00014

Sallis, J., \& Hovell, M. (1990). Determinants of exercise behavior. Exercise and Sport Sciences Reviews. Retrieved from http://journals.lww.com/acsmessr/Citation/1990/01000/Determinants_of_Exercise_Behavior.14.aspx

Sallis, J., McKenzie, T., \& Kolody, B. (1999). Effects of health-related physical education on academic achievement: Project SPARK. ... Quarterly for Exercise .... Retrieved from http://www.tandfonline.com/doi/abs/10.1080/02701367.1999.10608030

Sallis, J., Prochaska, J., \& Taylor, W. (2000). A review of correlates of physical activity of children and adolescents. ... in Sports and Exercise. Retrieved from https://www.researchgate.net/profile/Judith_Prochaska/publication/12521182_'A_Review_ of_Correlates_of_Physical_Activity_of_Children_and_Adolescents'/links/0fcfd509495ae32 123000000.pdf

Salmon, J., Ball, K., Hume, C., Booth, M., \& Crawford, D. (2008). Outcomes of a grouprandomized trial to prevent excess weight gain, reduce screen behaviours and promote physical activity in 10-year-old children: Switch-Play. International Journal of Obesity, 32, 601-612. http://doi.org/10.1038/sj.ijo.0803805 
Shelton, D., Gros, K. Le, \& Norton, L. (2007). Randomised controlled trial: A parent-based group education programme for overweight children. Paediatrics and Child .... Retrieved from http://onlinelibrary.wiley.com/doi/10.1111/j.1440-1754.2007.01150.x/full

Sterne, J. (2010). Social media metrics: How to measure and optimize your marketing investment. Retrieved from https://books.google.com/books?hl=en\&lr=\&id=OkkZhB2Yw7IC\&oi=fnd\&pg=PR10\&dq= $\% 09 \% 0$ ASocial+media+metrics+++how+to+measure+and+optimize+your+marketing+inve stment\&ots=1FlZtxOLHX\&sig=MvQ2KEfspdqwXrJrfii7EGXmJSo

Strauss \& Knight, J., R. S. (1999). Influence of the home environment on the development of obesity in children. . Pediatrics, 103(6), e85-e85.

Stroup, D., Johnson, V., Proctor, D., \& Hahn, R. (2009). Reversing the trend of childhood obesity. Prev Chronic Dis. Retrieved from http://origin.glb.cdc.gov/pcd/issues/2009/jul/08_0255.htm

Swift, D., Johannsen, N., Lavie, C., \& Earnest, C. (2014). The role of exercise and physical activity in weight loss and maintenance. Progress in. Retrieved from http://www.sciencedirect.com/science/article/pii/S0033062013001655

Tabachnick, B., Fidell, L., \& Osterlind, S. (2001). Using multivariate statistics. Retrieved from https://www.ulb.tu-darmstadt.de/tocs/135813948.pdf

Taras, H. (2005). Physical activity and student performance at school. Journal of School Health. Retrieved from http://onlinelibrary.wiley.com/doi/10.1111/j.17461561.2005.tb06675.x/abstract 
Thackeray, R., Neiger, B., \& Hanson, C. (2008). Enhancing promotional strategies within social marketing programs: use of Web 2.0 social media. Health Promotion. Retrieved from http://hpp.sagepub.com/content/9/4/338.short

Thrul, J., Klein, A. B., \& Ramo, D. E. (2015a). Smoking Cessation Intervention on Facebook: Which Content Generates the Best Engagement? Journal of Medical Internet Research, 17(11), e244. http://doi.org/10.2196/jmir.4575

Thrul, J., Klein, A. B., \& Ramo, D. E. (2015b). Smoking Cessation Intervention on Facebook: Which Content Generates the Best Engagement? Journal of Medical Internet Research, 17(11), e244. http://doi.org/10.2196/jmir.4575

Trost, S. G., Sallis, J. F., Pate, R. R., Freedson, P. S., Taylor, W. C., \& Dowda, M. (2003). Evaluating a model of parental influence on youth physical activity. American Journal of Preventive Medicine, 25(4), 277-282. http://doi.org/10.1016/S0749-3797(03)00217-4

Valle, C., Tate, D., \& Mayer, D. (2013). A randomized trial of a Facebook-based physical activity intervention for young adult cancer survivors. Journal of Cancer .... Retrieved from http://link.springer.com/article/10.1007/s11764-013-0279-5

Vandelanotte, C., Kirwan, M., Rebar, A., Alley, S., Short, C., Fallon, L., ... Duncan, M. J. (2014). Examining the use of evidence-based and social media supported tools in freely accessible physical activity intervention websites. Int J Behav Nutr Phys Act, 11, 105. http://doi.org/10.1186/s12966-014-0105-0

Velicer, W. F., Prochaska, J. O., Rossi, J. S., \& Snow, M. G. (1992a). Assessing outcome in smoking cessation studies. Psychological Bulletin, 111(1), 23-41. http://doi.org/10.1037/0033-2909.111.1.23 
Velicer, W. F., Prochaska, J. O., Rossi, J. S., \& Snow, M. G. (1992b). Assessing outcome in smoking cessation studies. Psychological Bulletin, 111(1), 23-41. http://doi.org/10.1037/0033-2909.111.1.23

Wannamethee, S., Shaper, A., \& Walker, M. (1998). Changes in physical activity, mortality, and incidence of coronary heart disease in older men. The Lancet. Retrieved from http://www.sciencedirect.com/science/article/pii/S0140673697123558

Warschburger, P., Kroeller, K., Haerting, J., Unverzagt, S., \& van Egmond-Fröhlich, A. (2016). Empowering Parents of Obese Children (EPOC): A Randomized Controlled Trial on Additional Long-Term Weight Effects of Parent Training. Appetite. http://doi.org/10.1016/j.appet.2016.04.007

Welk, G. J. (1999). Promoting Physical Activity in Children: Parental Influences.

Whitaker, R., \& Wright, J. (1997). Predicting obesity in young adulthood from childhood and parental obesity. ... England Journal of .... Retrieved from http://www.nejm.org/doi/full/10.1056/NEJM199709253371301

WHO, W. H. organization. (2015). Global Health Risks-Mortality and burden of disease attributable to selected major risks. The Lancet. Retrieved from http://obesity.thehealthwell.info/node/9612

Wing, R. R., \& Jeffery, R. W. (1999). Benefits of recruiting participants with friends and increasing social support for weight loss and maintenance. Journal of Consulting and Clinical Psychology, 67(1), 132-8. Retrieved from http://www.ncbi.nlm.nih.gov/pubmed/10028217 
Wofford, L. G. (2008). Systematic Review of Childhood Obesity Prevention. Journal of Pediatric Nursing, 23(1), 5-19. http://doi.org/10.1016/j.pedn.2007.07.006

Yu, C., Chan, S., \& Cheng, F. (2006). Are physical activity and academic performance compatible? Academic achievement, conduct, physical activity and self-esteem of Hong Kong Chinese primary. Educational Studies. Retrieved from http://www.tandfonline.com/doi/abs/10.1080/03055690600850016

\section{Appendix B: Stage-matched messages}

Precontemplation

\begin{tabular}{|l|l|l|}
\hline Week & Message & Strategy \\
\hline 1 & $\begin{array}{l}\text { Think about (at least once a day) the benefits you would expect if you } \\
\text { started being physically active every day. Would you feel better overall? } \\
\text { Lose weight? Feel less stress? Try thinking about what benefits you might } \\
\text { get from physical activity every day this week, and make a list of what you } \\
\text { have come up with. }\end{array}$ & $1 \mathrm{C}$ \\
\hline 2 & $\begin{array}{l}\text { What are some of the negative consequences of not changing to be more } \\
\text { physically active? }\end{array}$ & $1 \mathrm{~B}$ \\
\hline 3 & $\begin{array}{l}\text { Have you tried to change in the past? If so, what happened - were you } \\
\text { successful for a while? What are some lessons you learned from that } \\
\text { experience? }\end{array}$ & $1 \mathrm{E}$ \\
\hline 4 & $\begin{array}{l}\text { What would you describe as something that keeps you from being active? } \\
\text { Make a list of these things and circle the ones that you think you are able to } \\
\text { overcome. }\end{array}$ & $1 \mathrm{E}$ \\
\hline 5 & $\begin{array}{l}\text { Often people will list lack of energy as a reason they do not exercise; did } \\
\text { you know that regular exercise can increase your energy levels! }\end{array}$ & $1 \mathrm{~A}$ \\
\hline 6 & $\begin{array}{l}\text { What is available in your community that might make regular exercise more } \\
\text { enjoyable for you? }\end{array}$ & $1 \mathrm{~F}$ \\
\hline
\end{tabular}




\begin{tabular}{|c|c|c|}
\hline 7 & $\begin{array}{l}\text { Physical activity doesn't have to be running for thirty minutes or completing } \\
\text { an hour long aerobics class. Small increases in daily activity can have a } \\
\text { major impact on your health and wellness. Things like parking further away } \\
\text { from the store, taking the stairs instead of the elevator or taking a walk on } \\
\text { your lunch break can help you achieve a health enhancing level of physical } \\
\text { activity. }\end{array}$ & 1B \\
\hline 8 & $\begin{array}{l}\text { This week try to make a small change in your daily routine, maybe park } \\
\text { further from the store. Then login to your Fitbit account and compare the } \\
\text { difference between this week and last week. Let me know if you noticed a } \\
\text { difference! }\end{array}$ & $1 \mathrm{C}$ \\
\hline 9 & $\begin{array}{l}\text { Did you realize that your physical activity habits can have an effect on your } \\
\text { child? When parents support physical activity in the home children are } \\
\text { much more likely to adopt healthy behaviors for themselves. }\end{array}$ & $1 \mathrm{G}$ \\
\hline 10 & $\begin{array}{l}\text { Did you know regular physical activity of at least } 150 \text { minutes per week, } \\
\text { can reduce risk of premature death by almost } 17 \text { percent? Small changes in } \\
\text { daily habits can quickly add up to } 150 \text { minutes per week. }\end{array}$ & $1 \mathrm{C}$ \\
\hline 11 & $\begin{array}{l}\text { Walking can improve your mood, if you are stressed at work or at home } \\
\text { take a short walk. }\end{array}$ & $1 \mathrm{~A}$ \\
\hline 12 & $\begin{array}{l}\text { What is keeping you from being active this week? Check out the files folder } \\
\text { on the Facebook group to find activity ideas for all climates. }\end{array}$ & 1B \\
\hline 13 & $\begin{array}{l}\text { Physical activity may seem time consuming but you can integrate small } \\
\text { activities throughout the day in activities you already do, try these tips, park } \\
\text { further away, take the stairs, take a walk when you're on the phone. }\end{array}$ & $1 \mathrm{E}$ \\
\hline 14 & Walking up stairs burns almost $5 \mathrm{x}$ as many calories as riding in the elevator. & $1 \mathrm{~A}$ \\
\hline 15 & $\begin{array}{l}\text { Regular physical activity can drastically reduce your risk for cardiovascular } \\
\text { disease. }\end{array}$ & $1 \mathrm{~A}$ \\
\hline 16 & $\begin{array}{l}\text { If asked to make a pro's and con's list for being physically activity, would } \\
\text { you have a harder time creating a list of pro's or con's. }\end{array}$ & 1B \\
\hline 17 & $\begin{array}{l}\text { Do you have any physical activities that you could see yourself doing on a } \\
\text { regular basis? What resources do you need to do those activities? }\end{array}$ & 1B \\
\hline 18 & $\begin{array}{l}\text { When you evaluate your physical abilities what area do you feel most } \\
\text { confident? What activities do you associate with those strengths? }\end{array}$ & $1 \mathrm{D}$ \\
\hline 19 & $\begin{array}{l}\text { Is your child interested in any sports or active games? Create lasting } \\
\text { memories with your child by participating in the games and activities that } \\
\text { they enjoy! }\end{array}$ & $1 \mathrm{G}$ \\
\hline
\end{tabular}




\begin{tabular}{|l|l|l|}
\hline 20 & $\begin{array}{l}\text { Being active with your child is naturally social, it's harder to tune one } \\
\text { another out when you are participating in physical activity together. }\end{array}$ & $1 \mathrm{G}$ \\
\hline
\end{tabular}

\section{Contemplation}

\begin{tabular}{|c|c|c|}
\hline Week & Message & Strategy \\
\hline 1 & $\begin{array}{l}\text { How will you look, act, and feel when you have become physically active } \\
\text { on a regular basis? }\end{array}$ & $2 \mathrm{~A}$ \\
\hline 2 & $\begin{array}{l}\text { What will you have to do differently in order to become physically active } \\
\text { for a week? What will you need to help you? (address obstacles) }\end{array}$ & $2 \mathrm{C}$ \\
\hline 3 & $\begin{array}{l}\text { Can you come up with two reasons why it is important for you to change } \\
\text { your physical activity habits? }\end{array}$ & $2 \mathrm{C}$ \\
\hline 4 & Provide supportive resources and information & $2 \mathrm{~F}$ \\
\hline 5 & $\begin{array}{l}\text { What is one small thing you could do today to help you prepare to make a } \\
\text { positive change in your physical activity. }\end{array}$ & $2 \mathrm{C}$ \\
\hline 6 & $\begin{array}{l}\text { Provide a "first person account" (testimonial) of someone who has already } \\
\text { made the change that is inspiring (motivation) }\end{array}$ & $2 \mathrm{D}$ \\
\hline 7 & Take that initial first step of becoming more physically active. & $2 \mathrm{~A}$ \\
\hline 8 & $\begin{array}{l}\text { Establish a "start date" on your calendar. What do you need to do so that } \\
\text { you are mentally and physically prepared by that date? }\end{array}$ & $2 \mathrm{~A}$ \\
\hline 9 & $\begin{array}{l}\text { Tell your friends and family about your plans to become more physically } \\
\text { active. }\end{array}$ & $2 \mathrm{D}$ \\
\hline 10 & $\begin{array}{l}\text { When thinking about starting regular physical activity what do you think } \\
\text { will be your three biggest struggles? What practical solutions do you have } \\
\text { that will help you avoid those struggles? }\end{array}$ & $2 \mathrm{~F}$ \\
\hline 11 & $\begin{array}{l}\text { Create a list of all the things in your life that keep you from being } \\
\text { physically active on regular basis. Which of these things are significant and } \\
\text { will be difficult for you to overcome and which of these are minor hassles? }\end{array}$ & $2 \mathrm{C}$ \\
\hline 12 & $\begin{array}{l}\text { Regular physical activity drastically reduces your risk of many chronic } \\
\text { diseases, including diabetes, hypertension, cancer, heart disease, and many } \\
\text { others. Make sure you are doing everything you can do now to prevent } \\
\text { these problems later. }\end{array}$ & $2 \mathrm{H}$ \\
\hline
\end{tabular}




\begin{tabular}{|c|c|c|}
\hline 13 & $\begin{array}{l}\text { Can you think of anyone in your life who has made a major change in their } \\
\text { physical activity behaviors? What kind of effect has that change had on } \\
\text { their life? Do they seem happier? More confident? }\end{array}$ & $2 \mathrm{D}$ \\
\hline 14 & $\begin{array}{l}\text { Significant health benefits from physical activity can be achieved with only } \\
30 \text { minutes of physical activity per day. Where can you find } 30 \text { minutes per } \\
\text { day to get active with your family? }\end{array}$ & $2 \mathrm{E}$ \\
\hline 15 & $\begin{array}{l}\text { Take a moment and evaluate your community, what options are available } \\
\text { for you and your family to participate in physical activity year round? }\end{array}$ & $2 \mathrm{~F}$ \\
\hline 16 & $\begin{array}{l}\text { Regular physical activity can have a profound effect on your confidence } \\
\text { and self-worth. Go for a long walk or a short jog and challenge yourself to } \\
\text { do slightly more than you have done in the past. Prove to yourself that you } \\
\text { can be successful! }\end{array}$ & $2 B$ \\
\hline 17 & $\begin{array}{l}\text { As Michael Jackson famously said: "If you want to make the world a better } \\
\text { place takes a look at yourself, and make a change." Looking at your } \\
\text { physical activity habits what changes do you think you can make to } \\
\text { improve yourself? }\end{array}$ & $2 G$ \\
\hline 18 & $\begin{array}{l}\text { Parent physical activity and health behaviors are instrumental in the habits } \\
\text { that children develop. Do you feel like your physical activity behaviors are } \\
\text { a positive or negative influence for your child? }\end{array}$ & $2 \mathrm{H}$ \\
\hline 19 & $\begin{array}{l}\text { Short ten minute bouts of physical activity throughout your day can } \\
\text { improve concentration and memory. Don't have time for a full workout? } \\
\text { Try incorporating short activity breaks throughout your day. }\end{array}$ & $2 \mathrm{E}$ \\
\hline 20 & $\begin{array}{l}\text { Your belief in yourself plays a major role on your success. Set small scale } \\
\text { physical activity goals you believe you can be successful in achieving. } \\
\text { Small victories will help you achieve your long term goals. }\end{array}$ & $2 B$ \\
\hline
\end{tabular}

\section{Preparation}

\begin{tabular}{|l|l|l|}
\hline Week & Message & Strategy \\
\hline 1 & $\begin{array}{l}\text { Start with ten minute chunks of exercise a couple days a week. Walk } \\
\text { during a break. Dance in the living room to your favorite song. It all } \\
\text { adds up! }\end{array}$ & $3 \mathrm{G}$. \\
\hline
\end{tabular}




\begin{tabular}{|c|c|c|}
\hline 2 & $\begin{array}{l}\text { Create a family challenge, within the home set a step or active minutes' } \\
\text { goal to involve the whole family. Need idea's or help setting this up for } \\
\text { your family? Let us know. }\end{array}$ & $3 \mathrm{E}$ \\
\hline 3 & Plan your rewards. How will you celebrate reaching your small goals? & $3 \mathrm{H}$ \\
\hline 4 & $\begin{array}{l}\text { What adjustments to your environment and current schedule will you } \\
\text { need to make to start your physical activity action plan? }\end{array}$ & $3 \mathrm{~A}$ \\
\hline 5 & $\begin{array}{l}\text { Locate a friend, family member, or group that is interested in reaching } \\
\text { the same activity goals as you, and set up some times to exercise } \\
\text { together. }\end{array}$ & $3 \mathrm{E}$ \\
\hline 6 & $\begin{array}{l}\text { Do you have proper clothes and shoes for working out? Can you arrange } \\
\text { childcare for the time you want to exercise? }\end{array}$ & $3 \mathrm{E}$ \\
\hline 7 & $\begin{array}{l}\text { Are there any fitness classes that you can attend in your local } \\
\text { community that are free or that require little expense? }\end{array}$ & $3 \mathrm{G}$. \\
\hline 8 & $\begin{array}{l}\text { Develop your list of "keys" for making physical activity enjoyable for } \\
\text { you. Here are some suggestions: Have a set time for PA, Separate PA } \\
\text { from other activities, PA occurs in pleasant and safe surroundings, seek } \\
\text { to spend time with friends or people of your own age, Exercise to music. } \\
\text { What other "keys" will make you look forward to the time you set aside } \\
\text { for exercise? }\end{array}$ & $3 \mathrm{H}$ \\
\hline 9 & $\begin{array}{l}\text { How much physical activity are you getting right now? How much will } \\
\text { you change that by beginning a regular physical activity routine? }\end{array}$ & $3 \mathrm{D}$ \\
\hline 10 & $\begin{array}{l}\text { Do you have a SMART goal for getting active? This goal should be } \\
\text { Specific, Measurable, Attainable, Realistic and Time constrained. If you } \\
\text { haven't made one, contact us and we will help you establish SMART } \\
\text { goals for you and your family. }\end{array}$ & $3 \mathrm{~B}$ \\
\hline 11 & $\begin{array}{l}\text { Making achievable fitness goals are important. You do not have to run a } \\
\text { marathon on your first week of a new routine. The important thing is } \\
\text { making small changes that are sustainable for your lifestyle. }\end{array}$ & $3 \mathrm{C}$ \\
\hline 12 & $\begin{array}{l}\text { Have you told a loved one about becoming more active? Ask them to } \\
\text { encourage and support you. Tell someone you love about your goals and } \\
\text { ask them to hold you accountable. }\end{array}$ & $3 \mathrm{E}$ \\
\hline 13 & $\begin{array}{l}\text { Make a list of all of the things that might prevent you from being active } \\
\text { for at least } 30 \text { minutes a day } 5 \text { days a week. Next to each problem see if } \\
\text { you can come up with a creative solution to get around the problem. }\end{array}$ & $3 \mathrm{~F}$ \\
\hline
\end{tabular}




\begin{tabular}{|c|c|c|}
\hline 14 & $\begin{array}{l}\text { Technology can help you become more active on a regular basis, things } \\
\text { like geocaching in Pokémon go are great active games than you can } \\
\text { play with your child. If you have a question about how you can use } \\
\text { technology to keep you active let us know. }\end{array}$ & $3 G$ \\
\hline 15 & $\begin{array}{l}\text { There are } 1440 \text { minutes in everyday set aside } 30 \text { minutes to be } \\
\text { physically active to reach your goals! }\end{array}$ & $3 \mathrm{C}$ \\
\hline 16 & $\begin{array}{l}\text { When starting a regular exercise routine, it is important that we feel } \\
\text { supported. Make sure you share your physical activity goals with friends } \\
\text { and family. We would love to hear about your goals and how you're } \\
\text { doing with them. }\end{array}$ & $3 \mathrm{E}$ \\
\hline 17 & $\begin{array}{l}\text { Starting a new exercise routine can be difficult. What struggles have } \\
\text { you had in the past that have stopped you from being active? What are } \\
\text { some realistic ways you can avoid those struggles in the future? }\end{array}$ & $3 \mathrm{~F}$ \\
\hline 18 & $\begin{array}{l}\text { Have you been wearing your Fitbit? Keeping track of your activity will } \\
\text { help you realize how much activity you are actually getting each day! }\end{array}$ & $3 \mathrm{D}$ \\
\hline 19 & $\begin{array}{l}\text { Making exercise a regular habit is much easier if you find activities that } \\
\text { you enjoy doing. The key is to think about what you want to gain from } \\
\text { the exercise and then find an exercise that suits you. Don't suit yourself } \\
\text { to an exercise. }\end{array}$ & $3 B$ \\
\hline 20 & $\begin{array}{l}\text { You have been keeping track of your steps and physical activity for } \\
\text { several weeks now. What areas of your current activity need to improve } \\
\text { for you to meet your physical activity goals? }\end{array}$ & $3 \mathrm{~A}$ \\
\hline
\end{tabular}

\section{Action}

\begin{tabular}{|c|c|c|}
\hline Week & Message & Strategy \\
\hline 1 & $\begin{array}{l}\text { What advice could you offer to someone who is just preparing to start a } \\
\text { regular exercise routine? Would you share that advice on the group page? }\end{array}$ & $4 \mathrm{~A}$ \\
\hline 2 & $\begin{array}{l}\text { Are you celebrating your success? If not, take time to reward yourself. Let } \\
\text { us know when you reach a milestone we want to celebrate your success } \\
\text { with you! }\end{array}$ & $4 B$ \\
\hline 3 & $\begin{array}{l}\text { Do you have trouble fitting your planned physical activity in on a daily } \\
\text { basis? Use the Fitbit app or another of your favorite fitness apps to provide } \\
\text { you with reminders of your goals and keep you on track! Do you need help } \\
\text { or advice using the apps? Let us know. }\end{array}$ & $4 \mathrm{C}$ \\
\hline
\end{tabular}




\begin{tabular}{|c|c|c|}
\hline 4 & $\begin{array}{l}\text { Have you reached any of your short term goals? Do you need to create a } \\
\text { new short term goal or adjust your goals? }\end{array}$ & $4 \mathrm{D}$ \\
\hline 5 & $\begin{array}{l}\text { Do you have a contingency plan for exercise? Sometimes your regular } \\
\text { routine can get interrupted, rather than taking a cheat day what are some } \\
\text { things you can do to still get at least thirty minutes of physical activity? }\end{array}$ & $4 \mathrm{G}$ \\
\hline 6 & $\begin{array}{l}\text { What are the things in your life that make you want to skip out on physical } \\
\text { activity? How can you avoid those situations? }\end{array}$ & $4 \mathrm{E}$ \\
\hline 7 & $\begin{array}{l}\text { The example you set for your children has an impact on their physical } \\
\text { activity behaviors long term. Participating in physical activity as a family } \\
\text { not only helps you to reach your goals but also sets a great example for your } \\
\text { child to follow! }\end{array}$ & $4 \mathrm{~F}$ \\
\hline 8 & $\begin{array}{l}\text { Does your exercise routine seem like a chore? It will be much easier to } \\
\text { reach your goals if you think of exercise as a stress relief or social time } \\
\text { rather than a chore; if what you're doing now seems like a chore you may } \\
\text { want to consider some alternative activities. }\end{array}$ & $4 \mathrm{H}$ \\
\hline 9 & $\begin{array}{l}\text { If you can do this for } 6 \text { months, you are more likely to continue to maintain } \\
\text { your physical activity level. }\end{array}$ & $4 \mathrm{~A}$ \\
\hline 10 & $\begin{array}{l}\text { Treat yourself! Have you met a small or large milestone? Make sure you } \\
\text { continue to reward yourself for meeting your goals. }\end{array}$ & $4 B$ \\
\hline 11 & $\begin{array}{l}\text { Are you finding yourself slipping back into old habits, and letting your } \\
\text { physical activity plan slide? Let us know if you need support we are here to } \\
\text { help you reach your physical activity goals! }\end{array}$ & $4 C$ \\
\hline 12 & $\begin{array}{l}\text { To get the full benefit of regular physical activity you must progress, what } \\
\text { seemed difficult when you first started may now be easy for you. Make sure } \\
\text { you continue to challenge yourself when reaching a goal by setting a new } \\
\text { one. }\end{array}$ & $4 \mathrm{D}$ \\
\hline 13 & $\begin{array}{l}\text { Have you planned the details of your physical activity this week? It's easy to } \\
\text { slip out of exercise if you don't designate the place and time. Be specific, } \\
\text { instead of saying you're going to walk for } 30 \text { minutes a day this week, try } \\
\text { saying I'm going to walk for } 30 \text { minutes at lunch with Brainy Jones every } \\
\text { day this week. }\end{array}$ & $4 G$ \\
\hline 14 & $\begin{array}{l}\text { What habits in your home promote physical inactivity? What can you do to } \\
\text { change those habits or routines to help you stay active? }\end{array}$ & $4 \mathrm{E}$ \\
\hline 15 & $\begin{array}{l}\text { Are you involving your friends and family in your active lifestyle? } 5 \mathrm{C} \\
\text { makes being active much more enjoyable and can be a great time to catch } \\
\text { up with what's going on with your child. }\end{array}$ & $4 \mathrm{~F}$ \\
\hline
\end{tabular}




\begin{tabular}{|l|l|l|}
\hline 16 & $\begin{array}{l}\text { Physical activity doesn't have to be running for thirty minutes or completing } \\
\text { an hour long aerobics class. Small increases in daily activity can have a } \\
\text { major impact on your health and wellness. Things like parking further away } \\
\text { from the store, taking the stairs instead of the elevator or taking a walk on } \\
\text { your lunch break can help you achieve a health enhancing level of physical } \\
\text { activity. }\end{array}$ & $4 \mathrm{H}$ \\
\hline 17 & $\begin{array}{l}\text { Regular physical activity provides a variety of physical, mental and social } \\
\text { benefits. Have you noticed any positive improvements in your wellness } \\
\text { after incorporating physical activity into your regular routine? }\end{array}$ & $4 \mathrm{~B}$ \\
\hline 18 & $\begin{array}{l}\text { According to the CDC 80\% of Americans do not get the recommended 150 } \\
\text { minutes of physical activity per week. Given that statistic you are now } \\
\text { among the top 20\% of Americans, you should be proud! }\end{array}$ & $4 \mathrm{~A}$ \\
\hline 19 & $\begin{array}{l}\text { Slipping on your goal does not mean you have failed, while you want to be } \\
\text { diligent in your routine it's ok to have a slip up every now and then. You } \\
\text { don't want to burn out or begin to see physical activity as a chore. }\end{array}$ & $4 \mathrm{C}$ \\
\hline 20 & $\begin{array}{l}\text { Are you asking your friends and family to support you in being active? Try } \\
\text { having a conversation with someone so they know your goals for being } \\
\text { active and can hold you accountable. }\end{array}$ & $4 \mathrm{~F}$ \\
\hline
\end{tabular}

\section{Maintenance}

\begin{tabular}{|c|c|c|}
\hline Week & Message & Strategy \\
\hline 1 & $\begin{array}{l}\text { You are already doing a great job of maintaining regular physical activity } \\
\text { habits! Use your new Fitbit to keep track of your activity so you can continue to } \\
\text { improve. }\end{array}$ & $5 \mathrm{~A}$ \\
\hline 2 & $\begin{array}{l}\text { When you have been active as long as you have you can sometimes fall in to a } \\
\text { rut, try to keep your workouts fresh by varying your activities or trying a new } \\
\text { route. }\end{array}$ & $5 \mathrm{H}$ \\
\hline 3 & $\begin{array}{l}\text { Do you involve your children in your regular physical activity? Participating in } \\
\text { activity regularly with your child helps them to develop a sense of value for } \\
\text { lifetime physical activity. }\end{array}$ & $5 B$ \\
\hline 4 & Have you reassessed your physical activity goals lately? & $5 \mathrm{C}$ \\
\hline 5 & $\begin{array}{l}\text { It is difficult to keep up an exercise routine for an extended period of time, } \\
\text { when you begin to think about skipping a workout or you have a negative } \\
\text { thought about exercise try and think of three benefits to being active. }\end{array}$ & $5 \mathrm{D}$ \\
\hline
\end{tabular}




\begin{tabular}{|c|c|c|}
\hline 6 & $\begin{array}{l}\text { What is your weakness when it comes skipping out on physical activity? Do } \\
\text { you have strategies that you use to combat those weaknesses? }\end{array}$ & $5 \mathrm{E}$ \\
\hline 7 & $\begin{array}{l}\text { As someone who has been active for some time. What advice could you give to } \\
\text { someone just starting a new routine? Would you share that advice on the group } \\
\text { wall? }\end{array}$ & $5 \mathrm{~F}$ \\
\hline 8 & $\begin{array}{l}\text { When toddlers learn to walk they fall constantly, those falls do not represent } \\
\text { failure but are part of the learning process. The same is true of exercise if you } \\
\text { fall off of your routine, use that slip as a learning tool to see how you can be } \\
\text { better tomorrow. }\end{array}$ & $5 \mathrm{H}$ \\
\hline 9 & $\begin{array}{l}\text { After using your Fitbit for a few months, do you feel like you are getting more } \\
\text { or less activity? Are you keeping up with your daily activity? }\end{array}$ & $5 \mathrm{~A}$ \\
\hline 10 & $\begin{array}{l}\text { It takes } 21 \text { days to develop a new habit, it takes } 21 \text { months to develop a new } \\
\text { lifestyle. A good way to stay on track with your lifestyle goals is to involve } \\
\text { friends and family. Did you know the Fitbit app has weekly challenges that you } \\
\text { can do with your friends and family? }\end{array}$ & $5 \mathrm{H}$ \\
\hline 11 & $\begin{array}{l}\text { Sport and physical activity is a very special way to connect with your child. } \\
\text { Here are a few ways you can be active as a family: } \\
\text { http://www.parents.com/fun/sports/exercise/10-ways-to-exercise-as-a-family/ }\end{array}$ & $5 \mathrm{~B}$ \\
\hline 12 & $\begin{array}{l}\text { Have you tried the adventures feature with your Fitbit? Choose a scenic } \\
\text { adventure with your Fitbit, every day the app will analyze your step count and } \\
\text { increase or decrease the goal to help you progress. }\end{array}$ & $5 \mathrm{C}$ \\
\hline 13 & $\begin{array}{l}\text { What barriers are currently in your life that you know make it difficult for you } \\
\text { to be active? Do you have a strategy to get around those barriers? }\end{array}$ & $5 \mathrm{D}$ \\
\hline 14 & $\begin{array}{l}\text { Do you use reminders to keep you on track with your workout routine? The } \\
\text { Fitbit app can remind you and reward you when you reach your daily goal. }\end{array}$ & $5 \mathrm{E}$ \\
\hline 15 & $\begin{array}{l}\text { Are you a role model for physical activity in your home? It is important to show } \\
\text { your children the importance of physical activity in your life. }\end{array}$ & $5 F$ \\
\hline 16 & $\begin{array}{l}\text { Do you ever slip in your routine? What lessons can you take away from those } \\
\text { small lapses? How can you use those lessons to reinforce your routine in the } \\
\text { future? }\end{array}$ & $5 \mathrm{G}$ \\
\hline 17 & $\begin{array}{l}\text { One way to keep from getting bored in your routine is to set a tangible goal. } \\
\text { Have you tried signing up for a fun run or a } 5 \mathrm{k} \text { ? }\end{array}$ & $5 \mathrm{G}$ \\
\hline 18 & $\begin{array}{l}\text { How do you stay on track with your workouts? What things do you need to } \\
\text { avoid that encourage you to be sedentary. }\end{array}$ & $5 \mathrm{E}$ \\
\hline
\end{tabular}




\begin{tabular}{|l|l|l|}
\hline 19 & $\begin{array}{l}\text { As you know keeping up a regular exercise routine can be challenging. Do you } \\
\text { have any advice that you would be willing to share with the group that helps } \\
\text { you keep up your routine? Please share on the group wall. }\end{array}$ & $5 \mathrm{~F}$ \\
\hline 20 & $\begin{array}{l}\text { By getting at least } 150 \text { minutes of physical activity per week you get more } \\
\text { physical activity than } 80 \% \text { of Americans. Can you push yourself further? }\end{array}$ & $5 \mathrm{~B}$ \\
\hline
\end{tabular}

Note. Strategies are described in Table 2. 


\section{Appendix C: Parent Physical Activity Questionnaire}

activate! survey questions marked with an *

\section{Changes in Parent Behaviors}

\section{Stage of behavior change}

\section{In a typical week, how many days do you do physical activity for $\mathbf{3 0}$ minutes or more?}

*Physical activity - is any activity that increases your heart rate and makes you get out of breath some of the time.

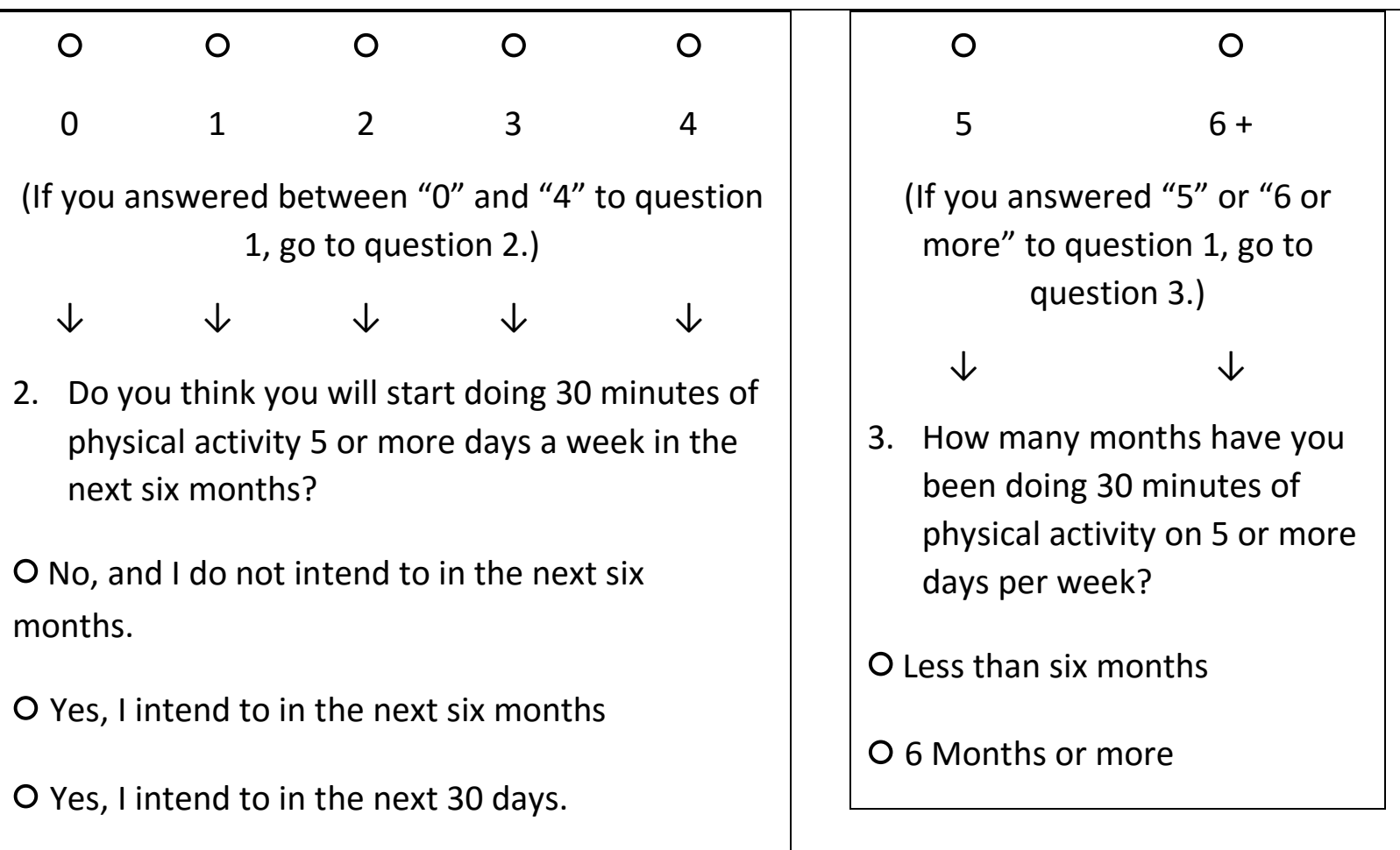

*How often do the following things prevent you from getting physical activity?

\begin{tabular}{|l|l|l|l|l|}
\hline & Never & Rarely & Sometimes & Often \\
\hline I am self-conscious about my looks when physically active & & & & \\
\hline I have too much work & & & & \\
\hline Lack of time & & & & \\
\hline Weather is too bad & & & & \\
\hline Lack of convenient places to do physical activity & & & & \\
\hline Lack of interest in physical activity & & & & \\
\hline Lack of skills & & & & \\
\hline Lack of equipment & & & & \\
\hline Lack of knowledge on how to do physical activity & & & & \\
\hline
\end{tabular}


I do not have anyone to do physical activity with

*How sure are you that you can do these things?

\begin{tabular}{|c|c|c|c|c|}
\hline & $\begin{array}{l}\text { I know } \\
\text { I } \\
\text { cannot }\end{array}$ & $\begin{array}{l}\text { Maybe } \\
\text { I } \\
\text { can }\end{array}$ & $\begin{array}{l}\text { I know } \\
\text { I can }\end{array}$ & $\begin{array}{l}\text { Does } \\
\text { not } \\
\text { Apply }\end{array}$ \\
\hline Get up early, even on weekends, to be active. & & & & \\
\hline $\begin{array}{l}\text { Stick to your physical activity program after a long } \\
\text { tiring day at work. }\end{array}$ & & & & \\
\hline $\begin{array}{l}\text { Be physically active even though you are feeling } \\
\text { depressed. }\end{array}$ & & & & \\
\hline $\begin{array}{l}\text { Set aside time for a physical activity program; that } \\
\text { is, walking, jogging, swimming, biking, or other } \\
\text { continuous activity for at least } 30 \text { minutes, } 3 \\
\text { times/week. }\end{array}$ & & & & \\
\hline $\begin{array}{l}\text { Continue to be physically active with others even } \\
\text { though they seem too fast or too slow for you. }\end{array}$ & & & & \\
\hline $\begin{array}{l}\text { Stick to your physical activity program when } \\
\text { undergoing a stressful life change (e.g., divorce, } \\
\text { death in the family, moving) }\end{array}$ & & & & \\
\hline Attend a party only after being physically active. & & & & \\
\hline $\begin{array}{l}\text { Stick to your physical activity program when } \\
\text { your family is demanding more time from you. }\end{array}$ & & & & \\
\hline $\begin{array}{l}\text { Stick to your physical activity program } \\
\text { when you have household chores to } \\
\text { attend to. }\end{array}$ & & & & \\
\hline $\begin{array}{l}\text { Stick to your physical activity program even } \\
\text { when you have excessive demands at work. }\end{array}$ & & & & \\
\hline $\begin{array}{l}\text { Stick to your physical activity program when socia } \\
\text { obligations are very time consuming. }\end{array}$ & & & & \\
\hline $\begin{array}{l}\text { Read or study less in order to be more physically } \\
\text { active. }\end{array}$ & & & & \\
\hline
\end{tabular}




\section{Changes in Parent Attitudes}

Your attitude towards physical activity: The following questions relate to your perceptions and attitudes concerning physical activity. Please select your level of agreement with the following statements.

\begin{tabular}{|l|l|l|l|l|}
\hline & $\begin{array}{c}\text { Strongly } \\
\text { agree }\end{array}$ & Agree & Disagree & $\begin{array}{c}\text { Strongly } \\
\text { disagree }\end{array}$ \\
\hline It is important to me to be strong and physically fit. & & & & \\
\hline $\begin{array}{l}\text { Maintaining good physical condition takes more } \\
\text { effort than it is worth. }\end{array}$ & & & & \\
\hline $\begin{array}{l}\text { Participation in physical activity is essential for a } \\
\text { quality life, regardless of sex and ethnic } \\
\text { background. }\end{array}$ & & & & \\
\hline $\begin{array}{l}\text { Good health throughout life is related to one's level } \\
\text { of physical activity. }\end{array}$ & & & & \\
\hline $\begin{array}{l}\text { I get all the exercise I need doing just normal daily } \\
\text { activities. }\end{array}$ & & & & \\
\hline Physical activity is of major importance to my life. & & & & \\
\hline
\end{tabular}

*How much do you enjoy physical activity?

Physical activity is very unenjoyable

Physical activity is somewhat unenjoyable

Neutral

Physical activity is somewhat enjoyable

Physical activity is very enjoyable

Changes in the Home Environment

Family support

*How often have you done the following: 


\begin{tabular}{|l|l|l|l|l|l|}
\hline & $\begin{array}{c}\text { Never/ } \\
\text { Almost }\end{array}$ & Monthly & Weekly & $\begin{array}{c}\text { Almost } \\
\text { Daily }\end{array}$ & Daily \\
\hline Established a bedtime for your child. & & & & & \\
\hline Expected family to eat as a group. & & & & & \\
\hline Expected family to do activities together. & & & & \\
\hline $\begin{array}{l}\text { Known what physical activities your } \\
\text { child was doing. }\end{array}$ & & & & & \\
\hline Participated in activities with your child. & & & & \\
\hline $\begin{array}{l}\text { Encouraged your child to do physical } \\
\text { activities or play sports. }\end{array}$ & & & & & \\
\hline $\begin{array}{l}\text { Provided transportation to a place } \\
\text { where your child could be physically }\end{array}$ & & & & & \\
\hline $\begin{array}{l}\text { Watched your child participate in } \\
\text { physical activities or sports. }\end{array}$ & & & & & \\
\hline $\begin{array}{l}\text { Told your child he/she was doing well in } \\
\text { physical activities or sports. }\end{array}$ & & & & & \\
\hline $\begin{array}{l}\text { Told your child that physical activity was } \\
\text { good for his/her health. }\end{array}$ & & & & & \\
\hline
\end{tabular}

*Overall, how would you rate other household member's level of physical activity (check one):

$\circ$ My family is very active (active 6-7 days/week on average for most family members)

- My family is somewhat active (active 4-5 days/week on average for most family members)

○ My family is slightly active (active 3-4 days/week on average for most family members)

○ My family is not that active (active $<2$ days/week on average for most family members)

\section{$\underline{\text { Family Health Climate }}$}


Please select the answer that best describes your opinion about each statement.

\begin{tabular}{|l|l|l|l|l|}
\hline & $\begin{array}{l}\text { Definitely } \\
\text { false }\end{array}$ & $\begin{array}{l}\text { Probably } \\
\text { false }\end{array}$ & $\begin{array}{l}\text { Probably } \\
\text { true }\end{array}$ & $\begin{array}{l}\text { Definitely } \\
\text { true }\end{array}$ \\
\hline $\begin{array}{l}\text { In our family, we make a point of being } \\
\text { physically active during daily life. }\end{array}$ & & & & \\
\hline $\begin{array}{l}\text { In our family, it is normal to be physically } \\
\text { active regularly. }\end{array}$ & & & & \\
\hline $\begin{array}{l}\text { In our family, it goes without saying that we } \\
\text { exercise and are physically active on a regular } \\
\text { basis. }\end{array}$ & & & & \\
\hline $\begin{array}{l}\text { In our family, it is normal to be physically } \\
\text { active in our leisure time. }\end{array}$ & & & & \\
\hline $\begin{array}{l}\text { In our family, we agree that physical activities } \\
\text { are part of daily life. }\end{array}$ & & & & \\
\hline $\begin{array}{l}\text { In our family, we like being together during } \\
\text { physical activities (e.g. bike tours, hikes). }\end{array}$ & & & & \\
\hline In our family, we enjoy exercising together. & & & & \\
\hline $\begin{array}{l}\text { In our family, we find it very pleasant to be } \\
\text { physically active together. }\end{array}$ & & & & \\
\hline $\begin{array}{l}\text { In our family, we like spending time together } \\
\text { in sports activities. }\end{array}$ & & & & \\
\hline $\begin{array}{l}\text { In our family, we watch TV-programs on } \\
\text { physical activity and exercise. }\end{array}$ & & & & \\
\hline
\end{tabular}

\section{Physical Environment}

*Please think about the time from when your child wakes up until he/she goes to bed. Please DO NOT include time when your child is in school during regular hours. Please mark the best answer for your child. 


\begin{tabular}{|l|l|l|l|l|l|l|l|}
\hline Activity & None & $\begin{array}{c}\mathbf{1 5} \\
\text { minutes }\end{array}$ & $\begin{array}{c}\mathbf{3 0} \\
\text { minutes }\end{array}$ & $\begin{array}{c}\mathbf{1} \\
\text { hour }\end{array}$ & $\begin{array}{c}\mathbf{2} \\
\text { hours }\end{array}$ & $\begin{array}{c}\mathbf{3} \\
\text { hours }\end{array}$ & $\begin{array}{c}\mathbf{4} \\
\text { hours }\end{array}$ \\
\hline Watching television/ videos/ DVDs & & & & & & & \\
\hline $\begin{array}{l}\text { Playing computer or video games } \\
\text { (like Nintendo or Xbox) that do } \\
\text { not include physical activity (e.g., }\end{array}$ & & & & & & & \\
\hline $\begin{array}{l}\text { Using the internet, emailing, or } \\
\text { other electronic media for }\end{array}$ & & & & & & & \\
\hline $\begin{array}{l}\text { Doing homework (including reading, } \\
\text { writing, or using the computer) }\end{array}$ & & & & & & & \\
\hline $\begin{array}{l}\text { Sitting listening to music (on radio, CD, } \\
\text { tape, MP3, iPod, etc.) }\end{array}$ & & & & & & & \\
\hline Sitting talking on the telephone or & & & & & & & \\
\hline $\begin{array}{l}\text { Sitting/hanging out/talking with } \\
\text { friends or family }\end{array}$ & & & & & & & \\
\hline $\begin{array}{l}\text { Reading a book or magazine NOT for } \\
\text { school (including comic books) }\end{array}$ & & & & & & & \\
\hline $\begin{array}{l}\text { Doing inactive hobbies (music, art, } \\
\text { crafts, clubs, going to movies, etc.) }\end{array}$ & & & & & & & \\
\hline Riding in a car/bus & & & & & & & \\
\hline
\end{tabular}




\section{Social Media Perceptions Questions}

Please respond to the following statements as they relate to your use of the activate! Facebook group.

\begin{tabular}{|l|l|l|l|l|}
\hline & $\begin{array}{c}\text { Strongly } \\
\text { agree }\end{array}$ & $\begin{array}{c}\text { Somewhat } \\
\text { agree }\end{array}$ & $\begin{array}{c}\text { Somewhat } \\
\text { disagree }\end{array}$ & $\begin{array}{c}\text { Strongly } \\
\text { disagree }\end{array}$ \\
\hline $\begin{array}{l}\text { The messaging I received through the } \\
\text { Facebook group influenced my physical } \\
\text { activity behaviors. }\end{array}$ & & & \\
\hline $\begin{array}{l}\text { The messaging I received through the } \\
\text { Facebook group encouraged me to be more } \\
\text { physically active. }\end{array}$ & & & & \\
\hline $\begin{array}{l}\text { The connection to the Facebook group made } \\
\text { me feel connected with the Activate! program. }\end{array}$ & & & & \\
\hline $\begin{array}{l}\text { I felt more confident in my ability to } \\
\text { participant in regular physical activity after } \\
\text { being connected to the Facebook group. }\end{array}$ & & & & \\
\hline $\begin{array}{l}\text { The Facebook group made me more aware of } \\
\text { the need for physical activity in my life. }\end{array}$ & & & & \\
\hline $\begin{array}{l}\text { The Facebook group made me more aware of } \\
\text { the need for physical activity in my child's life. }\end{array}$ & & & & \\
\hline $\begin{array}{l}\text { Receiving personal messages helped me to } \\
\text { achieve my physical activity goals. } \\
\text { more aware of my child's physical activity in } \\
\text { the home. }\end{array}$ & & & & \\
\hline
\end{tabular}




\section{Appendix D: Stage of Change Facebook Measure}



\section{Readiness ruler}



On a scale of $0-10$, how ready are you to be physically active?

0-3: Not ready

4-7: Unsure

8-10: Ready *

Please choose 


\section{Appendix E: Core Messaging Samples}

Focus of Core Messages

\begin{tabular}{|c|c|}
\hline Core Concept & mponents \\
\hline $\begin{array}{l}\text { Benefits and values of physical } \\
\text { activity for their child and } \\
\text { themselves. }\end{array}$ & $\begin{array}{l}\text { - Relationship between parent and child } \\
\text { physical activity } \\
\text { - Parents expression of belief in children's } \\
\text { physical activity competence } \\
\text { - Value of exercise for their children } \\
\text { - Physical activity as a topic of discussion in } \\
\text { the family }\end{array}$ \\
\hline Planning for Physical activity & - Establishing SMART goals \\
\hline $\begin{array}{l}\text { Influence of the home environment in } \\
\text { promoting physical activity }\end{array}$ & $\begin{array}{l}\text { - } \quad \text { Parent support } \\
\text { - } \quad \text { Parenting styles } \\
\text { - } \text { Family dining behaviors }\end{array}$ \\
\hline Overcoming barriers & $\begin{array}{l}\text { - } \text { Time } \\
\text { - Space } \\
\text { - Equipment } \\
\text { - Community support } \\
\text { - Knowledge } \\
\text { - } \text { Access to PA opportunities within the } \\
\text { community }\end{array}$ \\
\hline
\end{tabular}

Physical activity recommendations

- Informational factors

Monitoring physical activity

- Fitbit Check-in reminders

- Importance of tracking PA behaviors

\section{Benefits and values of physical activity for their child} and themselves.

- Parents expression of belief in children's physical activity comnetence

Children's self-esteem plays a big part in their interest in physical activity. If children are confident in their abilities, then they are much more likely to choose to be active. Between the

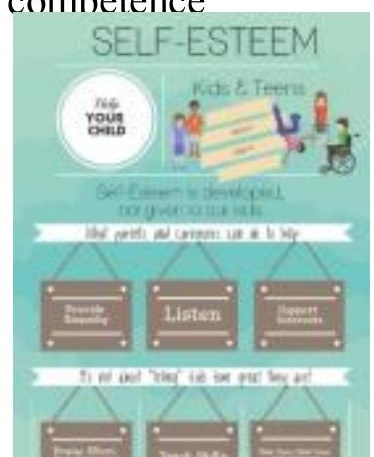


ages of 5 and 12 years-old, parents are the most influential contributors to children's self-esteem. Here are some tips to help build up your child's self-esteem.

\section{Planning for Physical activity}

\section{- Establishing SMART goals}

With the new year upon us, many of us will set new resolutions or goals for the new year. I'll probably try and get into my old pants for the third year in a row! But, in all seriousness setting goals is the critical first step to achieving goals. If we follow key goal setting principles by creating SMART ( S pecific, Measurable, Attainable, Realistic, and Time defined) goals we are much more likely to understand what we are signing up for and in the end will help us to reach these aims.

https://www.healthyfamiliesbc.ca/home/articles/set-smartgoals

\section{Influence of the home environment in promoting physical activity}

- Parent support

Have you considered all the ways that parents can influence your child's health? The home environment plays a significant role in our children's health. What can you do better to help your kids' live healthier life styles?

\section{$\underline{\text { Overcoming barriers }}$}

- Time

Getting active can seem difficult to fit into a hectic schedule, the key is to schedule your physical activity. If you put it on your calendar, you are more likely to follow through! Check out the link below for helpful tips on overcoming barriers!

http://www.nhs.uk/Livewell/c25k/Pages/overcoming-thebarriers-to-exercise.aspx

Physical activity recommendations

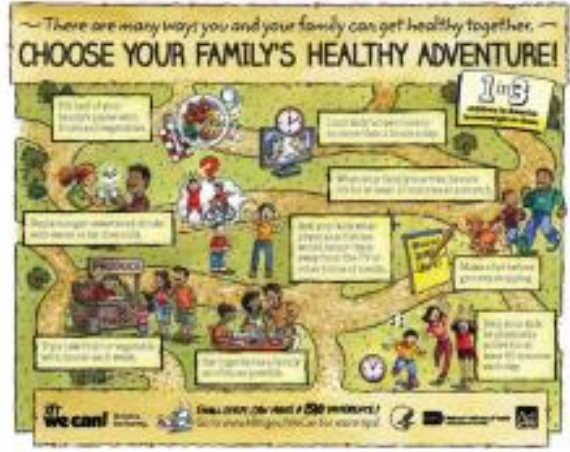


- Informational factors

Physical activity seems like an overwhelming thing at times. However, if we really think about our day there are probably 50 small things we can do to improve our health. Check out this quick (just 3 minutes) Ted talk on how she fits walking into her daily routine.

http://www.ted.com/talks/nilofer merchant got a meeting take a walk

\section{Monitoring physical activity}

- Fitbit checkin reminder

Let's play Fitbit Bingo can your family achieve each of these badges?

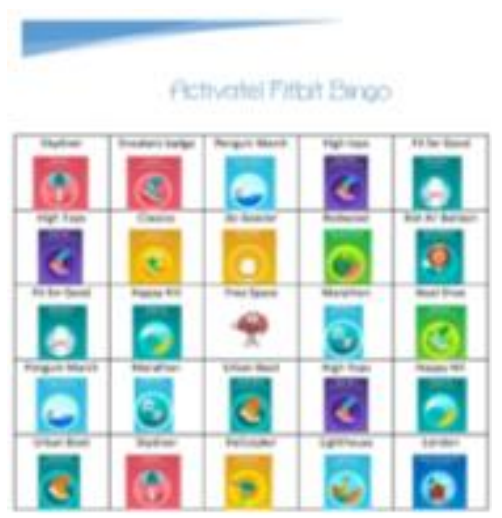

